\title{
استخدام الصحف الإكترونية لتفاعلية شبكات التواصل الاجتماعي وعلاقته بمُستويات التفاعلية تجاه قضايا الإرهاب لدي طلاب الجامعة "دراسة ميداتية"
}

\author{
د. إيمان محمد احمد حسن. \\ مدرس الإذاعة بكلية التربية النوعية- جامعة المنيا
}

مُلخص:

سعت هذه الدراسة للتعرف على استخدام الصحف الإلكترونية لتفاعلية شبكات التواصل

الاجتماعي وعلاقته بمستويات التفاعلية تجاه قضايا الإرهاب، واستخدمت هذه الدراسة منهج

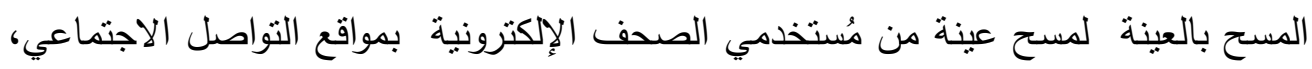

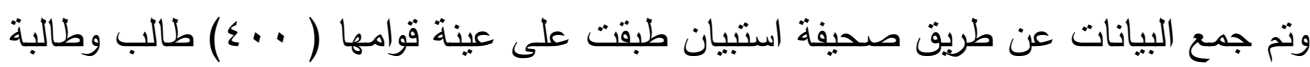
من مُستخدمي الصحف الالكترونية "متابعي قضايا الإرهاب" بمحافظتي القاهرة والمنيا،

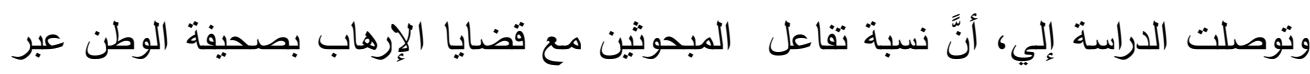

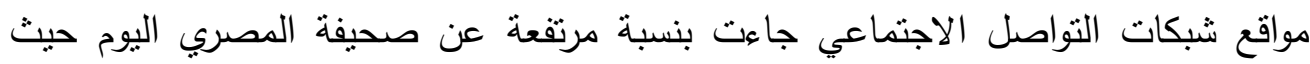

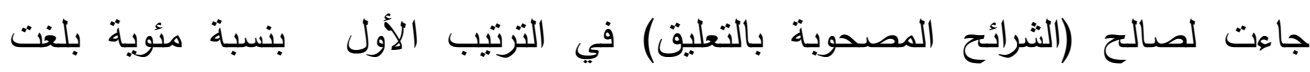

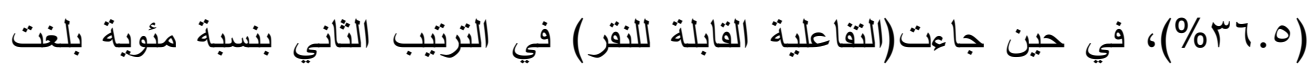

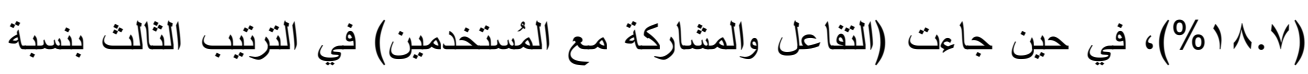

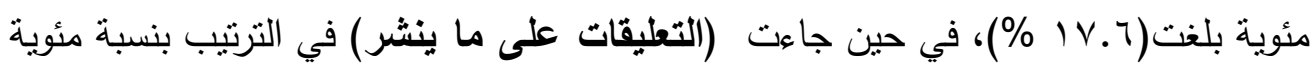

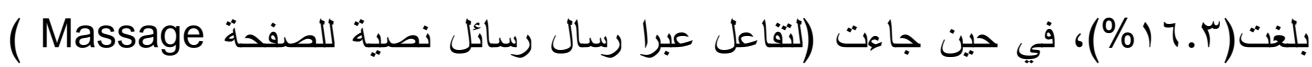

$$
\text { في الترتيب الخامس والأخير بنسبة مئوية بلغت( (9. . (1\%). }
$$

\section{Abstract}

This study used the methodology of the media survey to survey a sample of users of electronic newspapers in social media sites. The data were collected by means of a questionnaire newspaper that was applied to a sample of (400) The study found that the rate of interaction of respondents with terrorism issues in Al Watan newspaper through social networking sites came at a high rate from Al-Masry Al-Islami newspaper. (36.5\%), while (clickable interactive) came in the second ranking with a percentage of $(18.7 \%)$, while (interaction and participation with users) came in the order (17.6\%), while (comments on what is published) in the ranking by $16.3 \%$, while in the fifth and final order $(10.9 \%)$. 


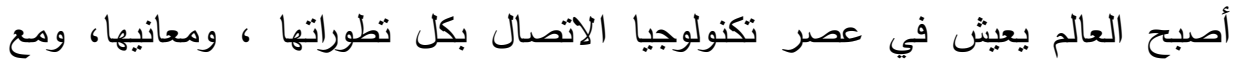

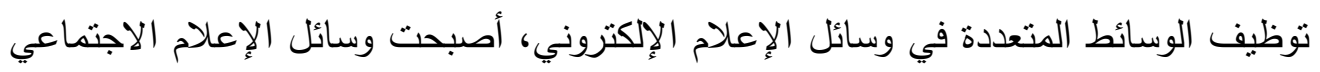

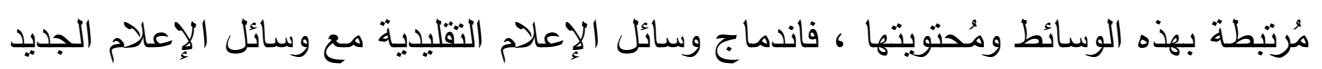

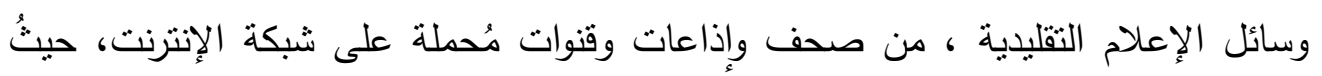
ساعد على خلق بيئة تفاعلية قائمة علي التفاعل، والحوار والمشاركة في وسائل الإعلام

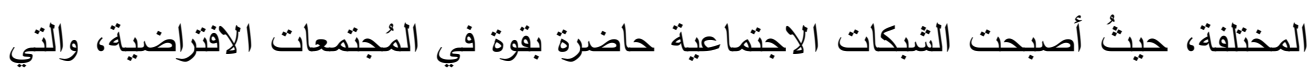

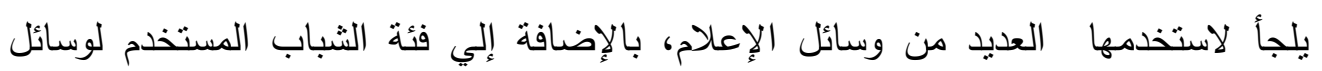
الإعلام المختلفة ، حيث ساعدا موقعا فيس بوك وتويتر في جذب مُستخدمي وسائل الإعلام الاجتماعي، والاثتراك بها عبر الصفحات الخاصة بها، سواء كانت صحف أو إذاعات، بهدف التعرف علي الأحداث المُختلفة، الأمر الذي أتاح حرية التعبير عبر هذه التهاء الوسائل،

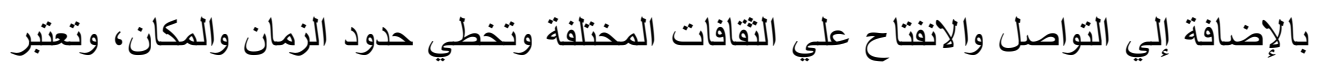

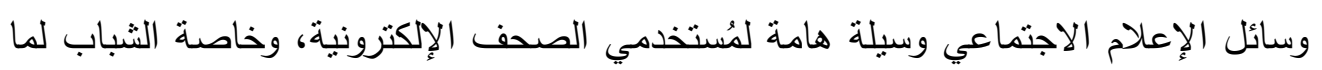

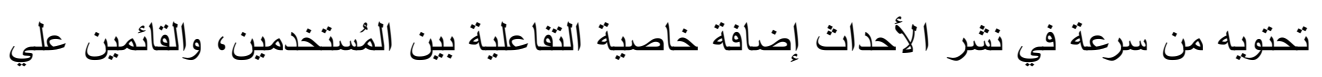
هذه الصفحات.

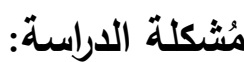

أصبحت التفاعلية لدى مُستخدمي الصحف الإلكترونية عبر مواقع شبكات التواصل

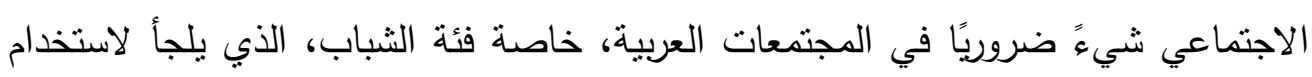

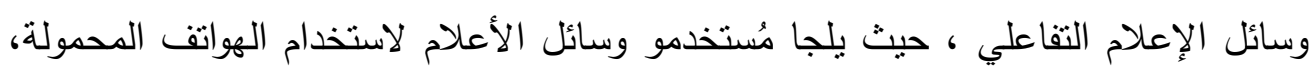

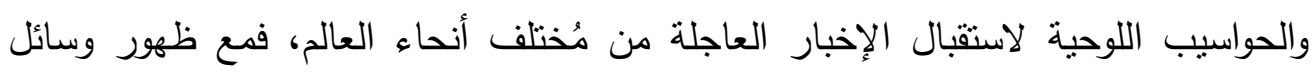

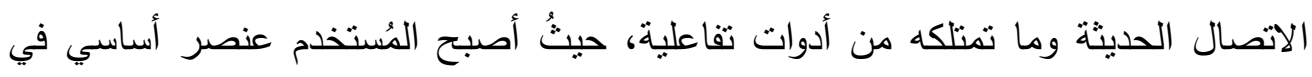
التفاعل مع مضدون الرسالة الإعلامية بمختلف أنواعها، وأصبح له القدرة النشطة علي التئي

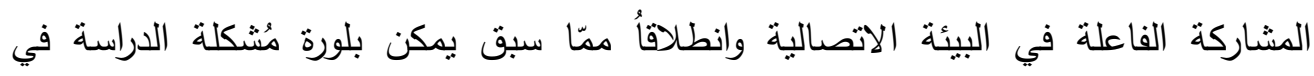

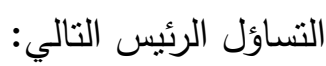
ما مدى استخدام الصحف الإكترونية لتفاعلية شبكات التواصل الاجتماعي؟ وعلاقة ذلك بمُستويات التفاعلية تجاه قضايا الإرهاب لدي طلاب الجامعة؟ ملإبه 


\section{أهمية الدراسة:}

تتبُع أهمية الدراسة من أهمية استخدام الصحف الإلكترونية لتقاعلية شبكات التواصل

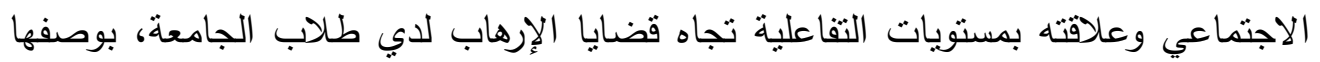
وسيلة إعلامية هامة في بث المضامين الإعلامية الصحف الإكترونية علي مواقع التواصل

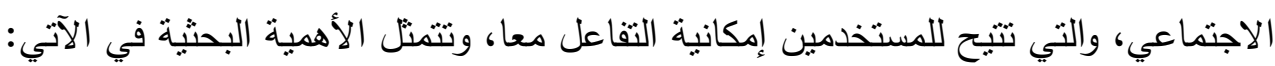
ا-تُعد هذه الدراسة من أحد الدراسات المُتعلقة باستخدام الصحف الإلكترونية لتفاعلية شبكات التواصل الاجتماعي وعلاقته بمُستويات التفاعلية تجاه قضايا الإرهاب، حيث بنداه

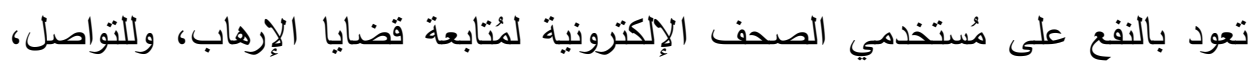

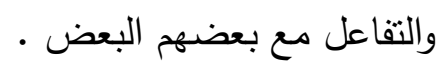
ץ-مجال الإعلام الجديد يُعد مجالاً خصبًا للباحثين والدارسين في مجال الاتصال، وذلك للوصول إلى نظريات وتصورات جديدة ومُبنكرة في إطار العلاقة بين الجمهور ووسائل الإعلام. r-أهمية التفاعلية كأداة تواصل ومُشاركة وحوار في المُجتمعات المعاصرة ؛ لذلك تُعد

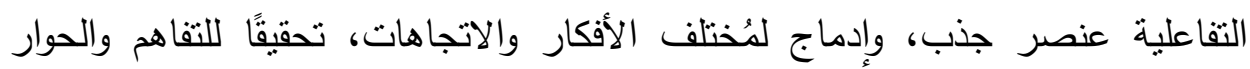

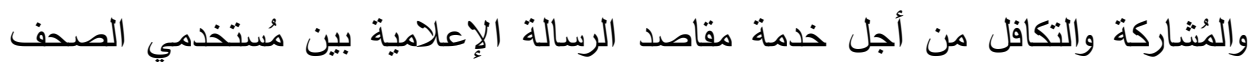
الإلكترونية علي مواقع التواصل الاجتماعي.

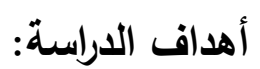

تسعي الدراسية الحالية للتعرف علي الهدف الرئيس التالي وهو: مدي استخدام الصحف الإكترونية لتفاعلية شبكات التواصل الاجتماعي، وعلاقته بمُستويات التفاعلية تجاه قضايا الإرهاب لدي طلاب الجامعة الإبترئ ويتفرع من الهدف الرئيس الأهداف الفرعية التالية:

1-التعرف علي طبيعة مُستخدمي الصحف الإكترونية، ومُستوي تفاعلهم تجاه قضايا الارهاب.

r-التعرف علي درجة استخدام المبحوثين للصحف إلكترونية، ومدي مُتابعتهم لقضايا الارهاب. r-التعرف علي دوافع استخدام طلاب الجامعة للصحف الإلكترونية، ومُعدل الوقت الذي يقضونه في متابعة قضايا الإرهاب. 


\section{تساؤلات الاراسة:}

يُمكن صياغة تساؤلات الدراسة في التساؤل الرئيس التالي:ما مدى استخدام الصحف الإكترونية لتفاعلية شبكات التواصل الاجتماعي؟ وما علاقة ذلك بمُستويات التفاعلية تجاه قضايا الإرهاب لاى طلاب الجامعة؟ ويتفرع من التساؤل الرئيس التساؤلات الفرعية التالية: 1-هل هناك علاقة بين استخدام المبحوثين للصحف عبر مواقع التواصل ومستويات التفاعلية تجاه قضايا الإرهاب ؟

ץ-ماهي درجة استخدام الطلا للصحف الإلكترونية، وما مدي متابعتهم لقضايا الإرهاب؟

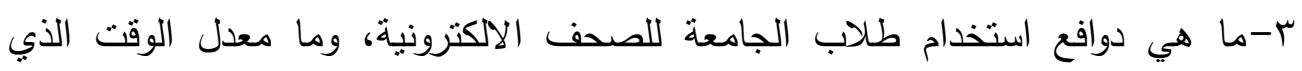

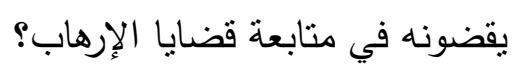

\section{فروض الاراسة:}

1-توجد علاقة ارتباطية دالة إحصائيًا بين استخدام المبحوثين للصحف عبر مواقع التواصل

$$
\text { الاجتماعي ومثشتويات التفاعلية تجاه قضايا الإرهاب. }
$$

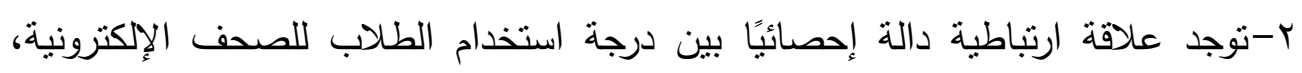

$$
\text { ومدي مُتابعتهم لقضايا الإرهاب. }
$$

r-توجد علاقة بين دوافع استخدام المبحوثين للصحف الإكترونية، ومُعدل الوقت الذي

$$
\text { يقضونه في متابعة قضايا الإرهاب. }
$$

\section{نوع منهج الدراسة:}

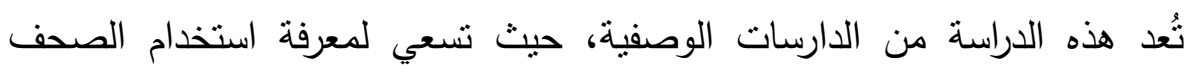

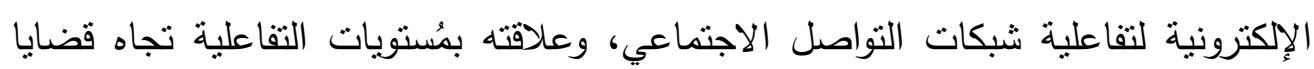

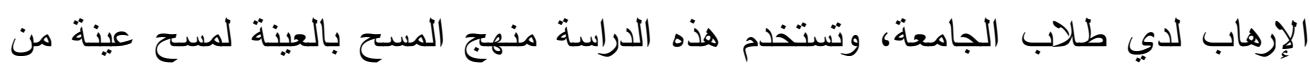

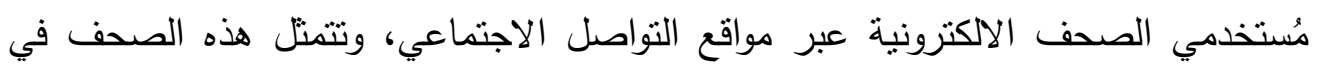

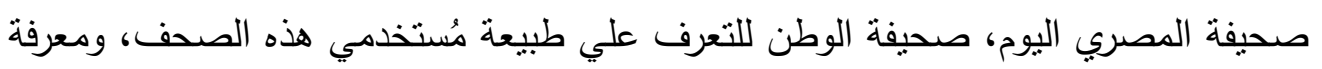
مُستويات التفاعلية تجاه قضايا الإرهاب.

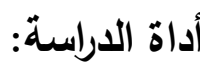

- صحيفة استبيان طبقت علي عينة من مُستخدمي الصحف الإكترونية عينة الدراسة بمواقع التواصل الاجتماعي، والتي تتمنل في صحيفتي (المصري اليوم، الوطن). 
مُتغيرات الاراسة:

- المُتغير المستقل:

استخدام الصحف الإلكترونية لتفاعلية شبكات التواصل الاجتماعي.

-

مُستوي تفاعل طلاب الجامعة تجاه قضايا الإرهاب.

مُجتمع وعينة الدراسة:

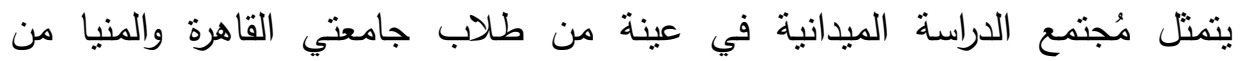

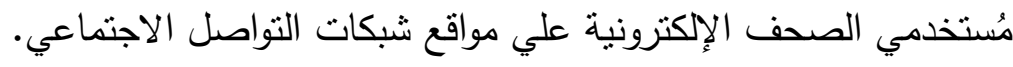
حدود الاراسة:

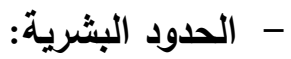

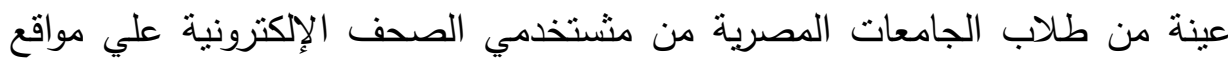
التواصل الاجتماعي من محافظتي المنيا، والقاهرة، وقد ثم اختيار العينة من تللك المحافظتنين لأنً محافظة القاهرة تمثل الوجه البحري، بينما تمثل محافظة المنيا الوجه القلبي.

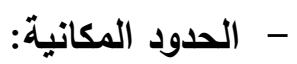
مُحافظتني المنيا، والقاهرة.

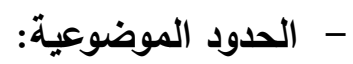

تقتصر علي الصحف الإكترونية وهى صحفيتي المصري اليوم، والوطن.

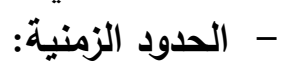
هي الفترة التي استغرقتها الباحثة في تطبيق أداه البحث والمُتمثلة في العام الجامعي

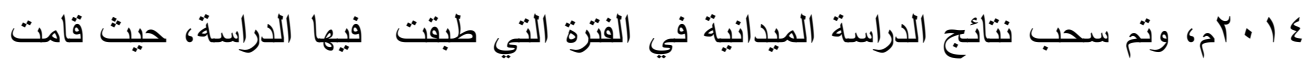

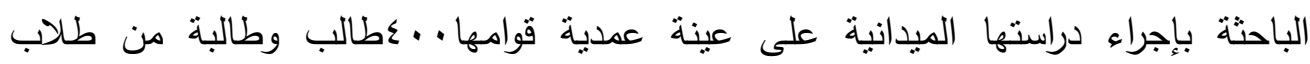

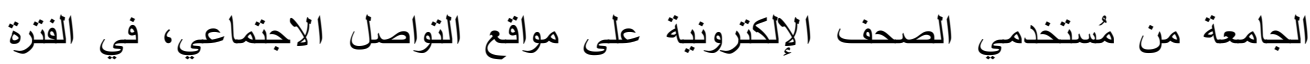

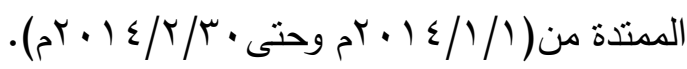

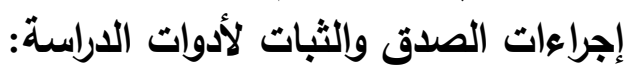
صحيفة الاستبيان: تم التحقق من الصدق الظاهري لصحيفة الاستبيان من خلال عرضها على مجموعة

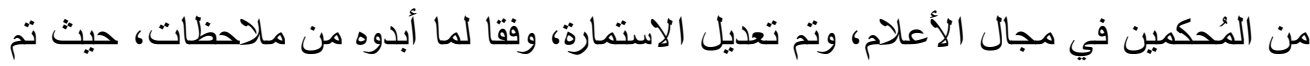

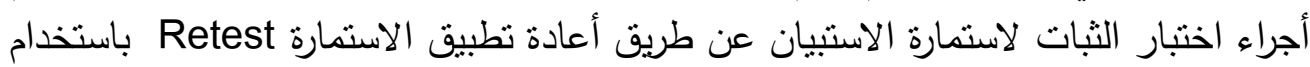

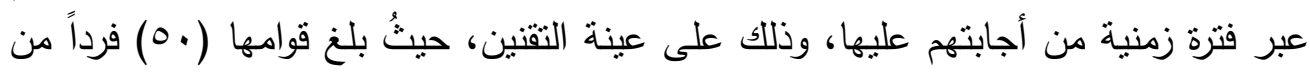

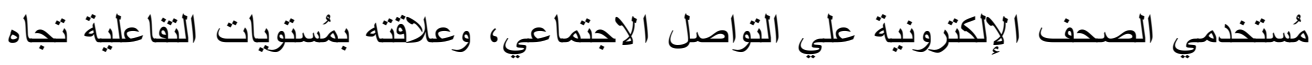
قضايا الإرهاب 


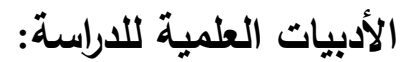

اعتدت الباحثة في تقسيم الأدبيات العلمية علي محورين: - الأول : دراسات تناولت الصحف الإلكترونية. - الثاني : دراسات تتاولت الثفاعلية ومواقع شبكات التواصل الاجتماعي. المحور الأول : دراسات تتاولت الصحف الإكترونية. أولاً : دراسات عربية حول الصحف الإكترونية. دراسة نوال محسن سالم مكيش (ع ا ب rم) بعنوان : الصحافة الإكترونية وأثرها في مجال الاتصال الإعلامي.

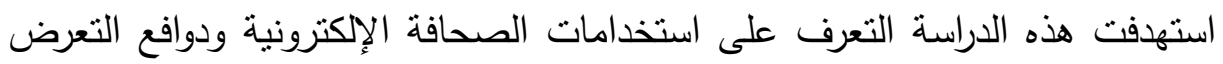

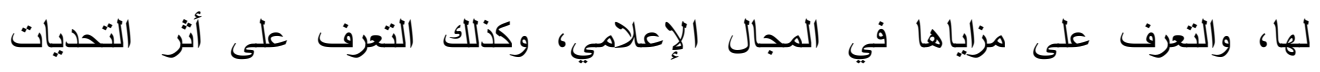

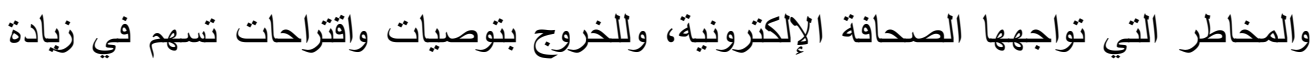
التفاعلية للصحافة الإككترونية ووسائل الإعلام التقليدية، وتتمنل أهمية هذه الدراسة في معرفة

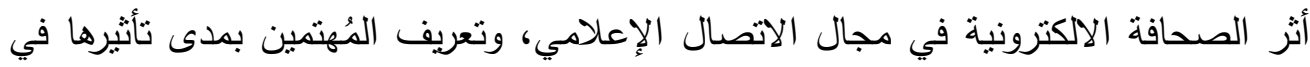

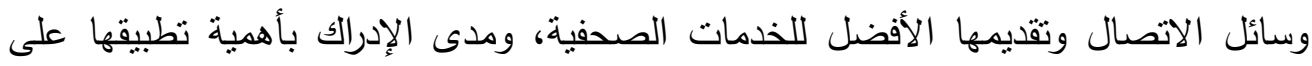
المُستوى اليمني من خلال رصد واقع الصحافة الالكترونية ومُستوى الاستفادة من خدماتها.

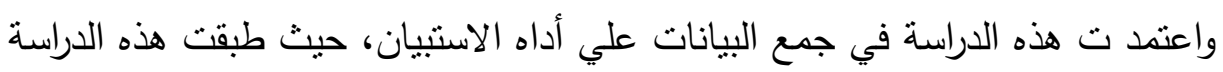

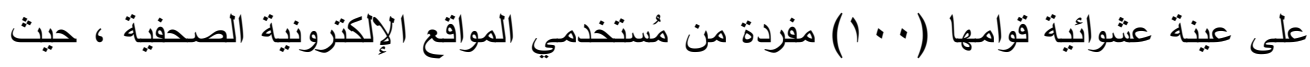

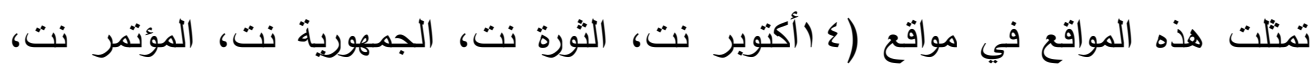

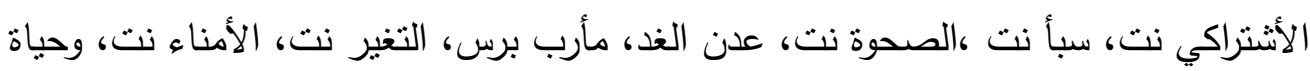

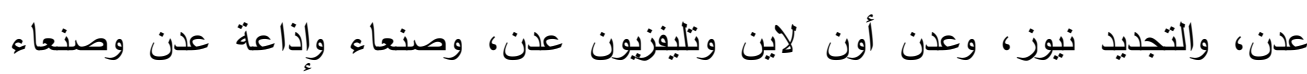
والطريق. وتوصثت الاراسة إلي: الني:

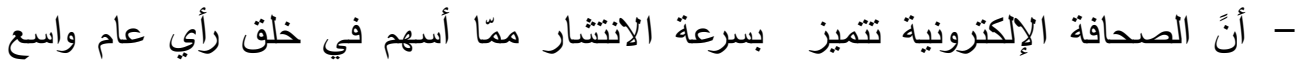

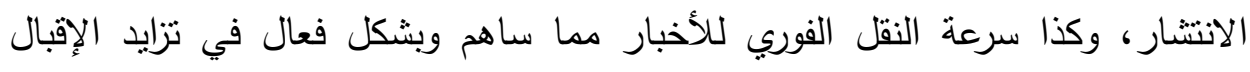

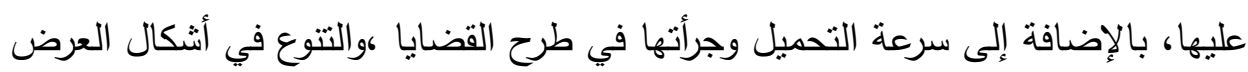

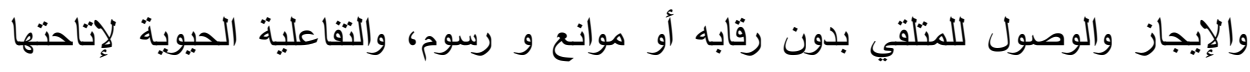
الإمكانية بالنواصل المباشر مع المتلقي وإظهار سلوك المُتستخدمين تجاه مصادر

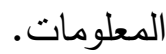


- أنً الصحافة الإلكترونية توفر للمتلقين المعلومات المقروءة والمسموعة والمرئية مع سهوله توثيقها، وتوفر الجهد والوقت في الحصول على المعلومات وبأقل التكاليف توني - أنً الصحافة الورقية لازالت تتمتع بجمهورها لسهولة التعامل معها لاسيما كبار السن ممّن

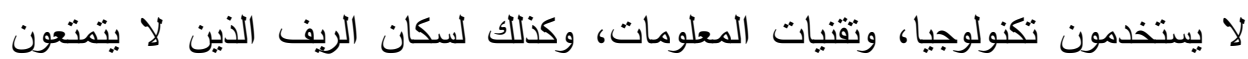

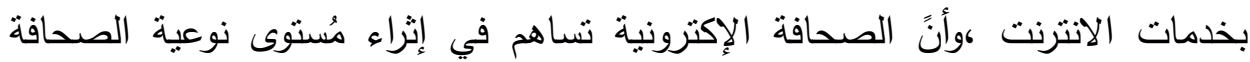
الورقية وتحسينها وإمداد الأخبار التليفزيونية بالمعلومات والتحليلات والتعليقات.

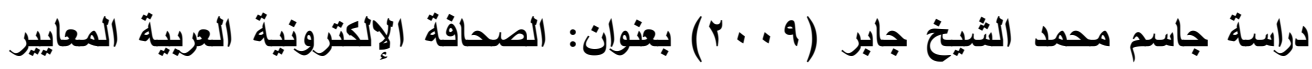

الفنية والمهنية دراسة تحليلية لعينة من الصحف الاليكترونية العربية "دراسة تطبيقية". استهدفت هذه الدراسة تحديد مفهوم الصحافة الإكترونية، وخصائصها ومعاييرها المهنية

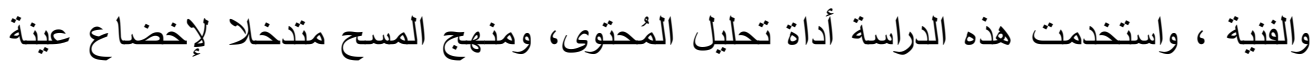

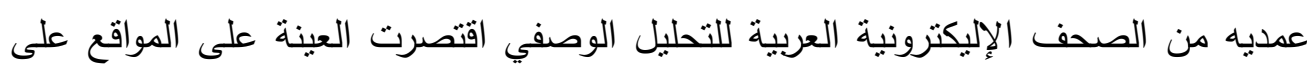
شبكة الإنترنت والتي تصف نفسها بجريدة، أو صحيفة إلكترونية. وتوصلت الدراسة إلى الإنى

- وجود عدد غبر قليل من الصحف الإليكترونية العربية يتمتع بخاصية الفورية والآنية،

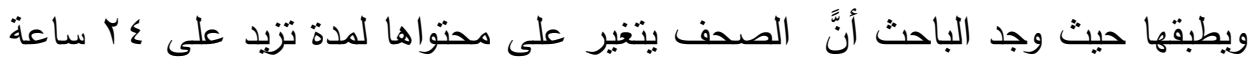

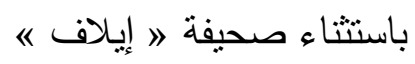

- أنَّ المُستخدم الصحف الإككترونية العربية خدمة الوسائط المتعددة مُكملان لإمكانات التقنية التي توفرها خدمة الإنترنت وبرامج الكمبيوتر .

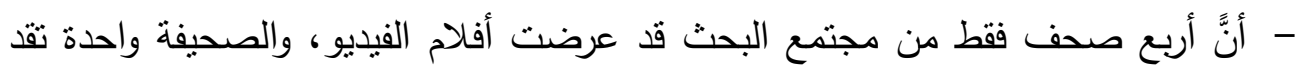
تسجيلات ومواد صوتية الجانب التفاعلي ما بينا لجمهور والصحيفة منوفرة واشتملت

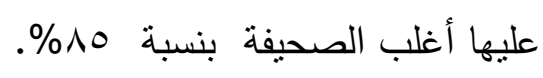

ثانيا : دراسات أجنبية حول الصحف الإكترونية.

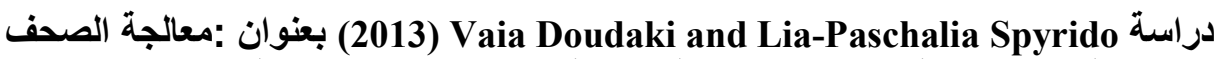
المطبو عة والإكترونية للمحتوى "دراسة تحليلية على الصحف اليونانية.

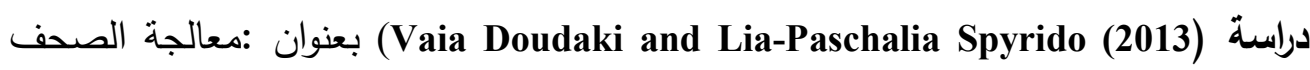
المطبوعة والإكترونية للمحتوى "دراسة تحليلية على الصحف اليونانية" دالئ 
استهوفت الدراسة التعرف على محتوى الصحف المطبوعة، والصحف الإكترونية اليونانية، واستخدمت هذه الدراسة منهج المسح الإعلامي، وتمثلت عينة الدراسة في صحيفة (Athens News،Athinorama ) المحتوي، وتوصلت الدراسة الى:

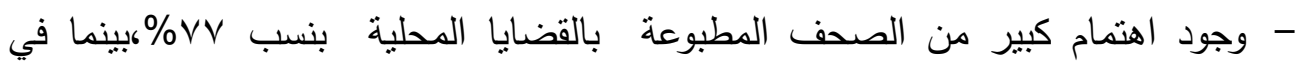

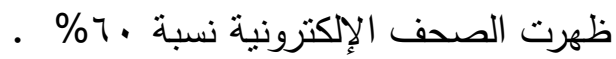

- أنَّ النسخ الإكترونية للصحف أهتمت بالتركيز على القضايا الخارجية السياسية . - جاءت تغطية القضايا الرياضية في الصحف المطبوعة أكثر، وجاءت القضايا الاقتصادية أعلى في النسخة الإلكترونية عنها في المطبوعة .

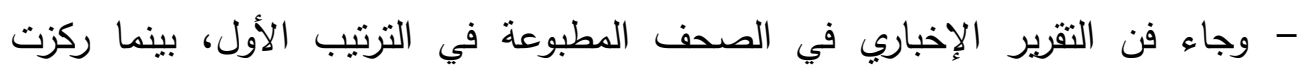

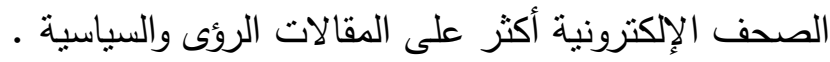
دراسة ميشيل كارلسون (Michael Karlsson (2007) بعنوان فورية الإخبار علي الإنترنت "دراسة حالة" دراسية مبئل

استهدفت الدراسة التعرف علي مدي تأثثر فورية الأخبار على جودة المعلومات ودقتها، استخدمت هذه منهج دراسة الحالة، وتمثلت عينة الدراسة في أربعة مواقع صحف إلكترونية

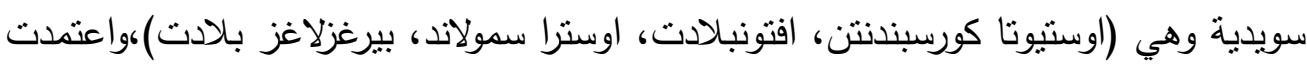
الدراسة في جمع البيانات علي أداة الاستبانة.

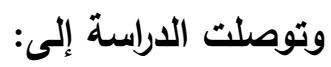

- أنَّ الفورية لمتأثز علي جودة المعلومات بل ساعدت الصحفيين علي تدعيم التواصل مع القراء.

- أنَّ إمكانات الإنترنت تعطي الفرص لنقديم تحديث الأخبار بصورة أفضل.

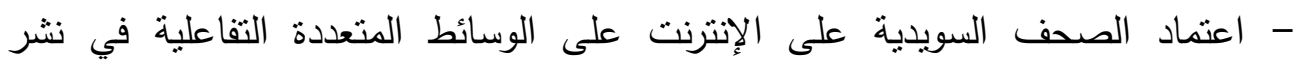
الإعلامية بجودة عالية.

المحور الثاني : دراسات حول التفاعلية ومواقع شبكات التواصل الاجتماعي أولا :دراسات عربية حول التفاعلية ومواقع شبكات التواصل الاجتماعي.

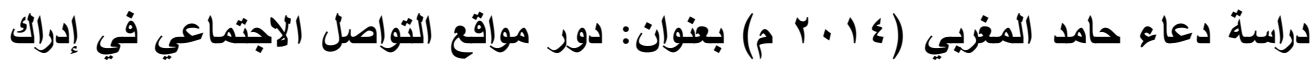

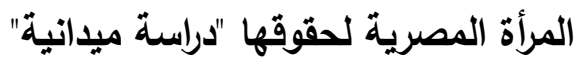


الاجتماعي لتعريفها بحقوقها كافة، ومعرفة مدى مواطن القوة والضعف التي يُمكن أن تؤثر بها

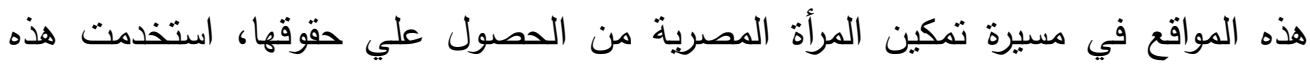
الدراسة منهج المسح، بالتطبيق على عينة . .ـ مفرده من المرأة المصرية بمُختلف الأعمار

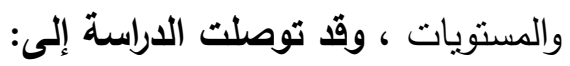
- وجود تفوق لمواقع التواصل الاجتماعي في جذب جمهور المرأة المصرية، ويعزز ذلك الحرية في نشر المعلومات بها مما انعكس في حرية التعبير والرأي.

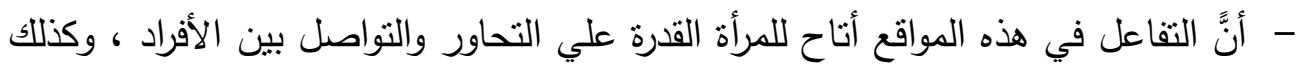

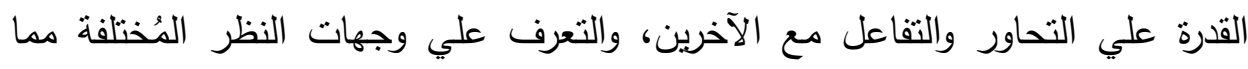

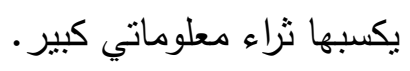

- أنَّ موقع الفيس بوك حصد المركز الأول في التفاعل والتأثنير في حين تراجعت باقي

$$
\text { المواقع. }
$$

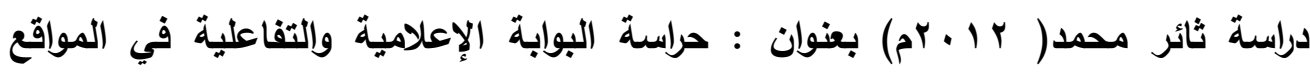

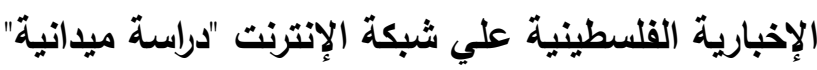
استهوفت هذه الدراسة إلي وصف الإمكانيات التفاعلية المتاحة من قبل حارس الإسبه البوابة الإعلامية في المواقع الإخبارية الفلسطينية علي شبكة الإنترنت ؛إذ أن هذه المواقع خاصة بشكل رئيس للسيطرة من قبل حارس البوابة، والذي يديرها وفق أسس مختلفة تتدرج تحت

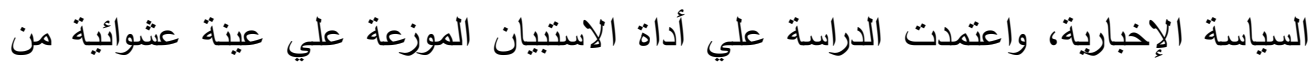

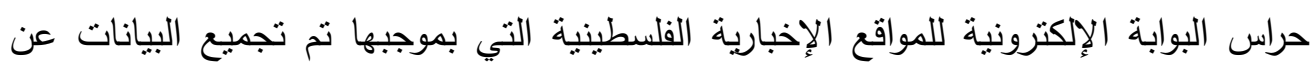
المتغيرات، كمّا توجد في المواقع وذللك من خلال إمكانيات التفاعلية المتاحة في المواقع لهن الإخبارية الفلسطينية، وتوصلت الدراسة إلي:

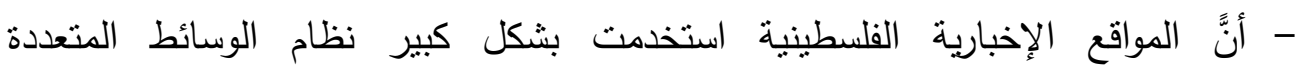
(multimedia) - وجود انخفاض بصورة عامة بين الزوار في المواقع الإخبارية الفلسطينية، وعدم توفر

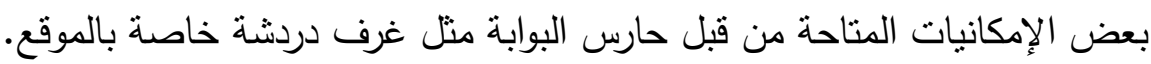
- أنَّ المواقع الإخبارية الفلسطينية اهتمت بشكل كبير بتحديث المادة الإخبارية المنشورة، المبنة كمّا أهتمت أيضا بتوفير آلية تحديث قاعدة البيانات للزوار . 


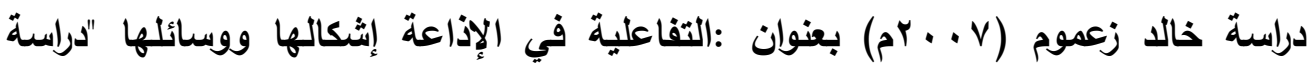
استهدفت هذه الدراسة إبراز أهم المواقع الإذاعية العربية الموجهة للعالم العربي، ومدي استخدمها للتقنيات المتاحة عبر شبكة الإنترنت والوسائط المُتعددة من اجل إتاحة فرص الإنه

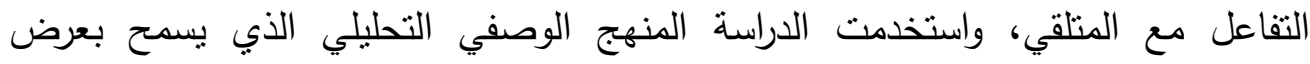

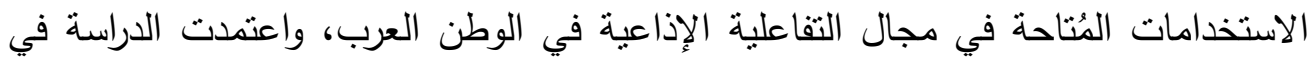
جمع البيانات علي الدُقابلة والملاحظة كما الدراسة عينة قصديه ممثلة في موقع مؤسسة الإمارات للإعلام وراديو ليالي بيروت وراديو سوا، وتوصلت الدراسة إلى الى

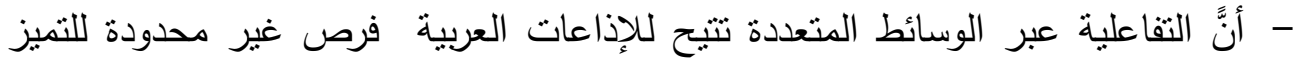
والمشاركة والمنافسة ليس فقط في المحافظة علي جمهورها بل لجذب جمهور جديد وعريض تصل إليه شبكة الويب في كافة أرجاء العالم. - أنَّ التفاعلية نساعد الإذاعات العربية الإككترونية في التحرر من شكلها التقليدي الذي يدل التهاه على الكسل الفكري وإبداعها ونفوذها نحو مزيد من الاهتمام بالمتلقي والتفاعل.

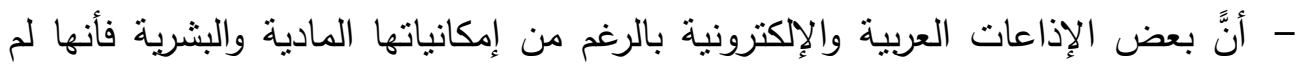
تستغلها من أجل الدخول في فضاء التفاعلية وظلت أسيرة لنمط الإعلام التقليدي. دراسة شريف اللبان (9 . . ب م) حول الفيس بوك والإعلام البديل "دراسة ميدانية". استهدفت هذه الدراسة التعرف علي وسائل الإعلام البديلة، حيث تشكل جرس إنذار لوسائل الإعلام التقليدية من جرائد ومجلات وقنوات تلفزيونية التي يشعر الناس بالإحباط تجاهها،

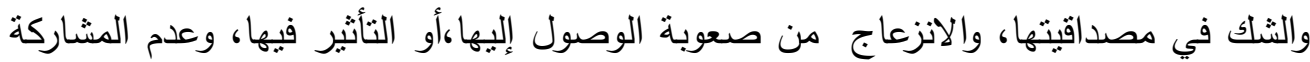
في صياغة الرسالة الإعلامية، وهو ما يجب أن يدفع المؤسسات الإعلامية العربية إلي التخلص من الأخطاء الفادحة التي وقعت فيها عبر عقود، واستخدمت هذه الدراسة منهج المسح الإعلامي، وتمثلت عينة الدراسة في .عفردة من مستخدمي وسائل الاعلام البديلة،

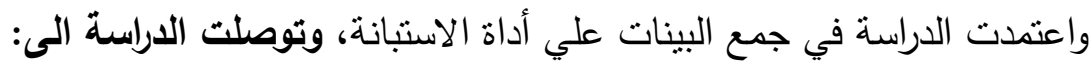
- أنَّ الإعلام البديل يعاني أيضًا من مجموعة من المُشكلات الأخرى التي قد تجعله بشكل

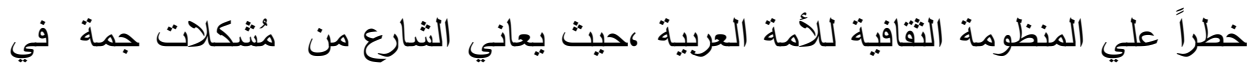
التفكير تجعل أراءه أقرب إلي السطحية، والتعميم، ومرتبطة أكثر بالثنائعات والثنعارات الايدلوجية التي تلاقي هواه حتي لو لم يقف المنطق إلي جانبها، أو يؤيدها التاريخ والعلم. 
دراسة عبد الجواد سعيد محمد ربيع(^ . . rم) بعنوان :المدونات كأداة اتصال تفاعلي في المشاركة السياسية "دراسة تطبيقية". استهدفت هذه الدراسة تحليل أطروحات الخطاب الخاص بقضية التعديلات الدستورية داخل مواقع بعض المدونات، وتتتمي هذه الدراسة للارسات الوصفية التحليلية؛ إذ اهتمت برصد وتوظيف المدونات علي شبكة الإنترنت كأداة اتصالية تفاعلية، واستخدمت هذه الدراسة منهـ لهنه الإعلامي المسح لمسح المواقف والاتجاهات المعبرة عن توجهات أصحاب هذه المدونات وموقفها من قضية التعديلات الدستورية، وتمثلت عينة الدراسة . ب rمدونة في الفترة الزمنية

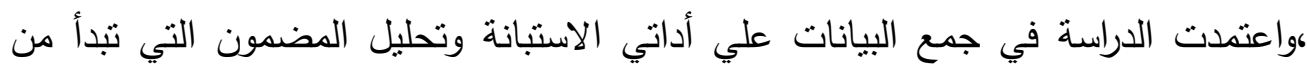

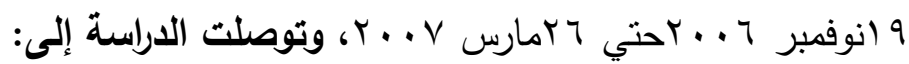

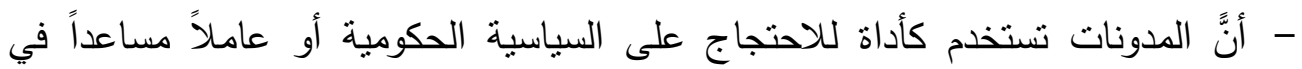
تتظيم تلك الفعاليات والتأثير علي شكل الرأي العام وتعبئته.

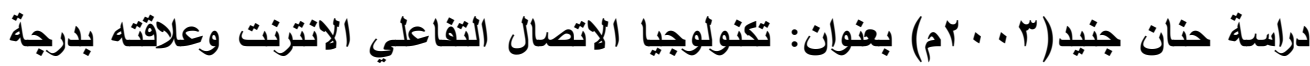
الوعي السياسي لاي طلاب الجامعة المصرية "دراسة ميدانية".

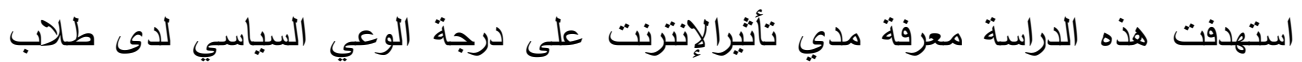

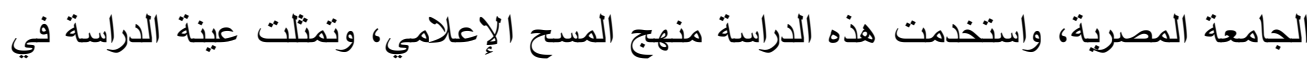

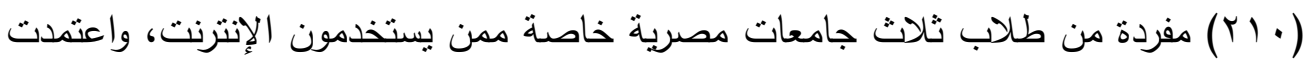
الدراسة في جمع البينات علي أداة الاستبانة، وتوصلت الاراسة إلى منات - ارتفاع نسبة المُشاركين في الحوار الإككتروني وتبادل الرأي حول الأمور العامة، كمّا تبين وجود علاقة بين استخدام شبكة الانترنت وتبادل الرأي حول الأمور العامة. - وجود علاقة بين استخدام الإنترنت وارتفاع درجة الوعي العام بالقضايا السياسية،

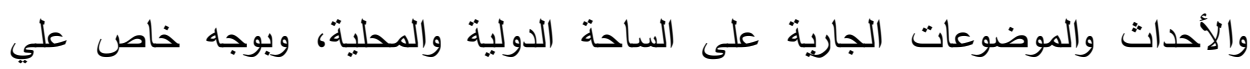
المُستوي الدولي.

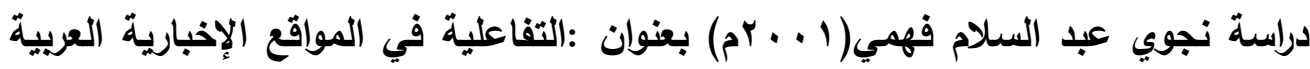
علي شبكة الإنترنت "دراسة تطبيقة". استهدفت هذه الدراسة تحليل عينة عشوائية من المواقع الإخبارية العربية علي شبكة الإنترنت

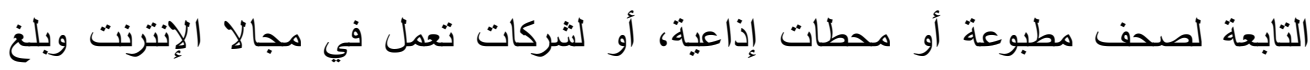
عددها هکموقعاً إخبارياً، واستخدمت هذه الدراسة المنهج الوصفي التحليلي ،وتمنلت عينة 
الدراسة التحليلية في (جريدة الأهرام، جريد السفير اللبنانية، جريدة أخبار الخليج البحرينية،

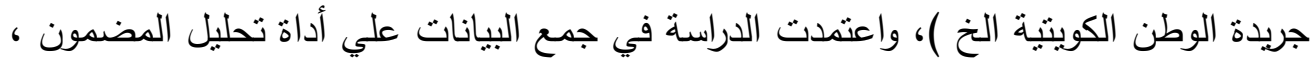
وتوصلت الدراسة إلىى: - أنَّ غالبية الصحف لا تهتم بإقامة وسيلة اتصالية ثنائية الاتجاه تربطها بالمتلقي مع عدم إلى

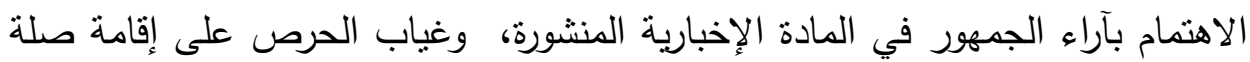

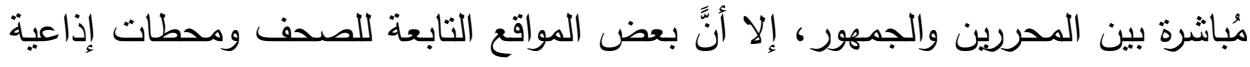
وفرت ساحة للمناقتشة حول موضوعات مختلفة، كما كانت المواقع التابعة لثركات تعمل في مجال الإنترنت أكثر اهتماماً لإتاحة الفرصة للمترددين عليها لإبداء الرأي حول القضايا المهمة، والدخول في مناقشات حولها.

ثانيا : دراسات أجنبية تناولت التفاعلية ومواقع شبكات التواصل فئل الاجتماعي: دراسة دورفلت فيليب (Durefelt, Filip (2014) بعنوان: الصحافة من خلال وسائل الإعلام الجديد في كيفية استخدام_طلاب الصحافة في جامعة السويد " التويتر "دراسة ميدانية". استهدفت هذه الدراسة التعرف على كيفية استخدام طلاب الصحافة ل "تويتر" كأحد مواقع التواصل الاجتماعي، واستخدمت هذه الدراسة منهج المسح الإعلامي، وتمثلت عينة الدراسة

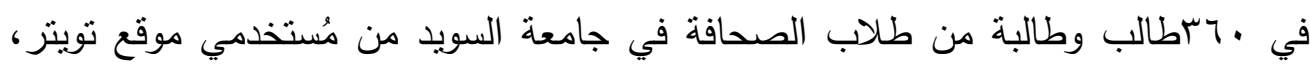

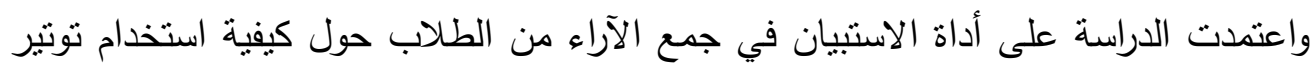

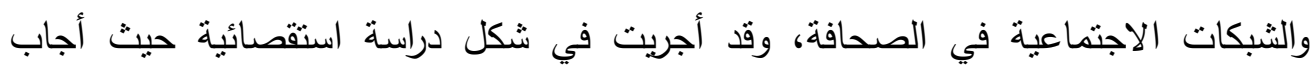

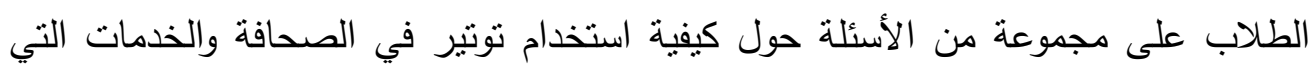
تقدمها مواقع التواصل الاجتماعي في مجال العمل، وتوصلت الدراسة إلى كئل - أنَّ الطلاب المُتخصصين في الصحافة بيتخدمون توتير كأداة صحفية ولكن ليس بمُعدل فئل مرتفع. - أنَّ استخدام الطلبة لتوتير ومواقع التواصل الاجتماعي تتعارض مع معتقداتهم حيث يرى

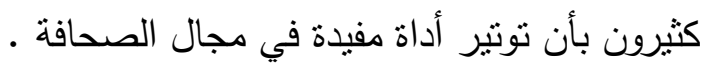
دراسة مارينا فستيا Marina Vastly (2012 بغوان: استخدام الشباب الجامعي الروسي

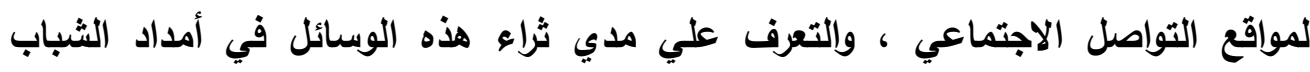
بالمعلومات "دراسة ميدانية". 
استهدفت هذه الدراسة التعرف على استخدام الثباب الجامعي الروسي لمواقع التواصل

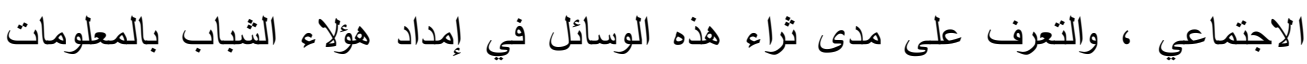

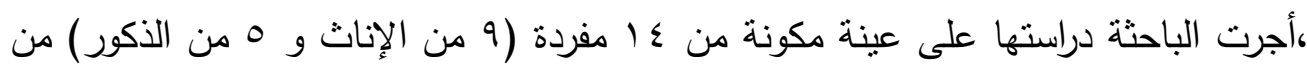

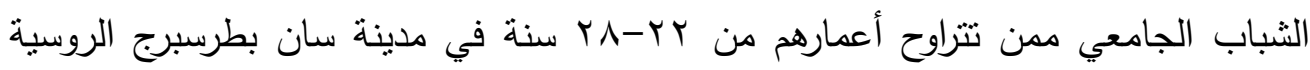

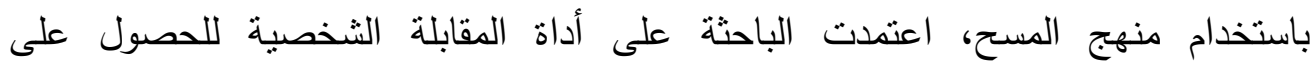
المعلومات. وتوصلت الدراسة إلى: بأن: - أنَّ مواقع التواصل الاجتماعي توفر العديد من مزايا الاتصال الثخصي مما يجعلها ثريه

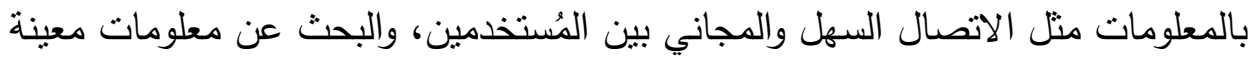
بسهولة ويسر وبشكل مجاني، بالإضافة إلى الخصوصية في الاتصال وإمكانية التعبير عن الذات . - أنَّ المبحوثين على دراية تامة بموضوعات الخصوصية على مواقع التواصل الاجتماعي،

$$
\text { ولكنهم لا يهنمون بهذه الموضوعات. }
$$

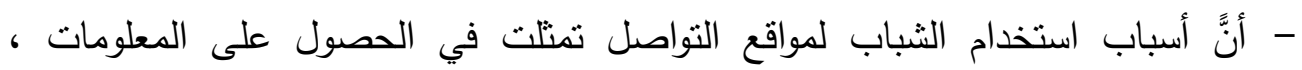
والاتصال الثخصي مع الأهل والأصدقاء، والاستفادة من تجارب الآخرين.

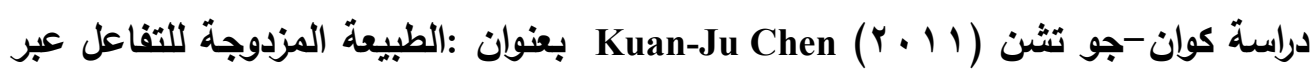
الشبكات الاجتماعية "دراسة تحليلية". استهدفت هذه الدراسة تحليل التقاعل عبر مواقع الثبكات الاجتماعية باستخدام نموذج Simmel's Dialectical Style and Micro sociological الاجتماعية لها أثار كثيرة وواضحة علي شكل الحياة الاجتماعية، حيث تغير نمط الحياة للإنسان باستخدام وتيرة وسرعة تغييرها وتطورها، من خلال دراسة الظواهر الاجتماعية

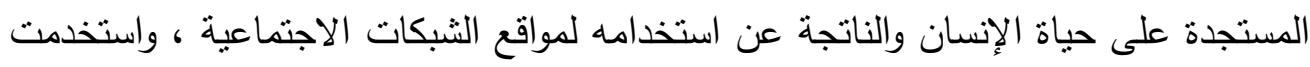

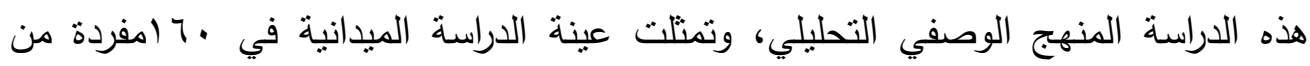

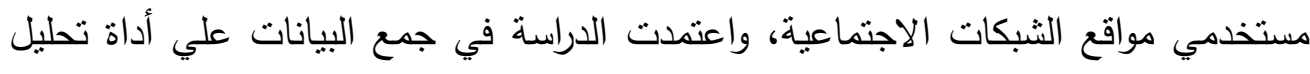

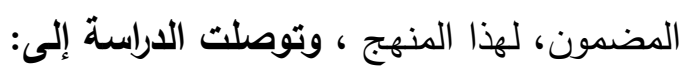

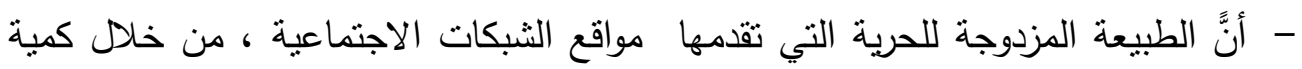

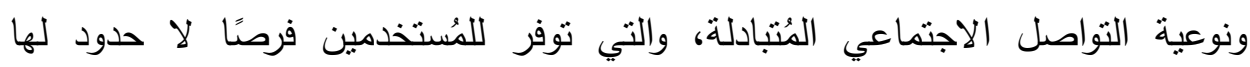


لممّارسة الحرية والتعبير عن الثخصية الفردي، والتي تتطوي في بعض الأحيان علي بعض المخاطر التي تهدد حرية التعبير وهوية الفرد الثخصية. - أنَّ التواصل والترابط عبر مواقع الثبكات الاجتماعية يعمل علي تدعيم الثقة بين الإفراد.

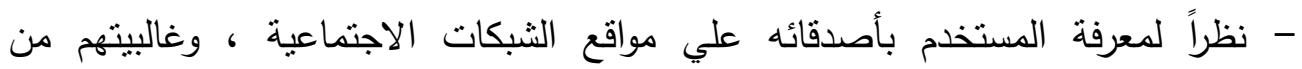

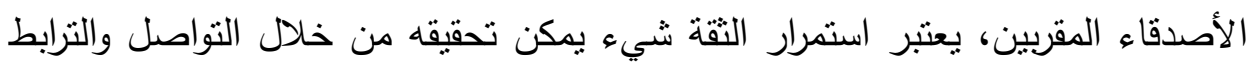
بينهم ، الأ أنَّ كمية المعرفة المطلوبة لتوافر التقة بالنسبة للعلاقة التي يوفرها المواقع ذاته من خلال توفير ما يفي من معلومات حول المُستخدمين الآخرين.

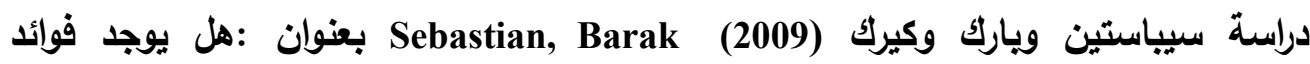
اجتماعية في مواقع التواصل الاجتماعي؟ درجة الرضا والثقة والمشاركة من خلال استخدام طلاب الجامعة لموقع الفيس بوكئ. استهدفت هذه الدراسة التعرف على ترتيب موقع الفيس بوك بين مواقع الثبكات الاجتماعية

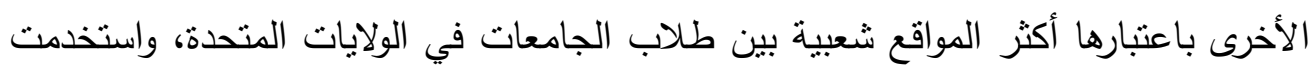

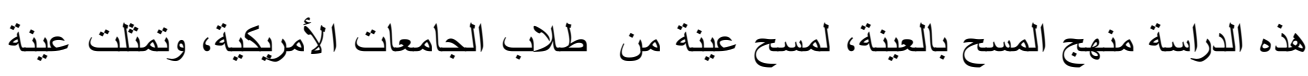

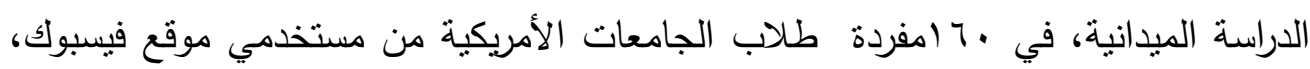

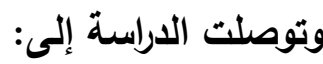
- أنَّ شبكات التواصل الاجتماعي تساعد على توطيد العلاقات والروابط وتبادل الرسالة

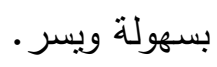

- أنً موقع الفيس بوك يتمتع بشعبية عالية عن غيره من المواقع الأخرى، حيث يعمل الفيس

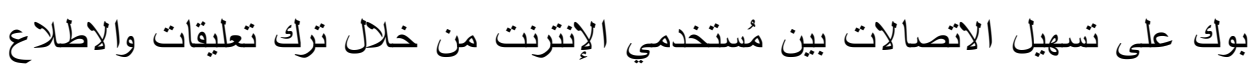

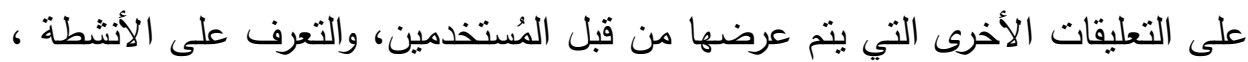

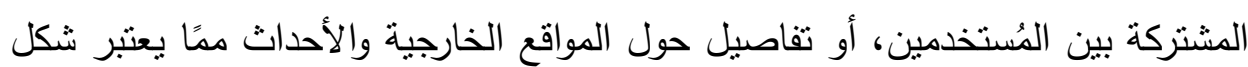

$$
\text { آخر من أنثكال ردود الفعل السريعة عبر الموقع. }
$$

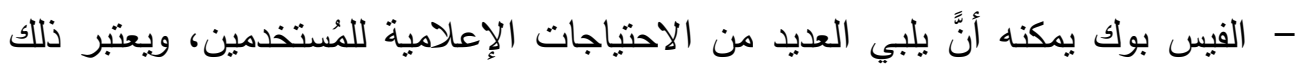

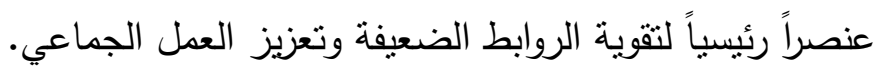

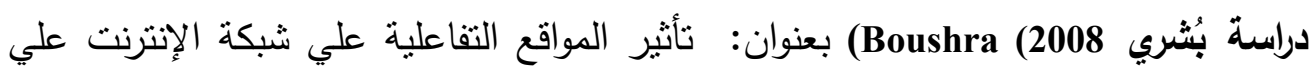

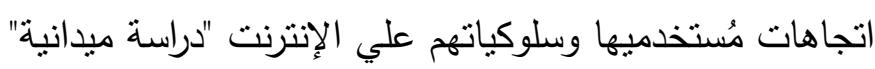

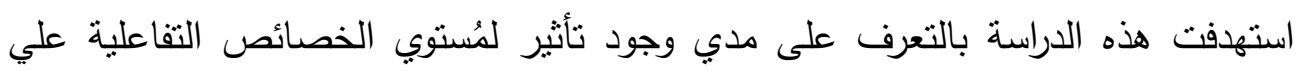
شبكة الإنترنت، ومدى تأثنير تفاعلية مُستخدمي هذه المواقع علي مدركات هؤلاء المستخدمين 
،واتجاهاتهما نحو هذه المواقع ،واستخدمت هذه الدراسة منهج المسح الإعلامي، وتمنلت عينة

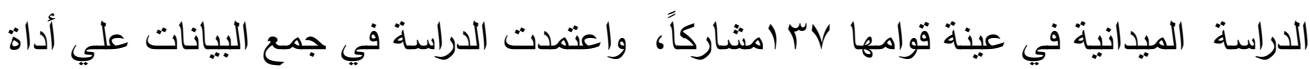
الاستبانة، وتوصلت الدراسة الى كئه - أنَّه كلما ارتفع مُستوبي الخصائص التفاعلية للمواقع الإلكترونية علي شبكة الإنترنت، كلمًا

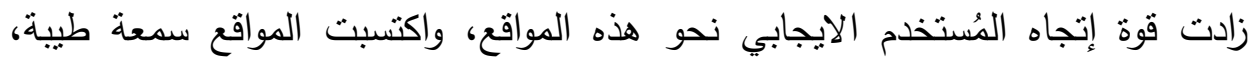
وارتقع مُستوي إدراك المُستخدمين للُُستوي تقاعلية هذه المواقع.

- أنً ارتفاع مُستوي التقاعلية أدي إلي اتجاهات وسلوكيات إيجابية علي شبكة الإنترنت. دراسة سونج (song 2008) بعنوان :الإنترنت كوسيلة تفاعلية وعلاقته بتتكيل الاتجاهات

السياسية "دراسة تجريبية" استهافت هذه الدراسة العلاقة بين التفاعلية التي يتيحها الإنترنت، وتتكيل الاتجاهات لدي درابي

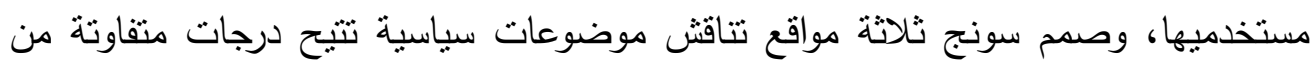

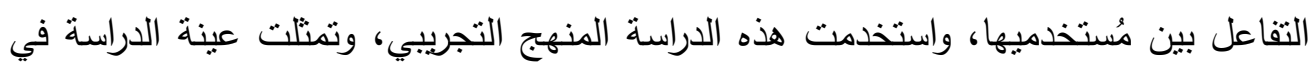

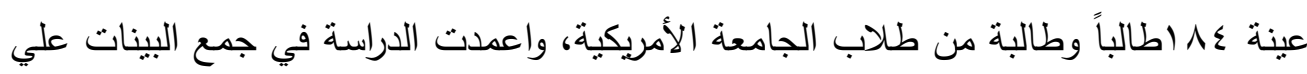

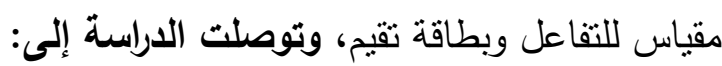
- وجود مجموعة من العوامل التي آثرت على فاعلية شبكة الإنترنت في تشكيل الاتجاهات

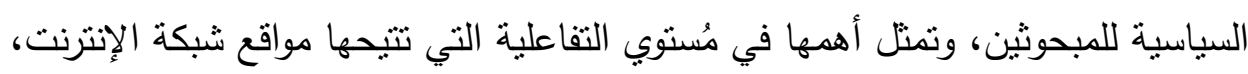

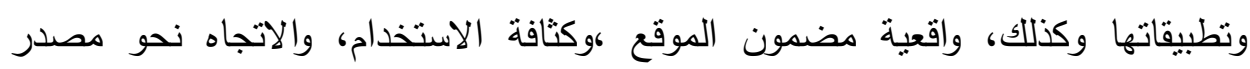

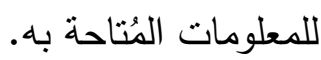

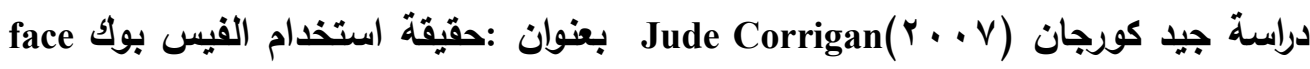
book

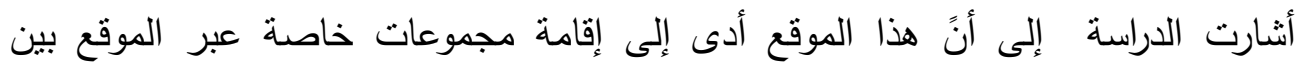

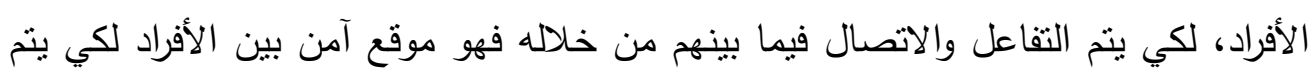

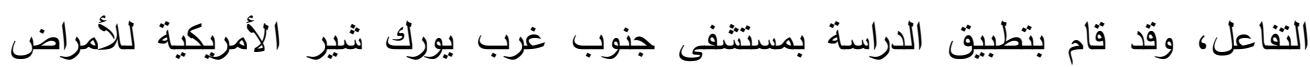

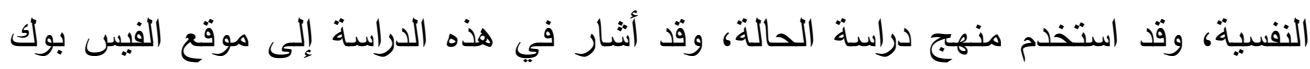
face book وأصبحت هذه المُستشفى منظمة ديناميكية كبيرة. 
التعليق علي الدارسات السابقة وأوجه الاستفادة منها:

عرضت الباحثة الدراسات السابقة، حيث أكدت علي أهمية استخدام الصحف الإداء منهات الإكترونية

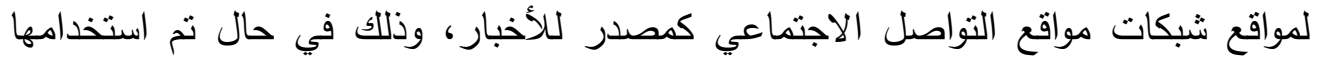

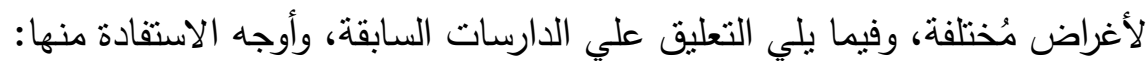

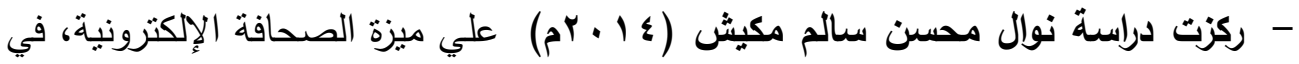

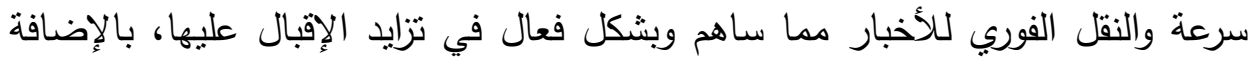

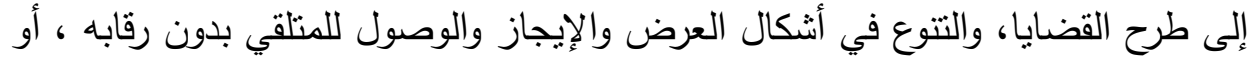

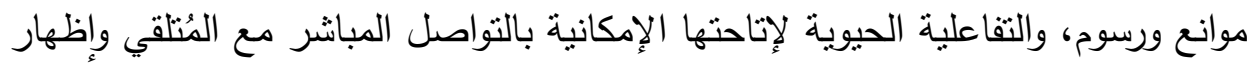
سلوك المستخدمين تجاه مصادر المعلومات. - ركزت الدارسات الأجنبية علي أهية التفاعلية عبر مواقع الثبكات الاجتماعية، حيثُ الأن ركزت الدارسات الأجنبية علي الآتي:

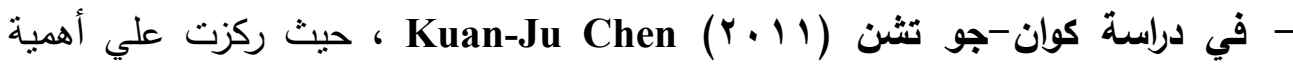

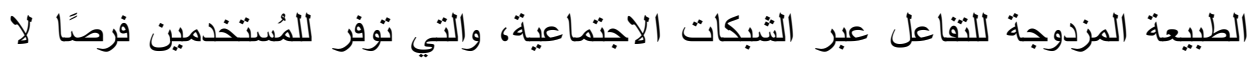

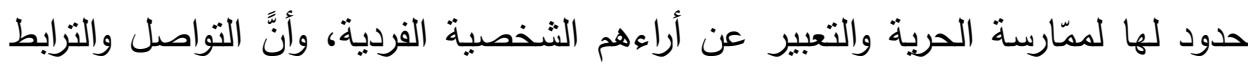
عبر مواقع الثبكات الاجتماعية يعمل علي تدعيم الثقة بين الإفراد.

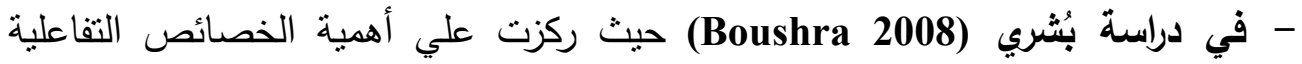

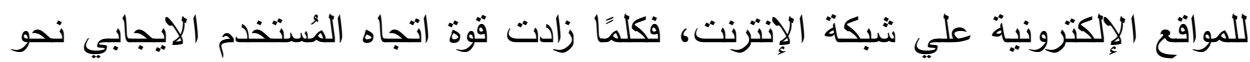

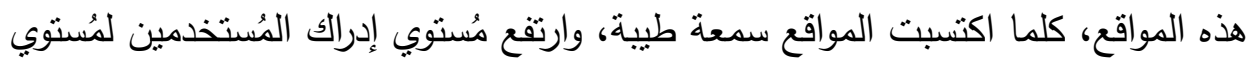
تفاعلية هذه المواقع. - استفادت الباحثة من الأدبيات العلمية للدراسة الحالية في تحديد مشكلة الدراسة، وأهدافها

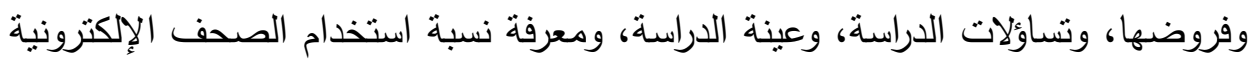

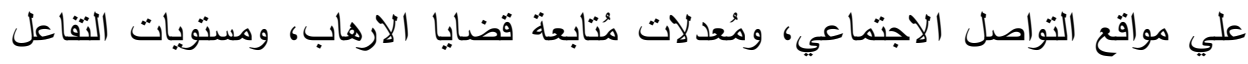
معها، حيثُ نرتبط الأطر النظرية للارسات السابقة التي تم التعليق عليها باتيات بالدراسة

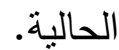

\section{الإطار المعرفي للاراسة: المانة}

ماهية الصحف الإكترونية على مواقع الثبكات الاجتماعية:

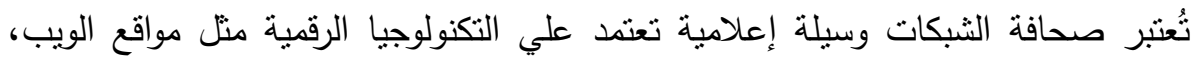

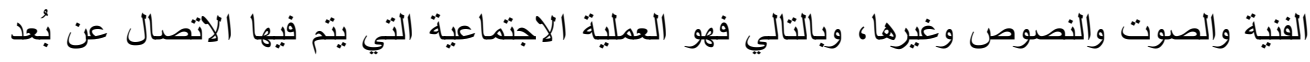

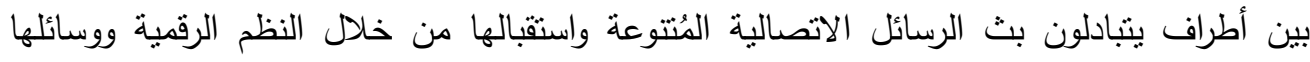
لتحقيق أهداف معينة، فهو يشمل وسائل الإعلام التي تعمل وفق النظم الرقمية بما فيها التلفزيون 
الثفاعلي الذي يستخدم النظم الرقمية في إنتاج وبث المضامين الإعلامية(رضا عبد الواجد، ....، .$(0) \mathrm{V}$

فالإعلام الثبكي عبارة عن عمليات صحفية تتم عبر مواقع الثبكات الاجتماعية، والتي تعتمد على بث المضامين الإعلامية الإذاعية والتلفزيونية والصحفية، حيث توفر

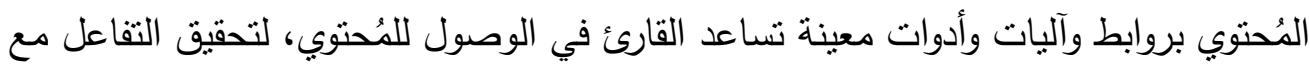

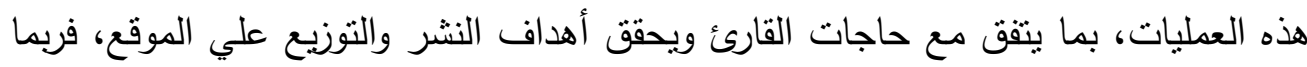

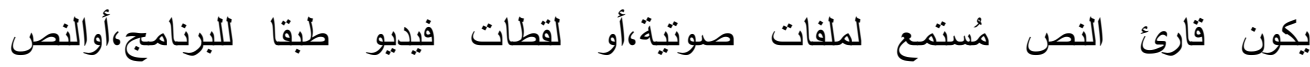

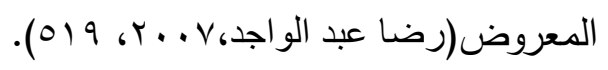
وتتميز صحافة الثبكات بانتشار أدوات الإنتاج مثل كاميرات الفيديو، الكاميرات الرقمية ،وأجزة الهواتف النقالة، والمستخدمة في الإعلام المسموع والمرئي، فمع انتشار المواقع الإكترونية التي تسمح بإرفاق وبث مقاطع الفيديو مثل موقع اليوتيوب، حيث يتيح

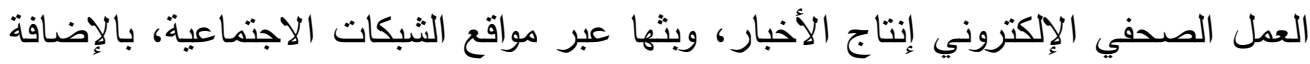

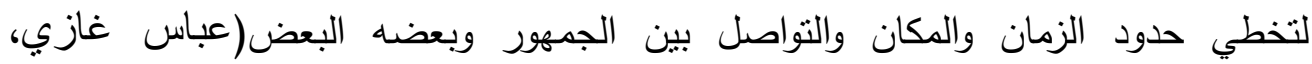
$\cdot(r \cdot)$.

\section{تعريف الصحافة الإكترونية عبر مواقع الشبكات الاجتماعية:}

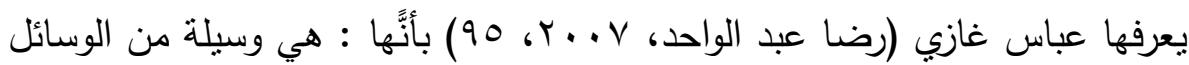
متعددة الوسائط multimedia تتشر فيها الأخبار والمقالات وكافة الفنون الصحفية عبر شبكة المعلومات الدولية الإنترنت بشكل دوري وبرقم مسلسل، باستخدام تقنيات عرض النصوص والرسوم والصور المُتحركة وبعض الميزات التفاعلية ، وتصل إلى القارئ من خلال شانشة الحاسب الآلي، سواء كان لها أصل مطبوع، أو كانت صحيفة إلكترونية خالصة.

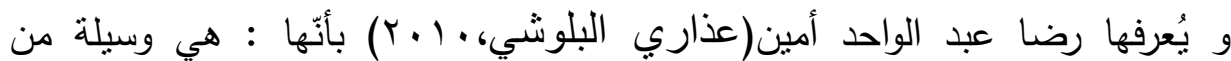
الوسائل متعددة الوسائط multimedia تتشر فيها الأخبار والمقالات وكافة الفنون الصحفية عبر شبكة المعلومات الدولية الإنترنيت بشكل دوري وبرقم مسلسل، باستخدام تقنيات عرض النصوص والرسوم والصور المُتحركة وبعض الميزات التقاعلية، وتصل إلى القارئ من خلال شاشة الحاسب الآلي ، سواء كان لها أصل مطبوع، أو كانت صحيفة إلكترونية خالصة. 
وتُعرف إجرائيًا بأنها : صحافة مقروءة ومسمُوعة ومرئية تستخدم الوسائط المتعددة

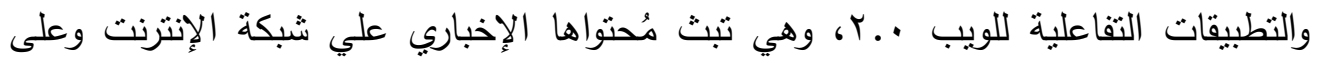
صفحتها بمواقع شبكات التواصل الاجتماعي. أهمية الصحف الإكترونية عبر مواقع التواصل الاجتماعي:

يكفي الصحافة الإلكترونية أنَّها في الغالب تتيح الحرية الكاملة التي يتمتع بها القارئ

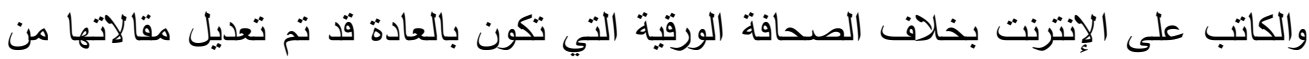

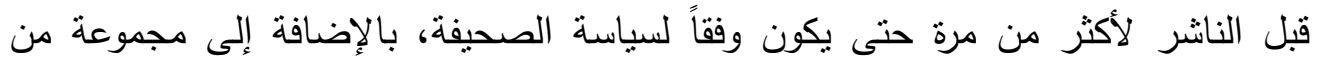

الكُميزات تم تلخيصها فيما يلي:(Shedden ,David,2005) 1-السرعة في تلقي الأخبار العاجلة، وتضمين الصور ، وأفلام الفيديو مما يدعم مصداقية

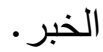
ץ-سرعة وسهولة تداول البيانات على الإنترنت بفارق كبير عن الصحافة الورقية التي يجب أن تقوم بانتظارها حتى صباح اليوم التالي. r-حدوث تفاعل مُباشر بين القارئ والكاتب حيث يُمكنهما أن يلتقيا في التوقيت واللحظة معاً. ع-أتاحت الصحافة الإلكترونية إمكانية مُشاركة مباشرة للقارئ في عملية التحرير من خلال التعليقات التي توفرها الكثثر من الصحف الإكترونية للقراء بحيث بمكن للمشارك أن يكتب تعليقه على أي مقال أو موضوع، ويقوم بالنشر لنفسه في نفس اللحظة. 0-عدم حاجة الصحف الإلكترونية إلى مقر موحد لجميع العاملين، حيث يُمكن إصدار الصحف الإككترونية بفريق عمل متفرق في أنحاء العالم. ؟-إمكانية مُتابعة الجديد من الأخبار في أي وقت خاصة مع وجود خدمة التحديث التي يتم إدخالها على الصحيفة الإلكترونية على مدار اليوم، ولا يتوافر هذا في الصحيفة الورقية نظرا للكلفة العالية لإصدار طبعات إضافية من الصحيفة لمُتابعة الجديد من الأحداث. نشأة الصحف الإكترونية علي مواقع الثبكات الاجتماعية:

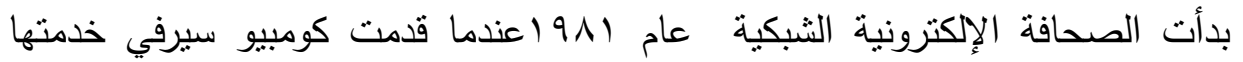

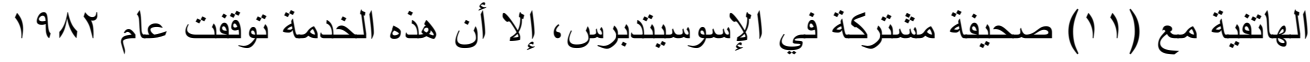

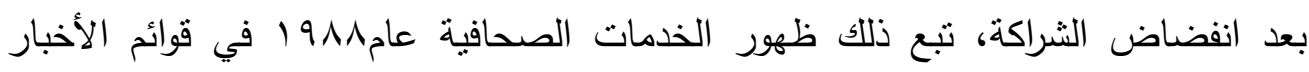

الإلكترونية(Kawamoto.k,2003) 
وفي عام 199 أنشأت شيكاغو أونلاين أول صحيفة إلكترونية على شبكة أمبركا

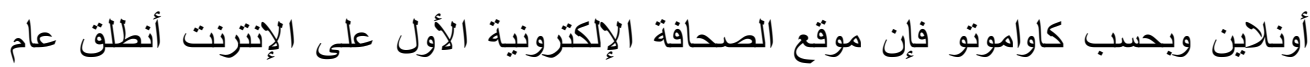
1991 في كلبة الصحافة والاتصال الجماهيري في جامعة فلوريدا، وهو موقع بالو الألتو

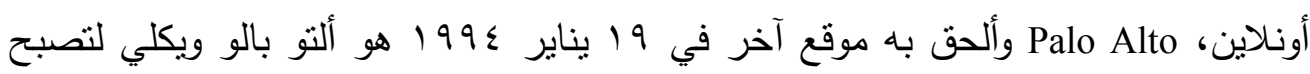

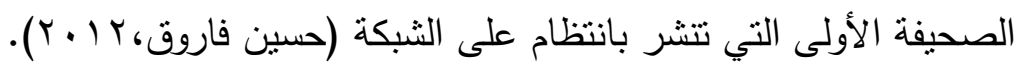

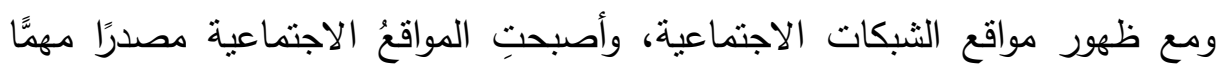

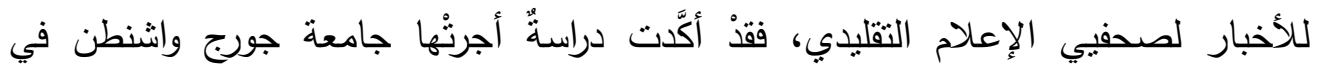

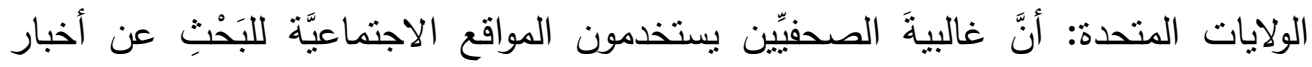

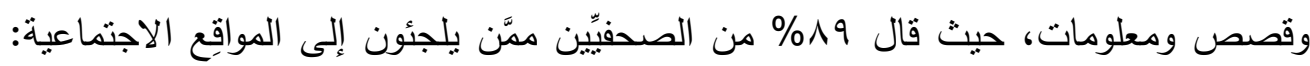

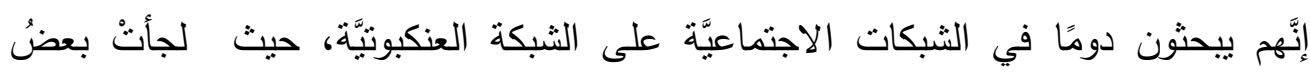

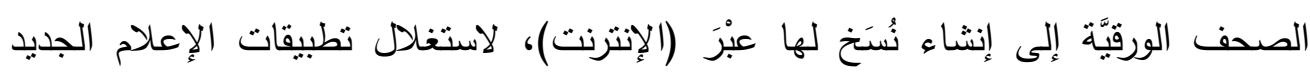

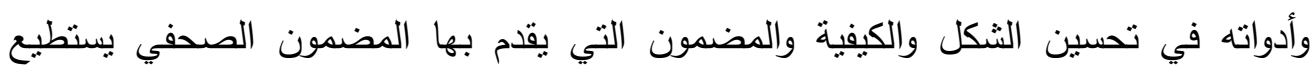

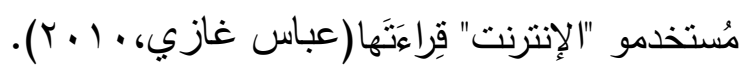

\section{خصائص الصحافة الإلكترونية وسماتها:}

هناك مجموعة من السمات والخصائص تتميز بها صحافة الثبكات ومنها: "( مي العبد

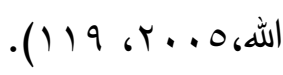
1- (-تعدد الوسائط. r-التفاعل والمُشاركة.

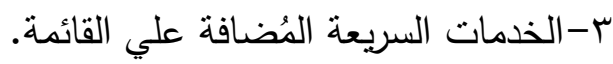

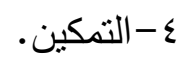

0-تخطي حدود الزمان والمكان •

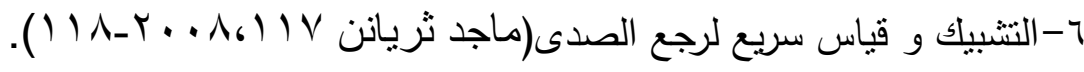

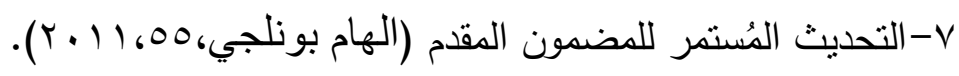
أنواع الصحف الإلكترونية عبر مواقع التواصل الاجتماعي:

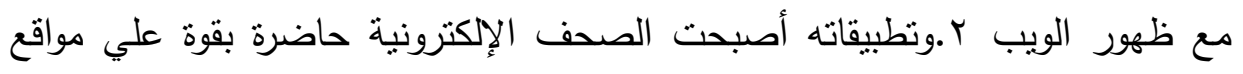
شبكات التواصل الاجتماعي وتعددت أنواع الصحف الإلكترونية عبر مواقع التواصل

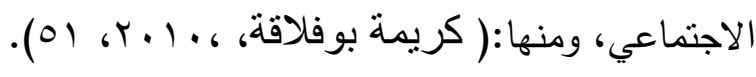


ا-المواقع الإخبارية :وهي تللك الصحف المستقلة بذاتها ، والتي تتبع مؤسسة إعلامية مثل شبكة أو قناة إخبارية، ومن أمتلة هذه المواقع موقع الجزيرة، موقع العربية، موقع البوابة

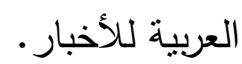
ץ-مواقع التعليق على وسائل الإعلام : وهى تللك المواقع التي تقوم بالنقد والتحليل للمضدون

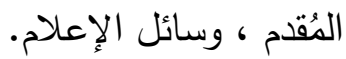

\section{الوسائط المُتعددة في الصحافة الإلكترونية الثبكية Multimedia :}

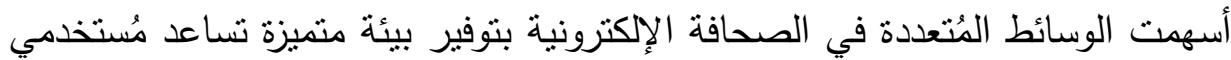

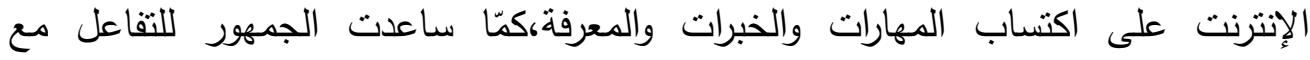
النصوص الجامدة من خلال تضمين النصوص لقطات مسموعة ومرئية، وصور ورسوما

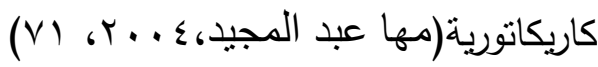

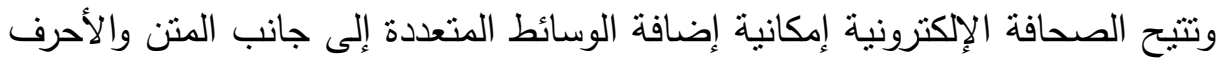
، حيث يُمكن إضافة الصوت، والصورة، والفيديو، والثأثثرات المُختلفة بكل سهولة ويسر مدّا

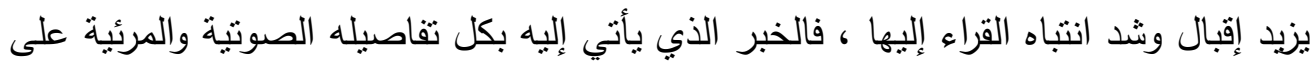

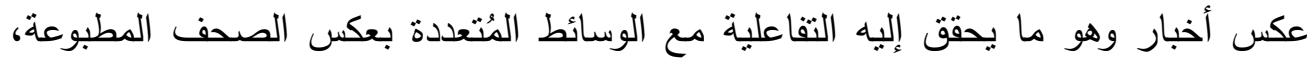

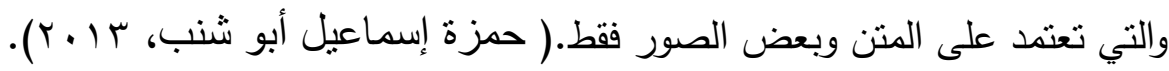

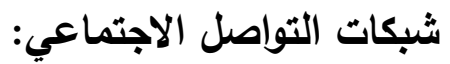
شهد العالم في السنوات الأخيرة نوعًا من التواصل الاجتماعي بين البشر في فضاء

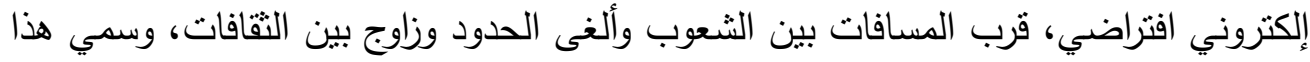

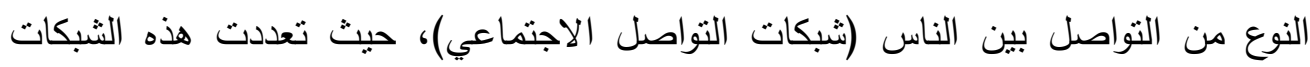

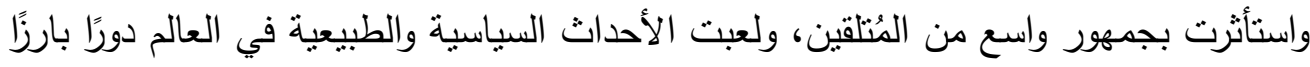

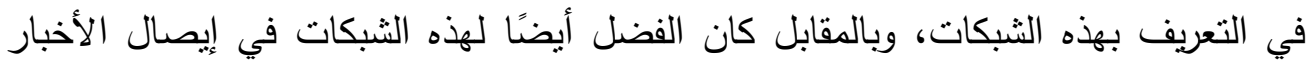

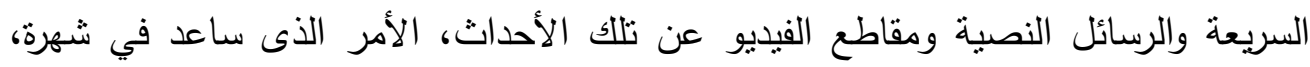

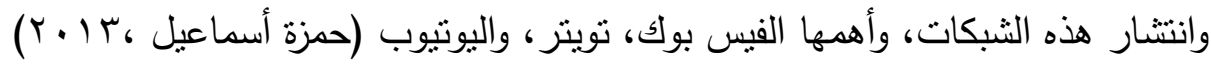

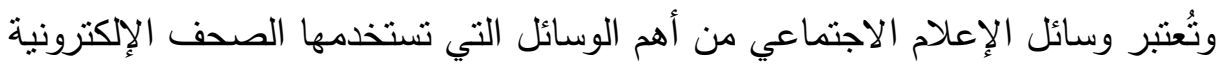

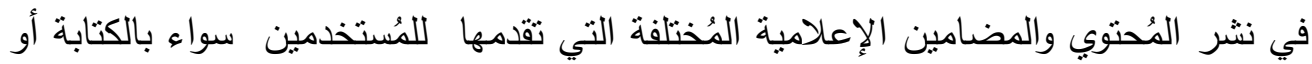

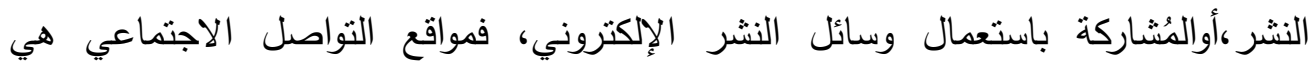

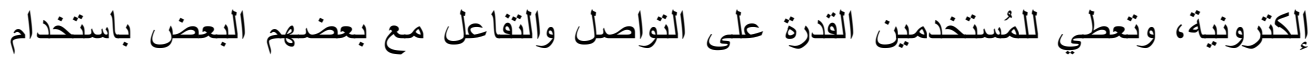

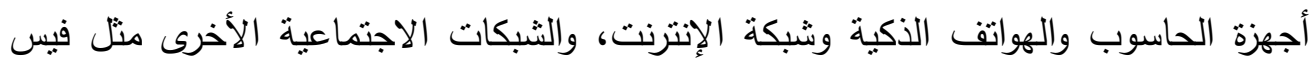

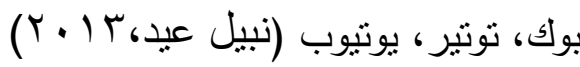




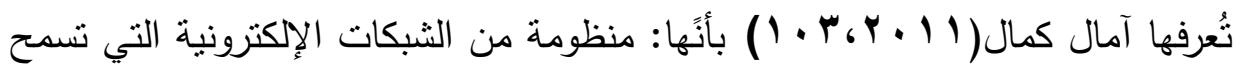

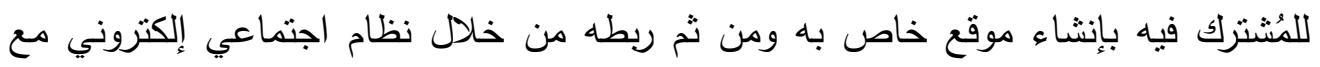

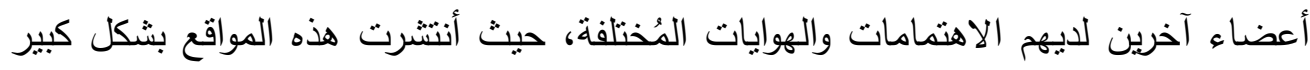

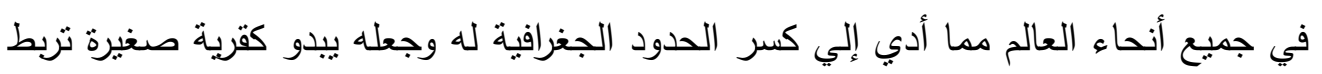
أبناءه بعضهم ببعض.

ويُعرفها جان كينزمن, Jan H Kietzmann(2014,241-251) بأنَّها :عملية تتألف من

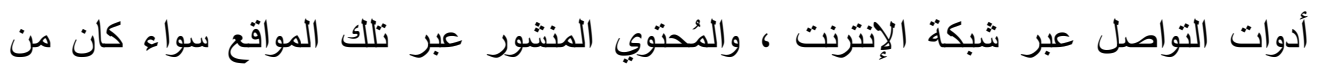

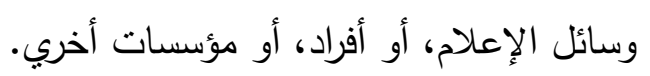
شبكة الفيس بوك كوسيلة تفاعلية للصحف الإكترونية:

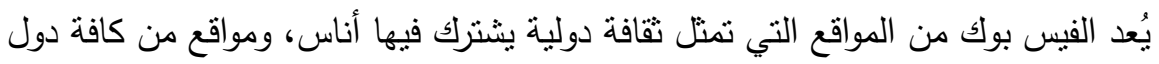

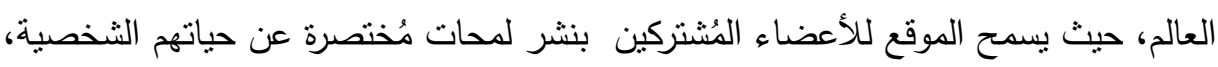

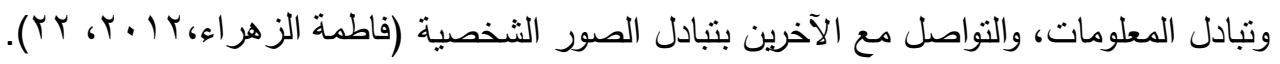
تأسست شبكة " الفيس بوك" على يد مارك زكربيرج mark zuckerberg وهو طالب في جامعة هارفرد، وقد كان هدفه إقامة شبكة تضم طلبة الجامعة في موقع واحد، ونفد الفكرة

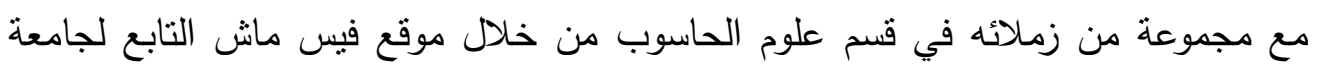

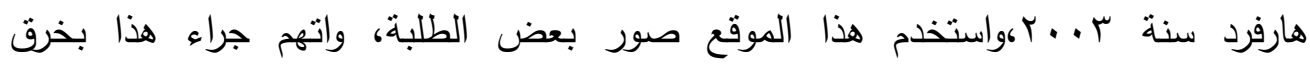

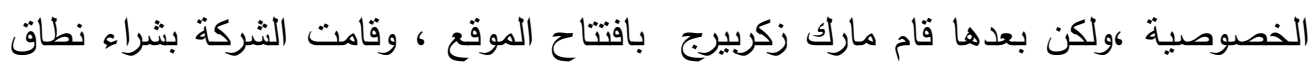

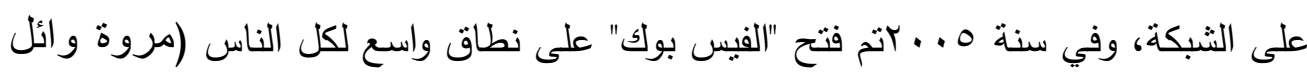

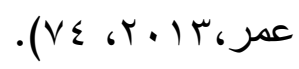
ويتضح استخدام الصحف الإكترونية لموقع شبكة التواصل الاجتماعي فيس بوك

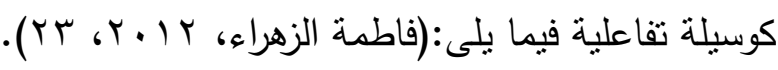

$$
\begin{aligned}
& \text { 1-برعة تبادل المعلومات والأخبار . }
\end{aligned}
$$

ץ-الحصول على تغذية راجعة، والتعرف علي آراء الناس تجاه الخدمات المُقدمة من الموقع.

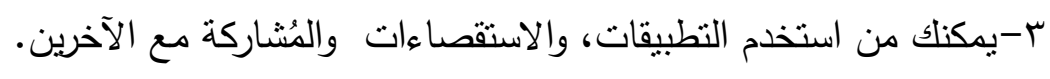
ع-يُمكن استخدامه للمراسلة كبديل للبريد الإككتروني.

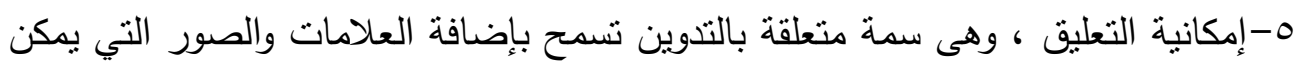

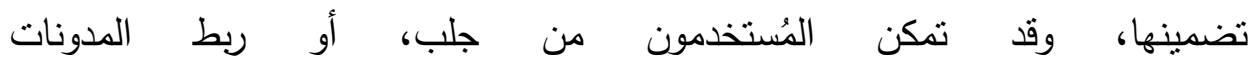
(CARROLLD.CLYNN,2012,117 Michael) 


\section{الصحف الإكترونية على مواقع التواصل الاجتماعي:}

أصبحت الصحف الإلكترونية تمتلك صفحات لها على موقع شبكة التواصل الاجتماعي الإسي الفيس بوك FACEBOOK، حيث أصبحت تتيح للمُستخدمين الاتشتراك في التغذية الإخباريةللمواد الغلامية المُختلفة ( Suzanne lysak, Michael,2012,187) وبدأت المؤسسات الإعلامية في بتوظيف محررين للإعلام الاجتماعي لتولى مسئولية الثبكات الاجتماعية (Charlie beckete,2088,44) وتتميز الصحف الإلكترونية على مواقع التواصل الاجتماعي بالتتوع في المضمون

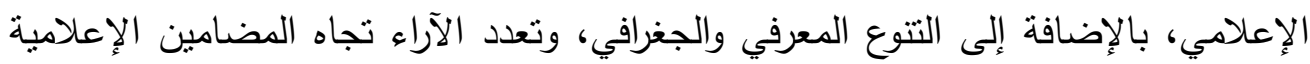

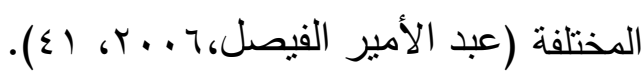
كمّا تتميز الصحف الإككترونية بالقدرة علي جذب القراء ، فمن خلال استخدام الوسائط

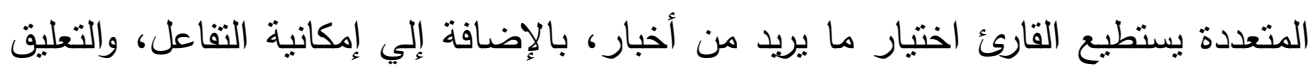

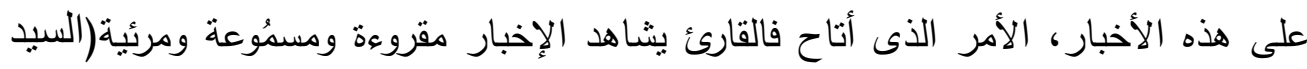

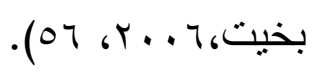

وأصبح بإمكان الصحف الإككترونية تحديث صفحاتها في فترات منقاربة من خلال

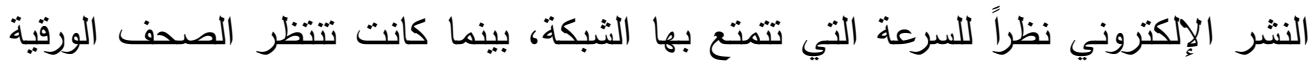

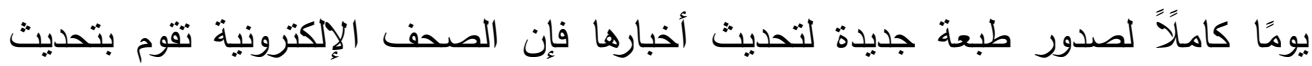

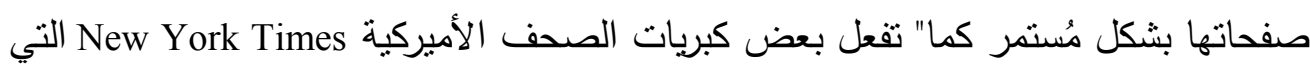

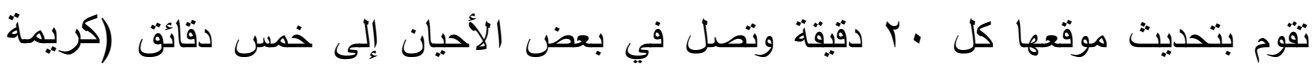

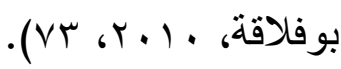

وقد ساعدت التفاعلية على تخصيص المواقع الإلكترونية صفحات للاهتمامات

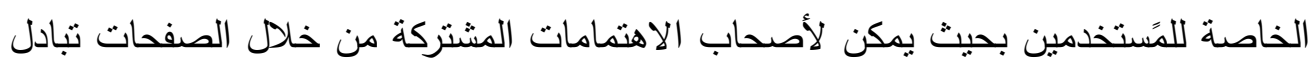

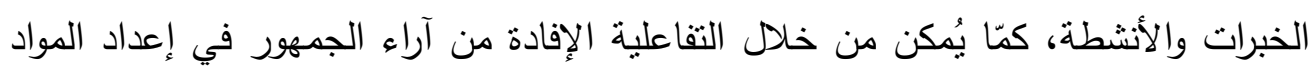

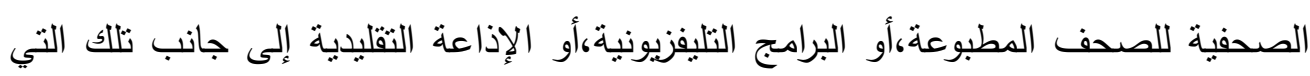
تتوفر عبر الإنترنت (حمزة إسماعيل، ب ا • ب). مميزات شبكات التواصل الاجتماعي كوسيلة تفاعلية في الصحف الإلكترونية: وبالرغم من ذللك فإن الثبكات الاجتماعية تتميز عن غيرها من المواقع في الثبكة

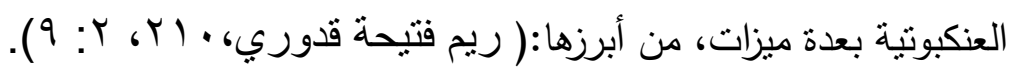


1-التفاعلية: فالفرد فيها كمّا أنه مُستقبل وقارئ، فهو مرسل وكاتب ومشارك في التعليق على الثى

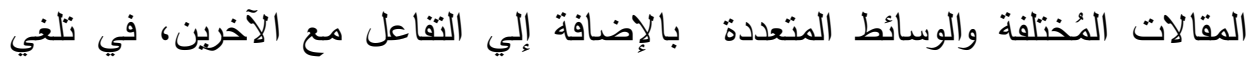

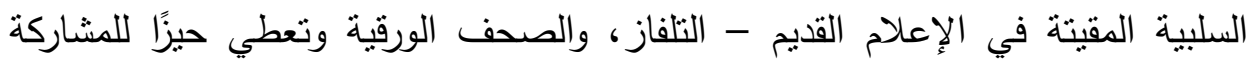
الفاعلة من المُشاهد والقارئ.

r-سهولة الاستخدام والتفاعل مع المحتوي : فالثبكات الاجتماعية تستخدم بالإضافة للحروف وبساطة اللغة، تستخدم الرموز والصور التي تسهل للمستخدم التفاعل.

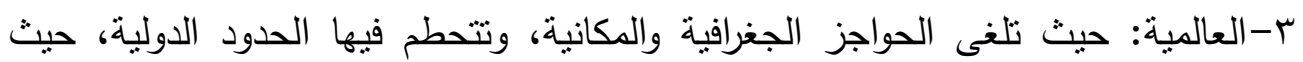
يسنطيع الفرد في الثرق التواصل مع الفرد في الغرب، في بساطة وسهولة.

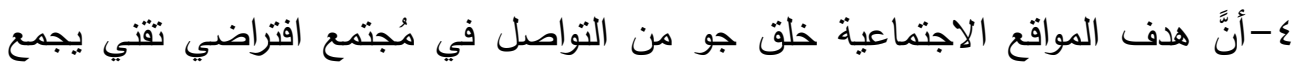

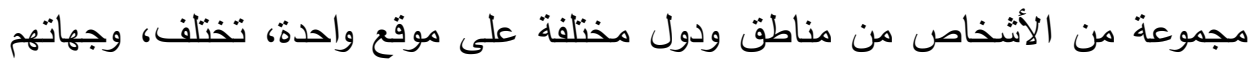
كومستوياتهم وألوانه، وتتفق لغتهم التقنية.

\section{التفاعلية في الصحافة الإلكترونية عبر مواقع الثبكات الاجتماعية:}

تُعتبر التفاعلية في الصحافة الإكترونية أحد الأدوات التي غيرت العملية الاتصالية

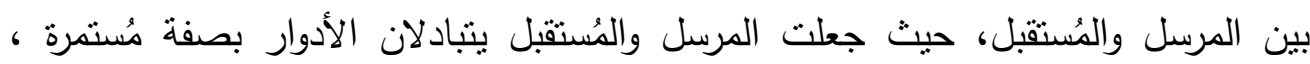
ويتوقف نجاح التفاعلية في الصحافة الإكترونية علي الأداء المهني للصحفيين القائمين علي لئي

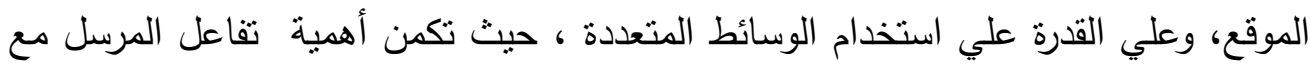

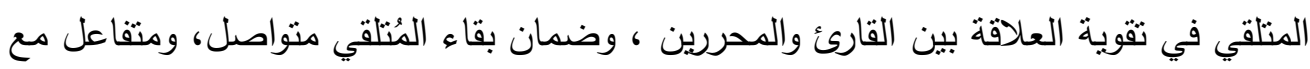
الموقع والرسائل الإعلامية التي ينشرها، كمّا ساهمت التفاعلية في رواج مُحتوي الصحافئ وضاء

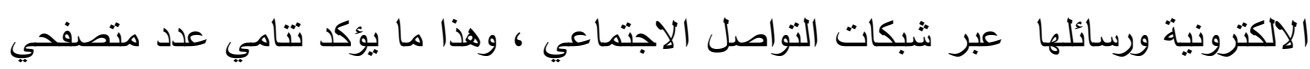

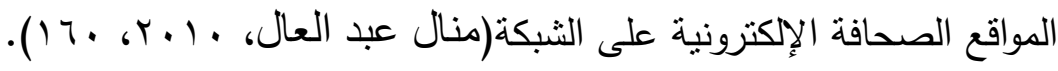
وتعتمد التفاعلية في الصحافة الإلكترونية على تفاعل المُستخدمين مع أنثكال عديدة الإنة

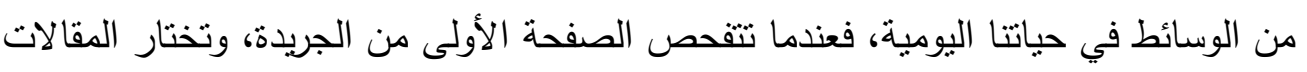

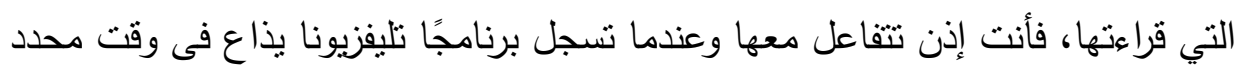
وتثاهده فيما بعد فأنت تستخدم التكنولوجيا التي تتيح للك التفاعل مع التليفزيون، لكن التفاعلية عادة تتسب إلى الكمبيوتر لما له من مُميزات في التخزين، والعرض، والبحثي فئ في كميات كبيرة جدًا من المعلومات (Dan Grigorovici, Siho Nam \& Chris Russill 2003,42) 
وتُشير التفاعلية إلى مُشاركة المُستقبل النشطة والفعّالة في العملية الاتصالية (Christopher,1998,43-45). وتعد الصحف الإلكترونية إحدى أهم وسائل الاتصال الجماهيري التي تتيح الاتصال التفاعلي بحيث يتمكن القارئ من التفاعل مع المصدر، وكذا لهذا

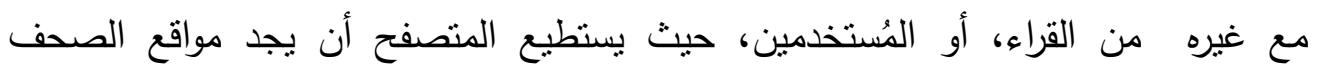
الإكترونية حقول خاصة في شتى الصفحات تتضمن الطلب من القراء أن يبدى أرائه حول يجل الموضوع المنشور ، أو يكتب تعليقاً عليه، وفى حالة قيام المُستخدم بذلك سيظهر تعليقه فورا

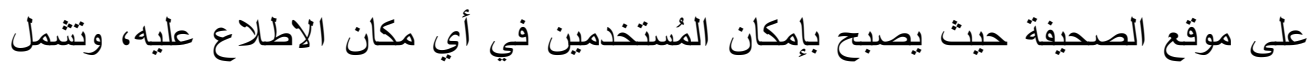

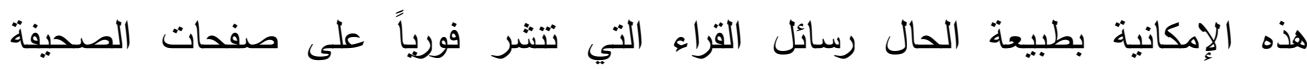

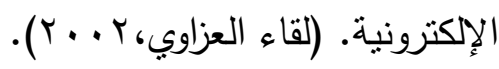

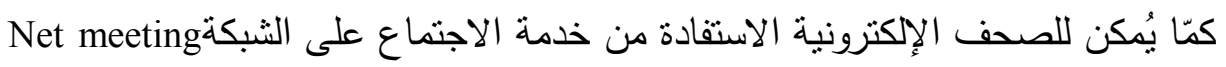

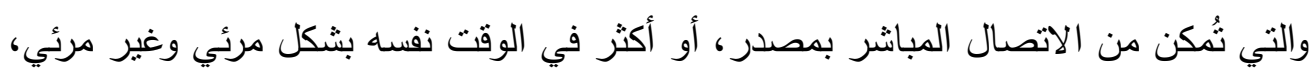

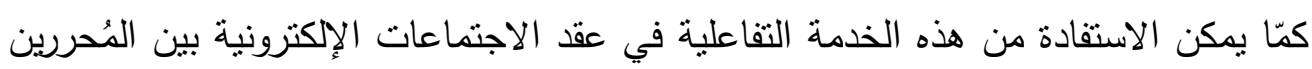

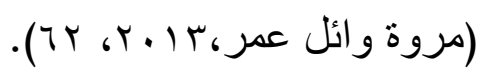
تعريف التفاعلية في الصحافة الإكترونية: تُعتبر التفاعلية في الصحافة الإلكترونية سمة من السمات التي تتميز بها وسائل الإعلام والاتصال الحديثة، والتي عملت علي خلق بيئة اتصالية قائمة على التفاعل، والحوار والمُشاركة بين أطراف العملية الاتصالية في وسائل الإعلام المختلفة: ولانه

\section{وتتعدد تعريفات التفاعلية باختلاف الباحثين، ومنها:}

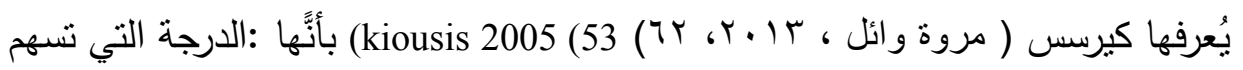

بها تكنولوجيا الاتصال في خلق بيئة اتصالية تسمح بالمُشاركة المُتساوية بين أطراف العملية

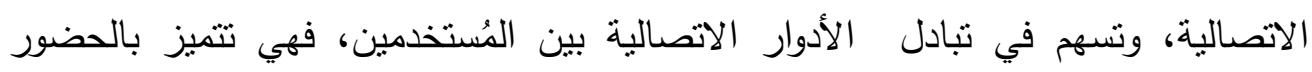

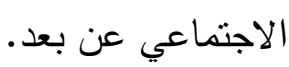

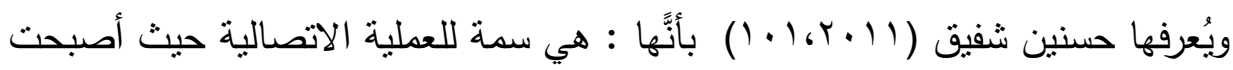
المرحلة التي نعيشها تعرف بالمرحلة التفاعلية، وليست أمراً توصف به الوسائط الاتصالية. 


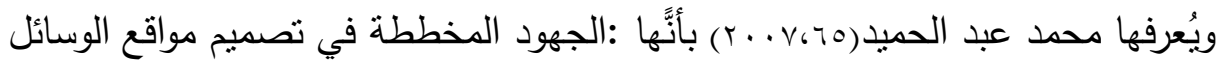

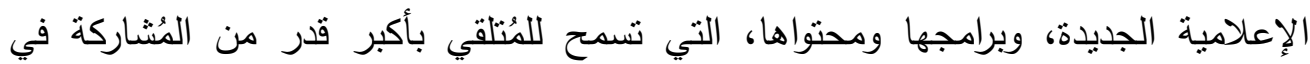

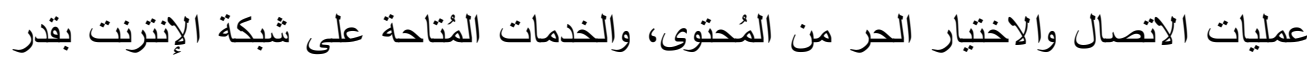
حاجاته، وتفضيله واهتمامه بالمضمون الكُقدم. وتُعد التقاعلية في نظر مشهور Mashihur هي تبادل للإثارات بين المرسل والمُستقبل للرسالة للوصول إلي الفهم المنبادل للإعلام، ويحدث التفاعل بين وسائل الإعلام وجمهورها،

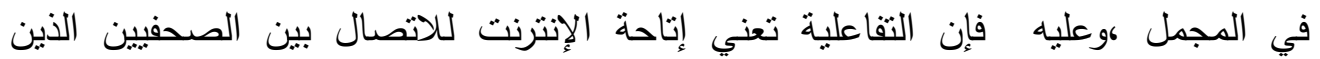
يحررون الصحف الإلكترونية وبين القراء، وبعضهم البعض-2008,620, Mashihur Rahm

مُستويات التفاعلية في الصحافة الإلكترونية عبر مواقع الثبكات الاجتماعية: أصبحت الصحف الإلكترونية حاضرة بقوة على شبكات التواصل الاجتماعي؛ حيث

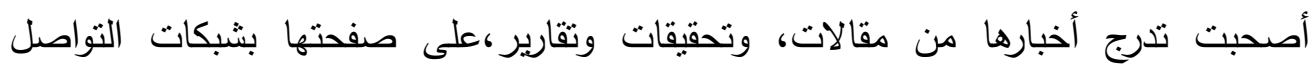

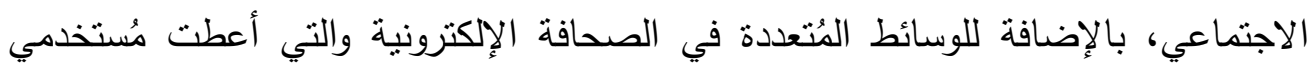
الصحف الإكترونية إمكانية التفاعل مع الوسائط، والإخبار المُلحقة بالفيديو، والصور

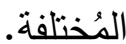

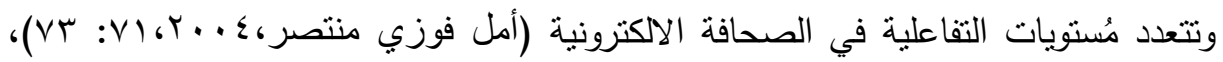
ومنها:

المُستوي الأول للتفاعل : هو من مصدر واحد للعديد من الملتقيين ويستهدف هذا

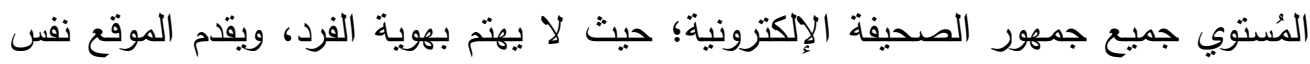

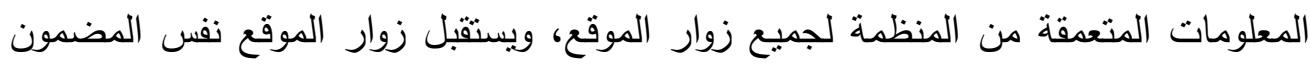

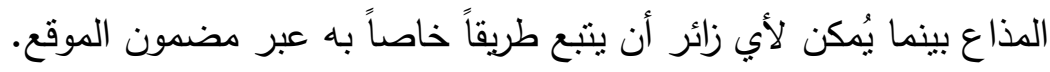

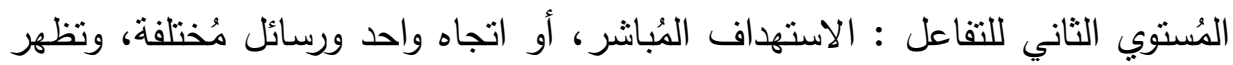

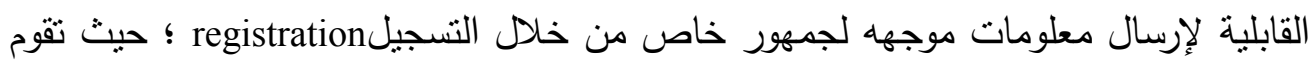
الصحف الإلكترونية على مواقع التواصل الاجتماعي بنشر احتياجات كل مجموعة من من فئ

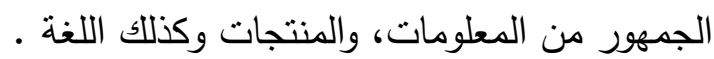

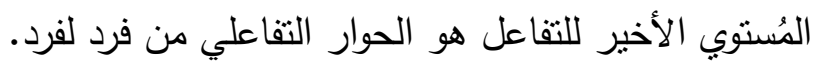

One - to - one interactive dialogue وبينما لا تزال غالبية المعلومات تتدفق من المنظمة إلى الجمهور يكون رجع الصدى والحوار مُمكنا في هذا المُستوى. غُلــ 


\section{أشكال التفاعلية في الصحافة الإكترونية عبر مواقع الثبكات الاجتماعية:}

التفاعلية القابلة للنقر:

التفاعلية القابلة للنقر Clickable Interactive هي نسخة تفاعلية للصّحيفة التقليدية

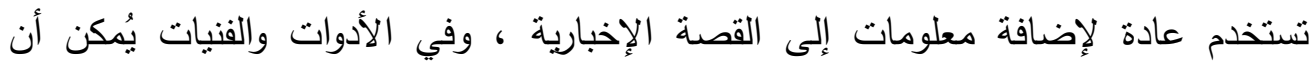

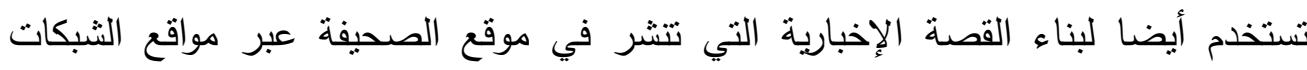

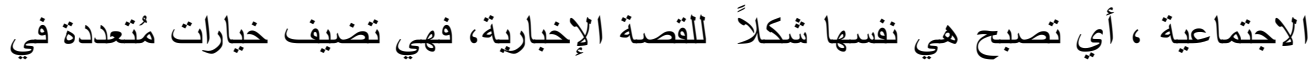

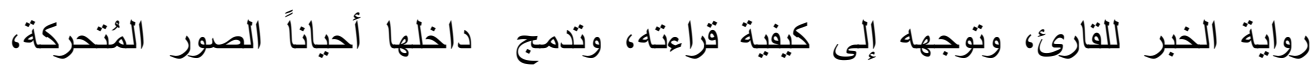

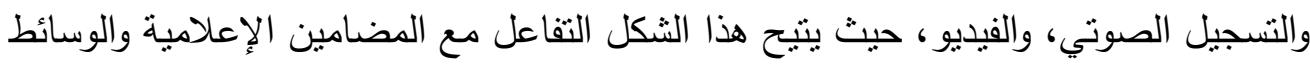

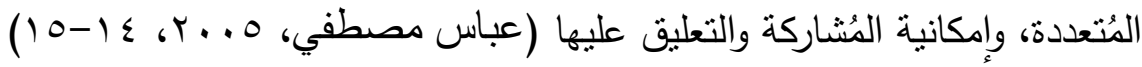
الشرائح المصحوية بالتعليق : في الثرائح المصحوبة بالتعليق Narrated Slideshows يتم دمج التسجيل الصوتي

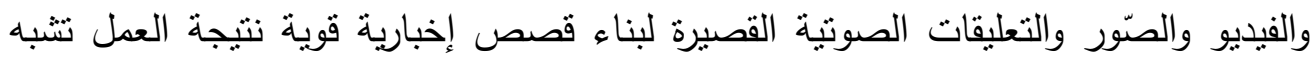

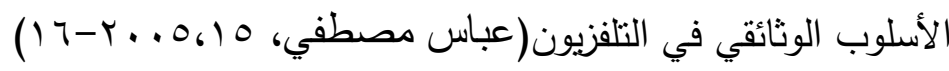

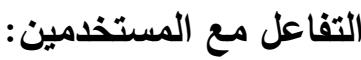
تري الباحثة أنه يُمكن لمُستخدمي الصحف الإلكترونية عبر مواقع التواصل الاجتماعي إمكانية التفاعل مع المضامين الاعلامية المُختلفة، والتفاعل مع الرأي والرأي

$$
\text { الأخر دون قيود. }
$$

التفاعل مع الوسيلة:

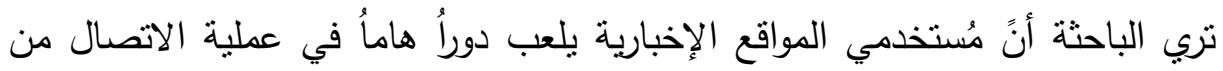

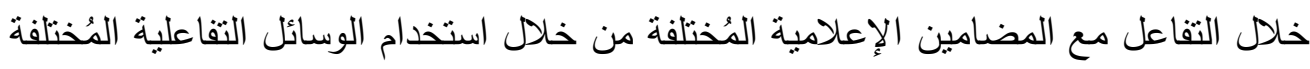

$$
\text { التُائتج الداحة علي الموقع. }
$$

يشمل هذا الجزء نتائج الاراسة الميدانية، بالإضافة إلى نتائج اختبار صحة الفروض

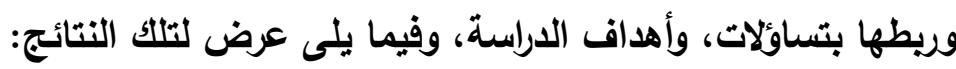
أولاًا توصيف عينة الدراسة:

أجريت الدراسة الميدانية على عينة عمديه قوامها ( (.ع) مفردة من مُّتخدمي الصحف الالكترونية لتفاعلية شبكات التواصل الاجتماعي، وعلاقته بمُستويات التفاعلية تجاه قضايا الإرهاب، وفيما يلي عرض لتوصيف عينة الدراسة. 


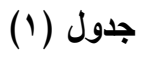

توصيف عينة الاراسة وفقًا النوع (ن= . . ؛ )

\begin{tabular}{|c|c|c|c|}
\hline$\%$ & s & النوع & م \\
\hline$\% 40$ & זч. & ذكر & 1 \\
\hline \%ro & $1 \leqslant$. & أنثى & $r$ \\
\hline$\% 1 \ldots$ & $\varepsilon \ldots$ & \multicolumn{2}{|c|}{ المجموع } \\
\hline
\end{tabular}

$$
\text { يتضح من جدول ( } 1 \text { ) ما يلي: }
$$

- - أنَّ نسبة كل من الذكور والإناث في عينة الدراسة من مستخدمي الصحف الإكترونية لتفاعلية شبكات التواصل الاجتماعي، حيث بلغت نسبة الذكور من مُستخدمي الصحف

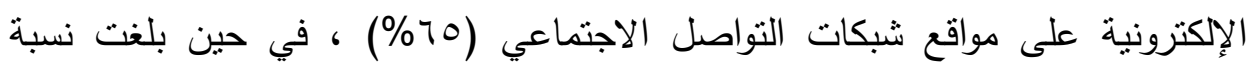

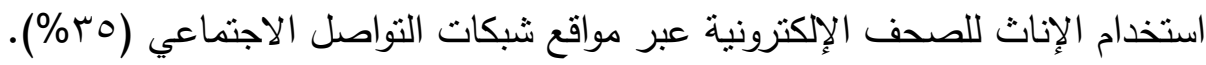

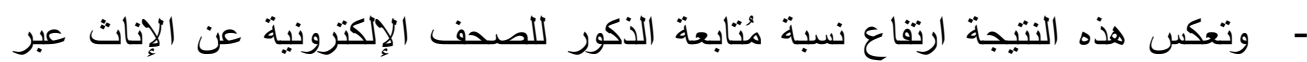

$$
\text { مواقع شبكات التواصل الاجتماعي. }
$$

جدول (r)

\begin{tabular}{|c|c|c|c|}
\hline$\%$ & ك & التواصل الاجتماعي الصحف الإكترونية على مواقع شبكات & م \\
\hline$\% 1 \ldots$ & $\varepsilon \ldots$ & نعم & 1 \\
\hline- & - & 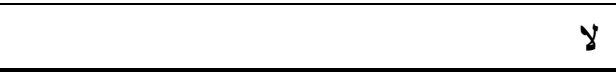 & $r$ \\
\hline$\% 1 \ldots$ & $\varepsilon \ldots$ & وع & \\
\hline
\end{tabular}

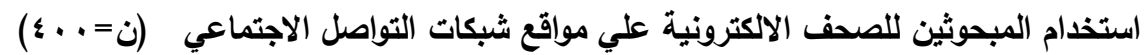

$$
\text { يتضح من جدول (r) ما يلي: }
$$

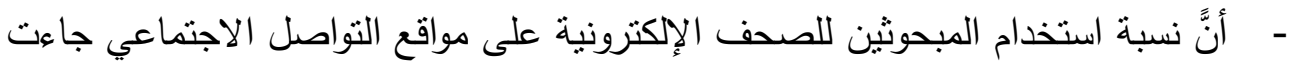

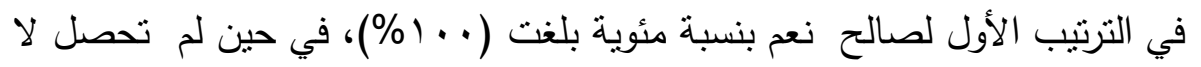
علي أي نسبة.

- وتعكس هذه النتيجة ارتفاع نسبية استخدام المبحوثين للصحف الإلكترونية على مواقع التواصل الاجتماعي.، وبالتالي زيادة نسبة مُتابعة المبحوثين لقضايا الإرهاب، والوصول للهدف المراد تحقيقه. 
جدول (r)

درجة استخدام المبحوثين للصحف الإكترونية عبر مواقع شبكات التواصل الاجتماعيا(ن= . . ؛)

\begin{tabular}{|c|c|c|c|}
\hline$\%$ & ك & التواصل الاجتماعي لمتلـ للصف الإكترونية عبر مواقع شبكات & م \\
\hline$\%$ \% & rq. & أستخدم بدرجة كبيرة & 1 \\
\hline$\%$ rr & $9 r$ & أستخدم بدرجة متوسطة & r \\
\hline$\%$ ir & $\varepsilon \wedge$ & أستخدم بدرجة ضعيفة & $r$ \\
\hline$\% 1 \ldots$ & $\{\ldots$ & \multicolumn{2}{|c|}{ المجموع } \\
\hline
\end{tabular}

$$
\text { بتضح من جدول (r) ما يلي: }
$$

- أنً درجة أستخدم المبحوثين للصحف الإلكترونية عبر مواقع شبكات التواصل الاجتماعي

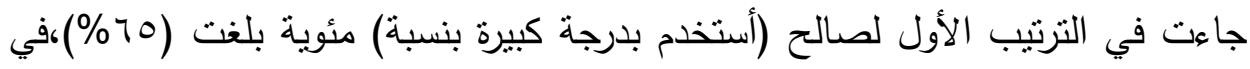

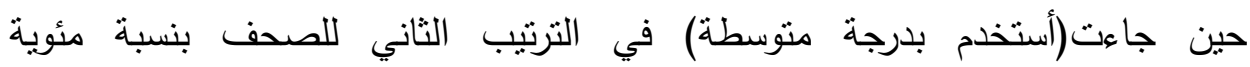
بلغت(rr\%)، بينما جاءت (أستخدم بدرجة ضعيفة) في الترتيب الثالث بنسبة مئوية

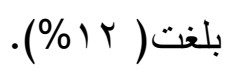

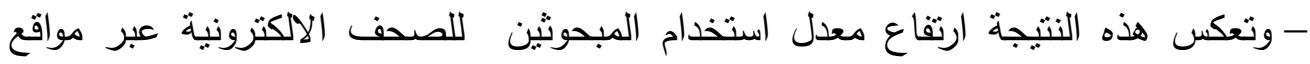

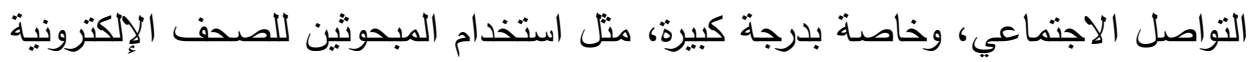

بالدرجات السابق ذكرها، لمعرفة المضامين الإعلامية التي بريدون الاطلاع علئ اليها.

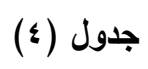

\begin{tabular}{|c|c|c|c|}
\hline$\%$ & ك & التُعدل الوقت الذي يقضيه المبحوثين لمتابعة قضايا & ? \\
\hline$\%$ \% 1 & $1 \leqslant$. & أقل من نصف ساعة & 1 \\
\hline$\%$ ro & $17 \varepsilon$ & من ساعة إلى ساعتين & r \\
\hline$\% r \leqslant$ & 99 & ثُلاث ساعات فأكثر & $r$ \\
\hline$\% 1 \ldots$ & $\{\ldots$ & \multicolumn{2}{|c|}{ المجموع } \\
\hline
\end{tabular}

مُعل الوقت الذى يقضيه المبحوثين لمتابعة قضايا الارهاب التي تنثر في الصحف الإكترونية عبر مواقع

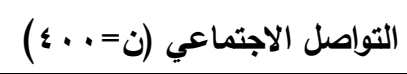




$$
\text { يتضح من جدول ( ) ما يلي: }
$$

- أنَّ نسبة مُعدل الوقت الذي يقضيه الطلاب لمُّتابعة قضايا الارهاب بالصحف الإلكترونية

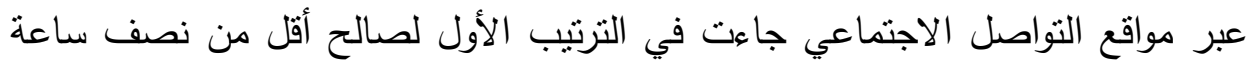

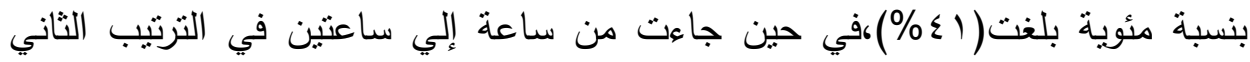

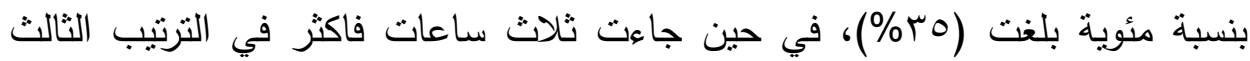

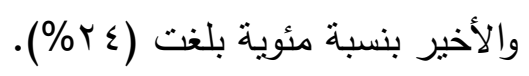

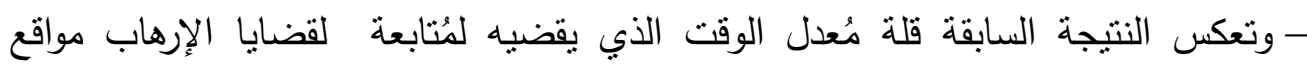

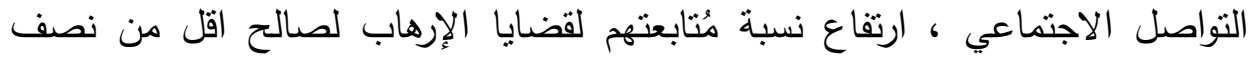

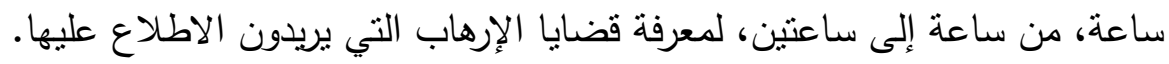

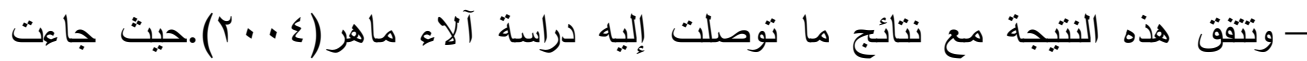
استخدام مواقع الثنبكات الاجتماعية من ساعة إلي ساعتين في الترتيب الأول بينما جاء التهاء

$$
\text { في الدراسة الحالية في المرتبة الثانية. }
$$

جدول (•)

\begin{tabular}{|c|c|c|c|}
\hline$\%$ & ك & مواقع التواصل استخام الاجبحوثين للصحف الإكترونية عبر & p \\
\hline$\% 19.17$ & IrT & لمعرفة الأخبار والأحداث الجارية & 1 \\
\hline$\% 10 . \wedge 0$ & 11. & لتكوين رأى حول قضية ما أو تعزيزها & r \\
\hline$\% १ r .4 \wedge$ & $\wedge \wedge$ & تخصتفي من مطالعتي للصحف الإكترونية في مجال & $r$ \\
\hline \%४ч.v & roo & التعرف على أكثر من رأى في القضية المطروحة & $\varepsilon$ \\
\hline$\% 1 . \wedge \mathrm{V}$ & Ir & الحصول على أكبر قدر من المعلومات بأقل كلفة & 0 \\
\hline$\% \wedge . . \uparrow$ & 09 & تناقش قضايا لا تتواجد في وسائل الإعلام الأخرى & 7 \\
\hline$\% 0.7 \leq$ & rq & أستخدمها كوسيلة للتسلية & $\mathrm{v}$ \\
\hline$\% 1 \ldots$ & $79 \varepsilon$ & 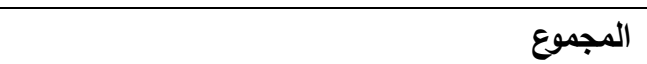 & \\
\hline
\end{tabular}

أسباب استخدام المبحوثين للصحف الإكترونية عبر مواقع التواصل الاجتماعي (يُمكنتك اختيار اكثر من

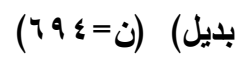

$$
\text { يتضح من جدول (0) ما يلي: }
$$

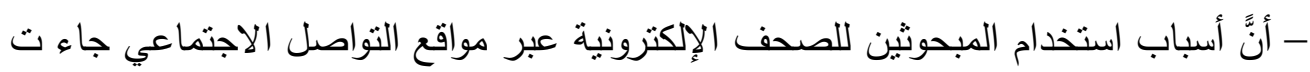

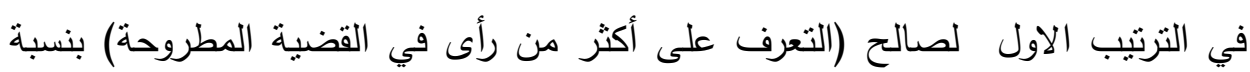

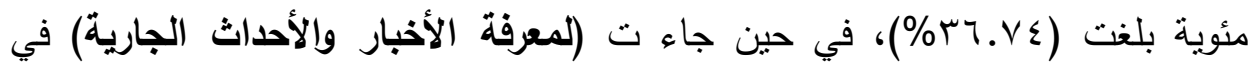

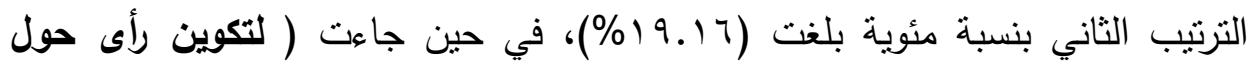


قضية ما أو تعزيزها) في الترتيب الثالث بنسبة مئوية بلغت(0.10 (1\%)، في حين جاءت (أستفيد من مطالعتي للصحف الإكترونية في مجال تخصصي) في الترتب

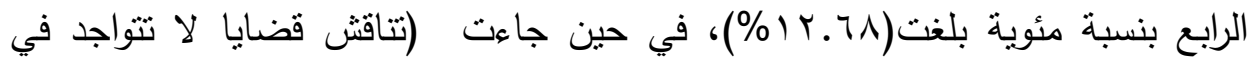

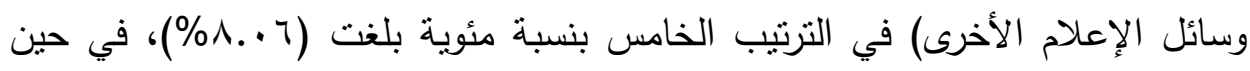

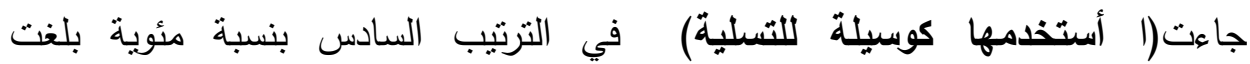

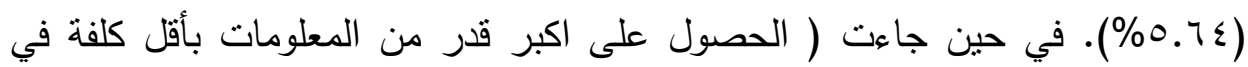

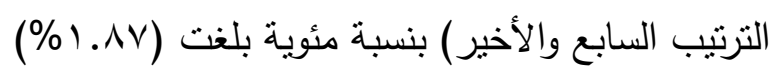

- وتعكس النتيجة السابقة إقبال المبحوثين علي استخدام الصحف عبر مواقع التواصل

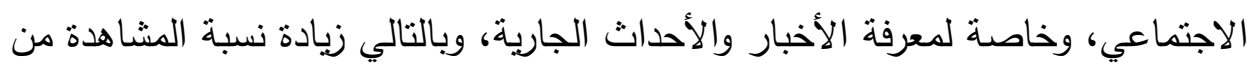

قبل المبحوثين، والوصول للهدف المراد تحقيقه.

جدول (7)

ميتابعة المبحوثين للوسائط المتعددة المستخدمة في عرض قضايا الارهاب في الصحف الإكترونية عبر

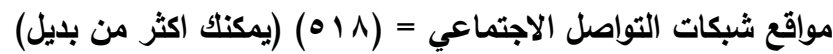

\begin{tabular}{|c|c|c|c|}
\hline$\%$ & ك & 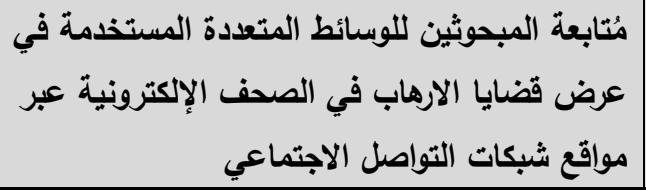 & r \\
\hline \%०r.r. & rvi & مقاطع الفيديو & 1 \\
\hline$\%$ \%१.०५ & 99 & مقاطع الصوت & r \\
\hline$\% ץ+. \leq 4$ & 1.7 & الصور & $r$ \\
\hline$\% \wedge . \vee$ & $\leq 0$ & الروابط التشعبية للأخبار & $\varepsilon$ \\
\hline$\% 1 \ldots$ & 011 & المجموع & \\
\hline
\end{tabular}

$$
\text { بتضح من جدول (7) ما يلي: }
$$

- أنَّ نسبة مُتابعة المبحوثين للوسائط المتعددة المستخدمة في عرض قضايا الارهاب بالصحف الإكترونية عبر مواقع شبكات التواصل الاجتماعي جاءت في النرتيب الأول

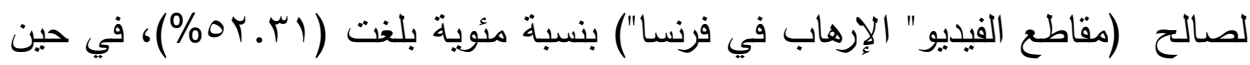

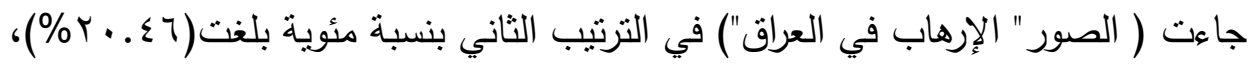
في حين جاءت (مقاطع الصوت" الإرهاب في تونس") في الترتيب الثالث بنسبة مئوية 
بلغت(1.01\%)، في حين جاءت (الروابط التشعبية للأخبار) في الترتيب الرابع

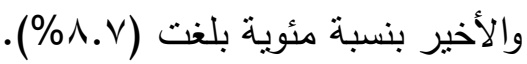

- وتعكس هذه النتيجة ارتفاع مُتابعة المبحوثين للوسائط المتعددة المستخدمة في عرض

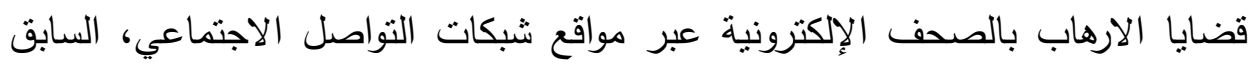
ذكرها في الجدول السابق لقضايا الإرهاب كونها وسيله هامة لهم تتقل الحقيقة.

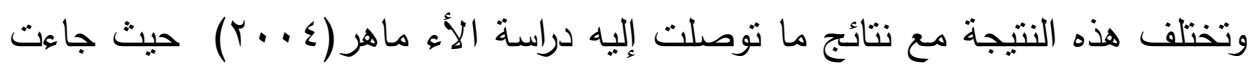
استخدام مقاطع الفيديو في المرتبة الثانية بينما جاء في الدراسة الحالية في المرنبة الأولي

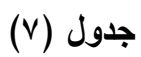

مدي مُتابعة المبحوثين للمنظمات الإرهابية المتهمة بارتكاب جرائم الإرهاب المذكورة بالصحف الإكترونية ن

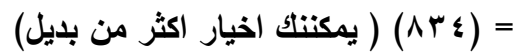

\begin{tabular}{|c|c|c|c|}
\hline$\%$ & ك5 & مدي مُتابعة المبحوثين للمنظمات الإرهابية المتهمة & م \\
\hline$\%$ \%०. 40 & YI纟 & داعش & 1 \\
\hline$\% 14.4$ & iro & جبهة النصرة & r \\
\hline$\% r \cdot . l$ & 171 & الجماعات الجهادية & $r$ \\
\hline$\% \wedge . \varepsilon$ & v. & جماعة بوكو حرام & $\varepsilon$ \\
\hline$\% \backslash \wedge . \vee$ & 109 & حركة الثباب الصومالية & • \\
\hline$\% 1 . .90$ & 91 & جماعة أنصار بيت المقدس & \\
\hline$\% 1 \ldots$ & צ & المجموع & \\
\hline
\end{tabular}

$$
\text { يتضح من جدول (V) ما يلي: }
$$

- أنَّ نسبة متابعة المبحوثين للمنظمات الإرهابية المتهمة بارتكاب جرائم الإرهاب المذكورة بالصحف الإكترونية جاعت في الترتيب الأول ( داعش) بنسبة مئوية بلغت

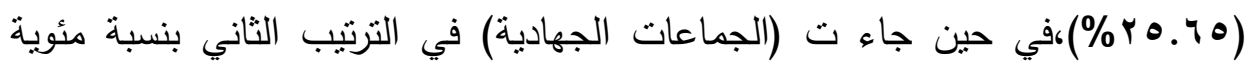

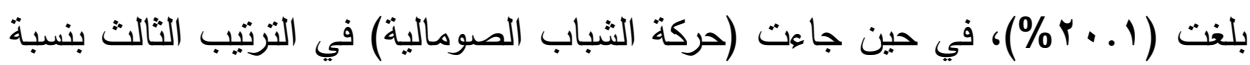

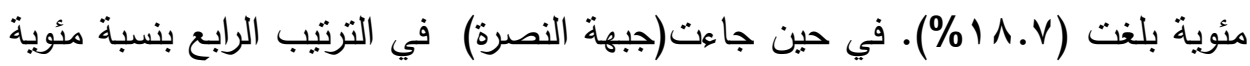

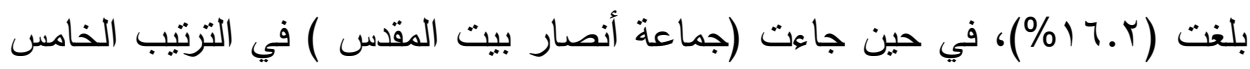
بنسبة مئوية بلغت (90. • (1\%)، في حين جاءت (جماعة بوكو حرام) في الترتيب السادس

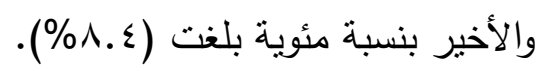


- وتعكس النتيجة السابقة ارتفاع نسبة مُتابعة المبحوثين للمنظمات الإرهابية المتهمة بارتكاب جرائم الإرهاب الدذكورة بالصحف الإككترونية سابقة الذكر، وبالتالي زيادة نسبة متابعة المبحوثين للجرائم التي ترتكبها هذه الجماعات.

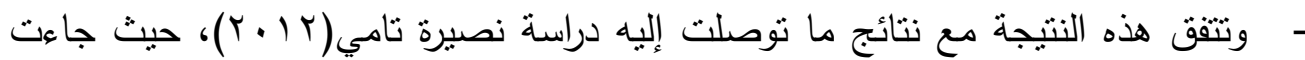
داعش في المرتبة الأولي بينما جاءت في دراسة نصيرة تامي في المرتبة الأولي.

$$
\text { جدول (^) }
$$

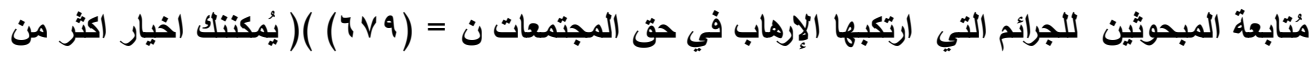
بديل)

\begin{tabular}{|c|c|c|c|}
\hline$\%$ & ك & متابعة المبحوثين للجرائم التي ارتكبها الإرهاب في حق & r \\
\hline \%।r.s & 91 & قتل المدنيين & 1 \\
\hline$\% \wedge$. ५ & 04 & تفجير المطارات ومحطات القطار & r \\
\hline$\% \leqslant 1 . \vee$ & rAT & أفكار متطرفة تحرض الثباب عبر مواقع التواصل الاجتماعي ونشر الكنف & $r$ \\
\hline$\%$ \%r.v & 94 & خطف واحتجاز الرهائن & $\varepsilon$ \\
\hline$\% 11.9$ & 11 & الاعتداء علي دور العبادة & 。 \\
\hline$\% 11.1$ & vo & بث الرعب والخوف في نفوس المواطنين & 7 \\
\hline$\% 1 \ldots$ & 789 & المجموع & \\
\hline
\end{tabular}

$$
\text { يتضح من جدول (^) ما يلي: }
$$

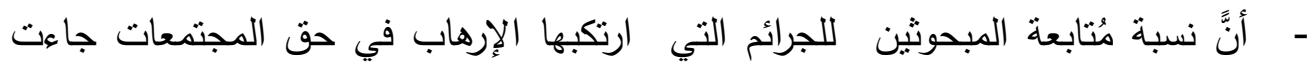
لصالح (استقطاب الشباب عبر مواقع التواصل الاجتماعي ونشر أفكار متطرفة تحرض الإرهابن

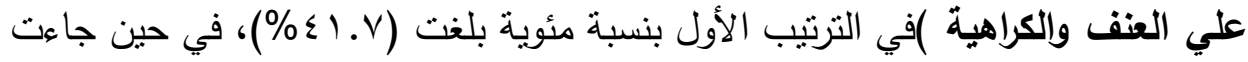

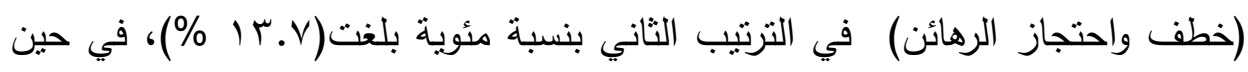

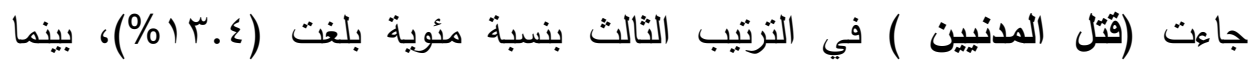

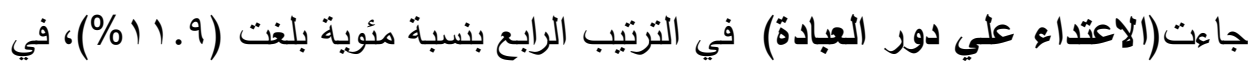
حين جاءت(بث الرعب والخوف في نفوس المواطنين) في الترتيب الخامس بنسبة مئوية بلغت(111%%)، في حين جاءت(تفجير المطارات ومحطات القطار) في الترتيب

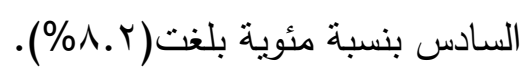


- وتعكس هذه النتيجة ارتفاع نسبة متابعة المبحوثين للجرائم التي ارتكبها الإرهاب في حق المجتمعات بالصحف الإلكترونية عينة الدراسة، سابقة الذكر ، وبالتالي زيادة نسبة مثابعة المبحوثين للجرائم التي ترتكبها هذه الجماعات. - كمّا يعكس الجدول السابق ارتفاع درجة استتكار المبحوثين ورفضهم لقتل المدنيين

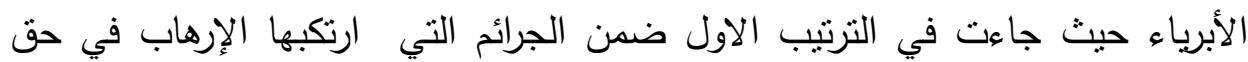

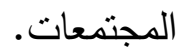

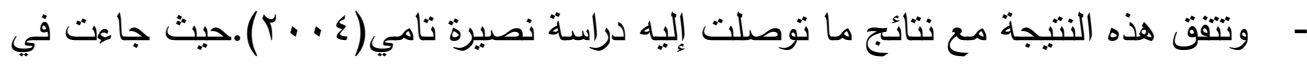
المرتبة الخامسة بينما جاء في الدراسة الحالية في المرتبة الخامسة .

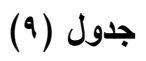

ترتيب المبحوثين لقضايا الإرهاب و مُتابعتها في صحيفة المصري اليوم حسب أفضليتها لهم ن = (ب جاج)

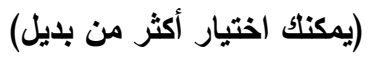

\begin{tabular}{|c|c|c|c|}
\hline$\%$ & ك5 & ترتيب المبحوثين لقضايا الإرهاب المفضل متابعتها في & 5 \\
\hline \%rr & $1 \leq 7$ & الإرهاب في فرنسا & 1 \\
\hline$\% \wedge . r$ & 00 & الإرهاب في ألمانيا & r \\
\hline$\% \backslash$ Y.० & $\Lambda r$ & الإرهاب في تونس & $r$ \\
\hline$\% \vee . \vee$ & 01 & الإرهاب في اليمن & $\varepsilon$ \\
\hline$\% 1 \vee .7$ & 118 & الإرهاب في سوريا & 0 \\
\hline$\% \backslash 9 . \wedge$ & $|r|$ & الإرهاب في العرلق & 7 \\
\hline$\% 7.7$ & $\varepsilon \varepsilon$ & الإرهاب في ليبيا & V \\
\hline$\% 0.0$ & r & الإرهاب في السعودية & $\wedge$ \\
\hline$\% 1 \ldots$ & 97 & المجموع & \\
\hline
\end{tabular}

يتضح من جدول (9) ما يلي: - أنَّ نسبة متابعة المبحوثين لقضايا الإرهاب بصحيفة المصري اليوم جاءت في الترتيب

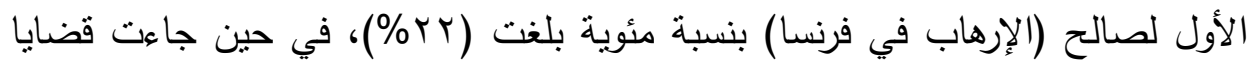

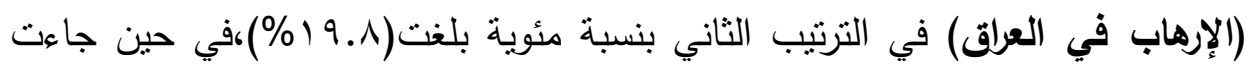

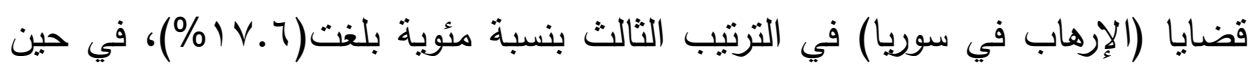

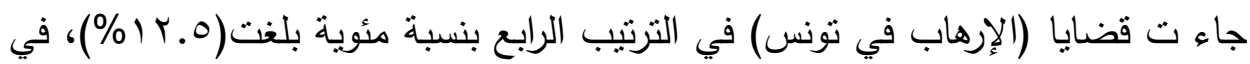


حين جاءت قضايا ( الإرهاب في ألمانبا)في الترتيب الخامس بنسبة مئوية بلغت(r.^\%)، في حين جاءت قضايا ( الإرهاب في اليمن) في الترتيب السادس بنسبة

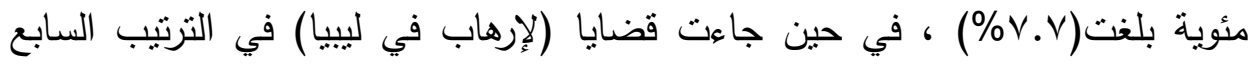
بنسبة مئوية بلغت (ך ـ ؟\%)، في حين جاءت قضايا ( الإرهاب في السعودية) في

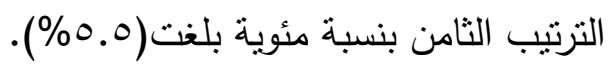

- وتعكس هذه النتيجة ارتفاع نسبة متابعة المبحوثين لقضايا الإرهاب سابقة الذكر بصحيفة الوطن، وبالتالي زيادة نسبة متابعة المبحوثين للجرائم التي ترتكبها هذه الجماعات.

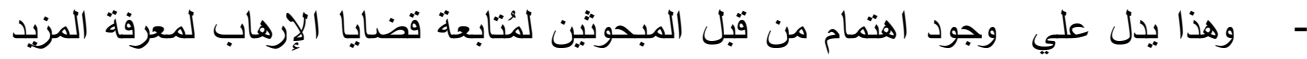
من الأخبار حول هذه القضايا.

\section{جدول (·) (1)}

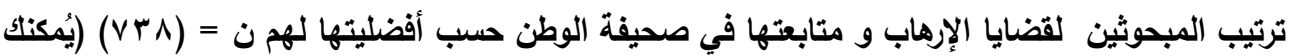
(اختيار أكثر من بديل)

\begin{tabular}{|c|c|c|c|}
\hline$\%$ & ك & قضايا الإرهاب المفضل متابتها في صحيفة الوطن & م \\
\hline$\%$ १r.r & 91 & الإرهاب في فرنسا & 1 \\
\hline$\% 1 \cdot . r$ & $v_{4}$ & الإرهاب في ألمانيا & r \\
\hline$\%$ \%... & 101 & الإرهاب في سوريا & $r$ \\
\hline$\%$ \% r.r & 91 & الإرهاب في اليمن & $\varepsilon$ \\
\hline$\% 11.9$ & $\wedge \wedge$ & الإرهاب في تونس & ० \\
\hline$\%$ r l.V & 19. & الإرهاب في العرلق & 9 \\
\hline$\%$ \%. & r & الإرهاب في ليبيا & $v$ \\
\hline$\% \bullet .0$ & \& & الإرهاب في السعودية & $\wedge$ \\
\hline$\% 1 \ldots$ & VrA & المجموع & \\
\hline
\end{tabular}

$$
\text { يتضح من جدول ( • () ما يلي: }
$$

- أنَّ نسبة متابعة المبحوثين لقضايا الإرهاب بصحيفة الوطن جاءت في الترتيب الأول

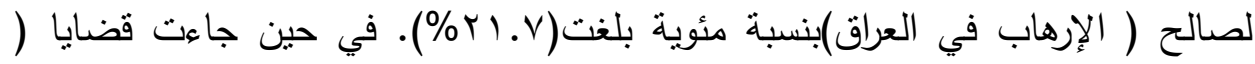

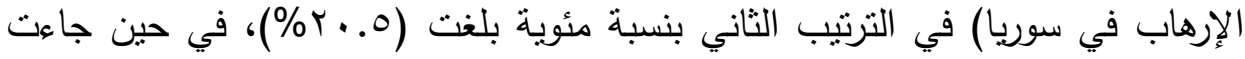

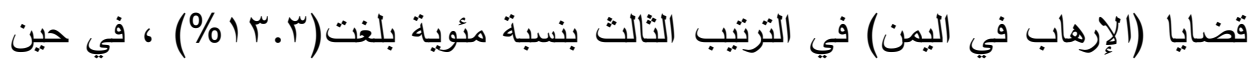

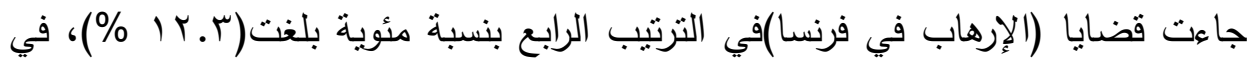


حين جاءت قضايا (الإرهاب في تونس) في الترتيب الخامس بنسبة مئوية

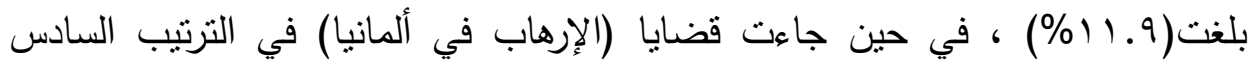
بنسبة مئوية بلغت(ب. (1\%) ، في حين جاءت قضايا ( الإرهاب في السعودية )، في الترتيب السابع بنسبة مئوية بلغت(0.0\%)، في حين جاءت قضايا (الإرهاب في ليبيا)،

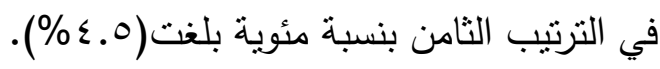
وتعكس هذه النتيجة ارتفاع نسبة متابعة المبحوثين لقضايا الإرهاب سابقة الذكر بصحيفة الوطن، وبالتالي زيادة نسبة متابعة المبحوثين للجرائم التي ترتكبها هذه الجماعات.

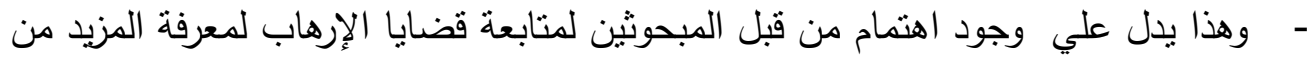
الأخبار حول هذه القضايا. وتأكيد لنتائج الجدول السابق في دراسة غابرييل وينان Gabriel Weinann (1991 (1)حول التغطية الإخبارية لموضوع الإرهاب الدولي، ،حيث أكدت علي اهتمام وسائل الإعلام

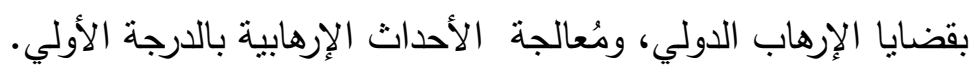

$$
\text { جدول (II) }
$$

أثكال تفاعل المبحوثين مع قضايا الإرهاب بصحيفة المصري اليوم عبر مواقع شبكات التواصل الاجتماعي

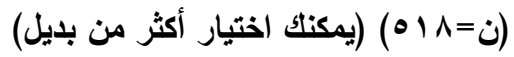

\begin{tabular}{|c|c|c|c|}
\hline$\%$ & ك & أثكال التفاعل بصحيفة المصري اليوم & م \\
\hline$\% \backslash \wedge . r$ & 90 & التفاعلية القابلة للنقر & 1 \\
\hline$\%$ \%ч. & $1 \mathrm{rA}$ & التعليقات على ما ينشر & r \\
\hline \%rr.s & 171 & التفاعل والمشاركة مع المستخدمين & $r$ \\
\hline$\% \curlywedge \wedge . \wedge$ & 07 & الشرائح المصحوية بالتعليق & $\varepsilon$ \\
\hline$\% r . q$ & 91 & Massage التفاعل عبر إرسال رسائل نصية للصفحة & 0 \\
\hline$\% 1 \ldots$ & 011 & المجموع & 7 \\
\hline
\end{tabular}

$$
\text { يتضح من جدول (1) (1) ما يلى: }
$$

- أنَّ نسبة تفاعل المبحوثين مع قضايا الإرهاب بصحيفة المصري اليوم عبر مواقع

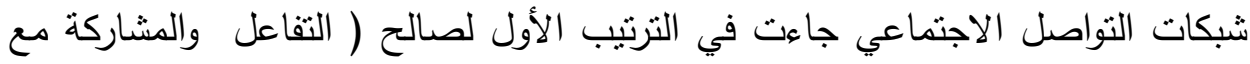
المستخدمين) بنسبة مئوية بلغت (ع.rr\%)، في حين جاءت (التعليقات على ما ينشر)

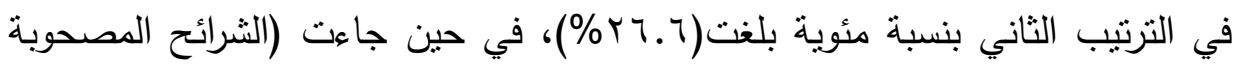


بالتعليق) في الترتيب الثالث بنسبة مئوية بلغت (1/. (1\%)، بينما جاءت (التفاعلية

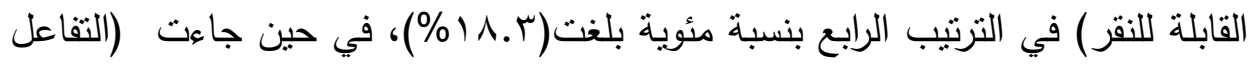
عبر إرسال رسائل نصية للصفحة Massage في الترتيب الخامس والأخير) بنسبة

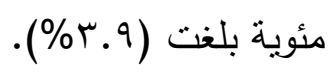

- وتعكس هذه النتيجة ارتفاع نسبة استخدام المبحوثين لأشكال التفاعل مع قضايا الإرهاب بصحيفة المصري اليوم عبر مواقع شبكات التواصل الاجتماعي لتكوين اراء مختلفة بين المستخدمين وبعضهم البعض حول هذه القضايا.

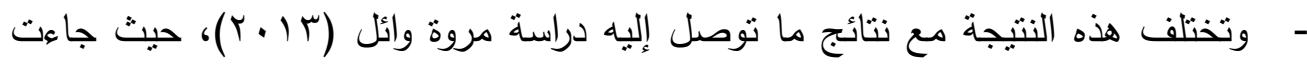

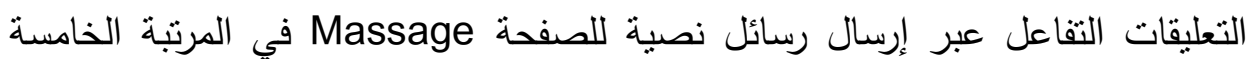
بينما جاءت في دراسة مروة وائل في المرتبة الأولي.

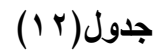

أثكال تفاعل المبحوثين مع قضايا الإرهاب بصحيفة الوطن عبر مواقع شبكات التواصل الاجتماعي (اكثر

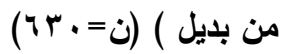

\begin{tabular}{|c|c|c|c|}
\hline$\%$ & ك & أثثكال تفاعل المبحوثين مع قضايا الإرهاب بصحيفة & b \\
\hline$\% \backslash \wedge . \vee$ & 111 & التفاعلية القابلة للنقر & 1 \\
\hline$\% 14 . r$ & $1 \cdot \varepsilon$ & التعليقات على ما ينشر & r \\
\hline$\% \backslash \vee .7$ & 111 & التفاعل والمشاركة مع المستخذمين & $r$ \\
\hline$\%$ \%ч.० & $r \cdot r$ & الثرائح المصحوية بالتعليق & $\varepsilon$ \\
\hline$\% 1 \cdot .9$ & $9 \leq$ & Massage التفاعل عبر إرسال رسائل نصية للصفحة & 0 \\
\hline$\% 1 \ldots$ & זי. & المجموع & 7 \\
\hline
\end{tabular}

$$
\text { بتضح من جدول (r ا ) ما يلي : }
$$

- أنَّ نسبة تفاعل المبحوثين مع قضايا الإرهاب بصحيفة الوطن عبر مواقع شبكات

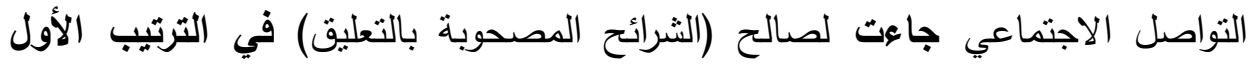

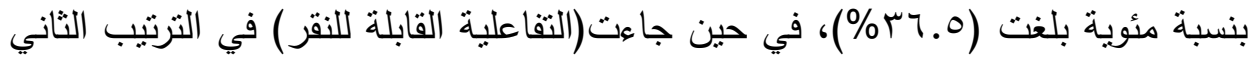

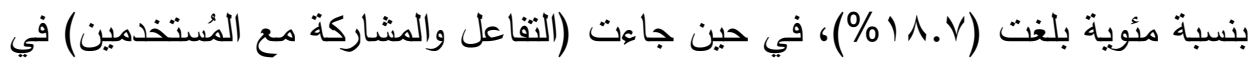

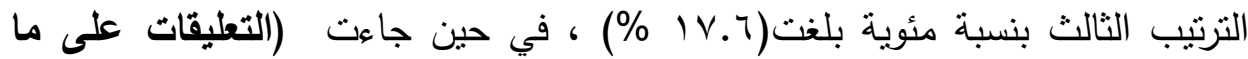

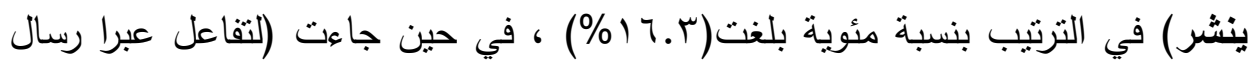


رسائل نصية للصفحة Massage ) في الترتيب الخامس والأخير بنسبة مئوية

$$
\text { بلغت (9. - 1\%). }
$$

وتعكس هذه النتيجة ارتفاع نسبة استخدام المبحوثين لأثكال التفاعل مع قضايا الإرهاب

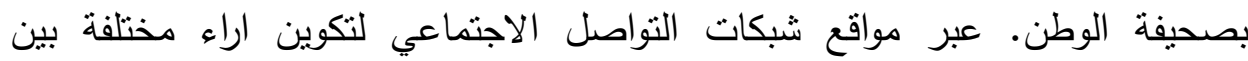
المستخدمين وبعضهم البعض حول هذه القضايا.

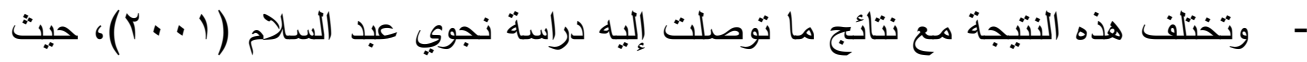

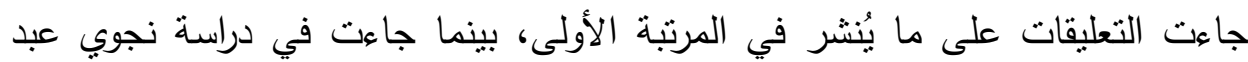
السلام في المرتبة الرابعة.

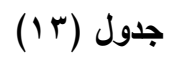

دوافع استخذام المبحوثين للصحف الإكترونية عبر مواقع شبكات التواصل الاجتماعي (ن= (ب) . ؛)

\begin{tabular}{|c|c|c|c|}
\hline$\%$ & ك5 & مواقع شبكات التواصتخد المبحوثين للصحف الإلكترونية عبر & 5 \\
\hline$\%$ Y. $\varepsilon$ & $r r$ & تُساعدني في تكوين آراء ومعلومات حول الأوضاع التي & 1 \\
\hline$\% \backslash 1 . \wedge r$ & $11 \%$ & التعليق والمُشاركة بالرأي & r \\
\hline$\%$ o.rr & 0. & لأنها تطرح قضايا شديدة الصلة باهتماماتي & $r$ \\
\hline \%1..74 & $1 \cdot r$ & لأن أخبارها متجددة وسريعة في تغطية الأحداث & $\varepsilon$ \\
\hline$\% 9.01$ & 91 & الحصول علي المعلومات & 0 \\
\hline$\% r . q v$ & $r \Lambda$ & المُحتوى الإعلامي المُقدم عالّي الدقة & 7 \\
\hline$\% \wedge . . \diamond$ & VV & التعليق على المنشورات وعرض أفكاري الخاصة & V \\
\hline \%r.qr & $r \wedge$ & بناء علاقات جديدة وتكوين صداقات & $\wedge$ \\
\hline \%ro.or & $r \leq \varepsilon$ & التواصل والتفاعل مع الآخرين تجاه قضايا الإرهاب & 9 \\
\hline 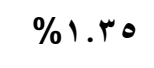 & ir & قضاء وقت الفراغ & 1. \\
\hline$\%$ \%.r. & 117 & لأن مميزاتها تجمع بين مميزات وسائل الإعلام الأخرى & 11 \\
\hline$\%$ r.. $q$ & $r$. & للاطلاع على ما هو جديد من أخبار & ir \\
\hline$\% \varepsilon . Y \wedge$ & $\leqslant 1$ & الاستفادة من خدمات البريد الإكتروني & ir \\
\hline$\% 1 \ldots$ & 907 & المجموع & \\
\hline
\end{tabular}

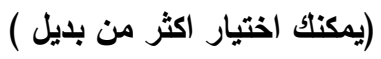
يتضح من جدول (T ا ) ما يلي: 
- أنَّ نسبة دوافع استخدام الصحف الإككترونية عبر مواقع شبكات التواصل الاجتماعي

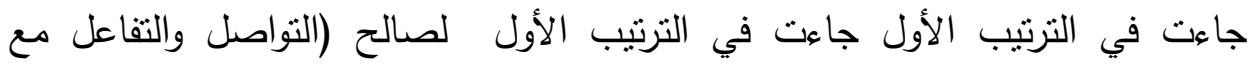

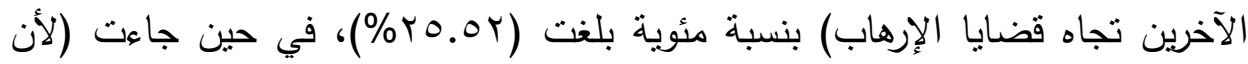

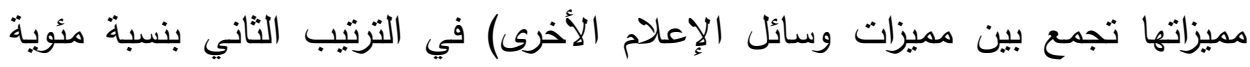

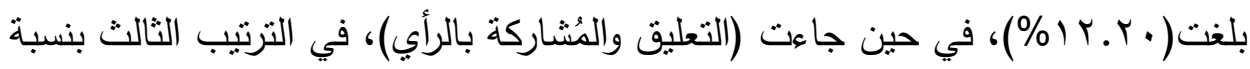

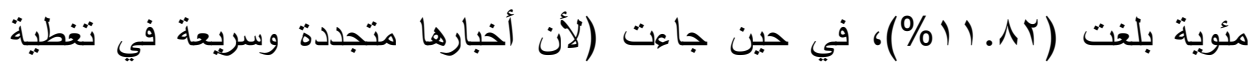

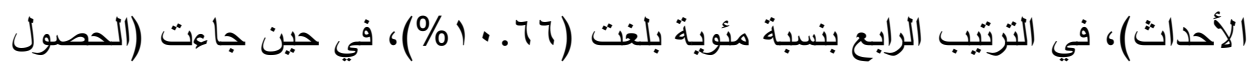

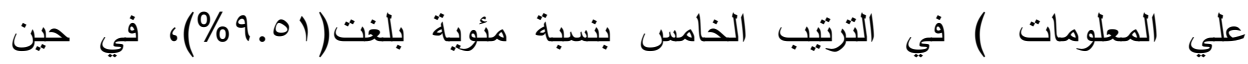

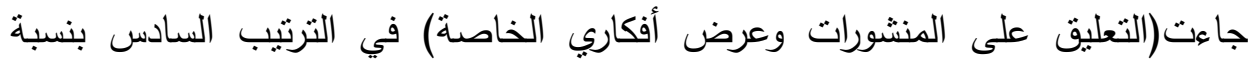

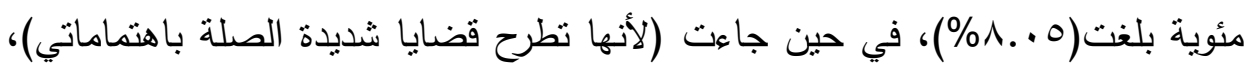

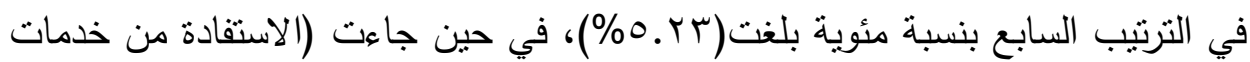

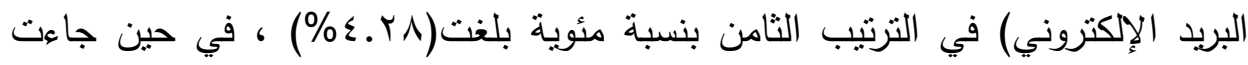

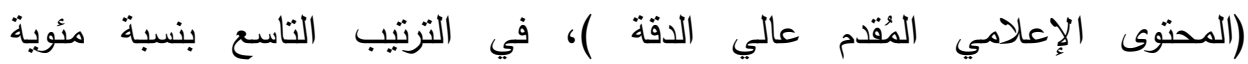

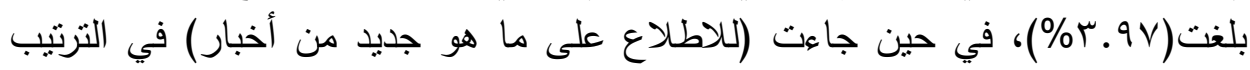

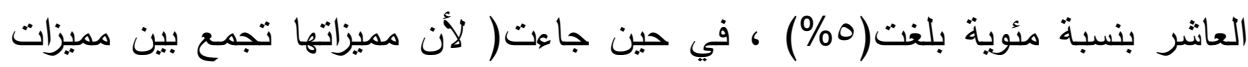

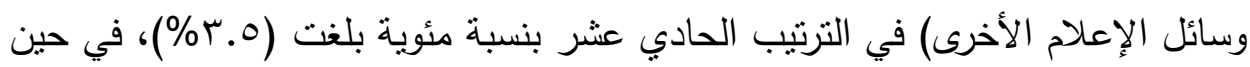

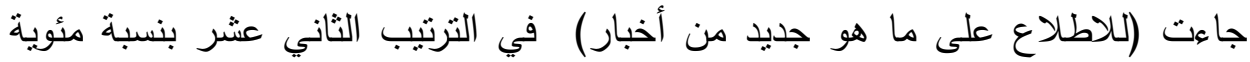

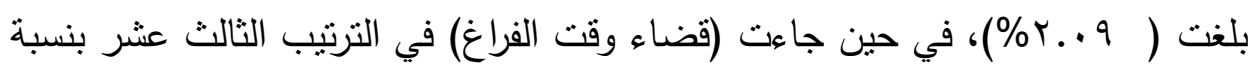

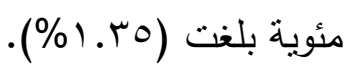

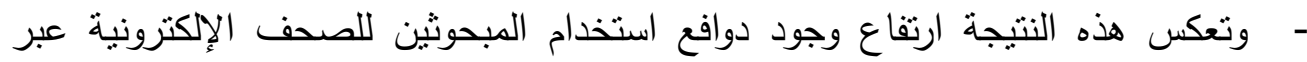

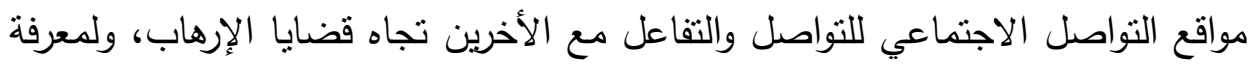
المزبد من الأخبار حول هذه القضايا.

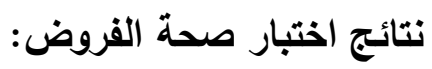
التحقق من صحة الفرض الأول:

جدول (؛ 1)

مُعامل الارتباط بين استخدام المبحوثين للصحف عبر مواقع التواصل ومُستويات التفاعلية تجاه قضايا الإرهاب

\begin{tabular}{|c|c|c|}
\hline \multicolumn{2}{|c|}{ استخام المبحوثين الصحف الإكترونية عبر مواقع التواصل الاجتماعي } & \multirow{2}{*}{ المُتغيرات } \\
\hline مستوي الدلالة & قيمة ر & \\
\hline$\cdots 1$ & $* * \ldots \leqslant V$ & مُستويات التفاعلية تجاه قضايا \\
\hline
\end{tabular}




\section{يتضح من جدول (ع أ) ما يلي:}

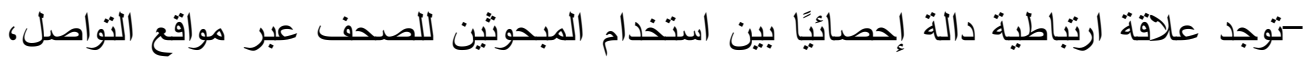

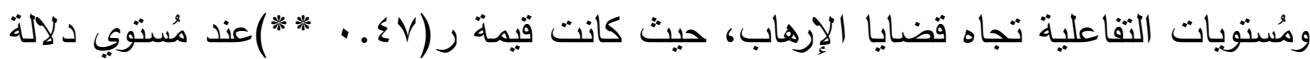

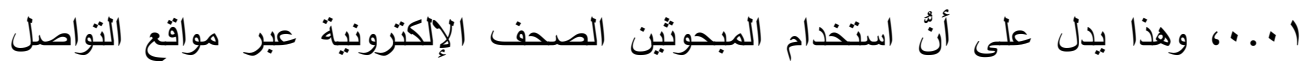

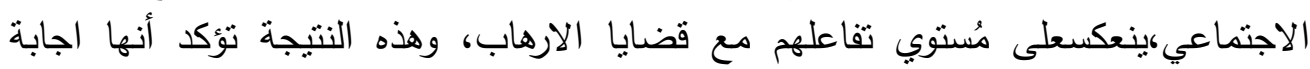

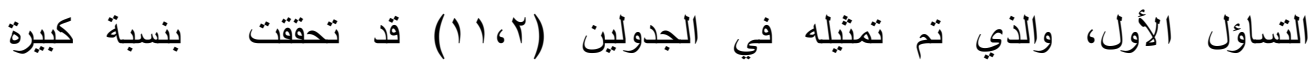
.التحقق من صحة الفرض الثاني:

توجد علاقة ذات دالة إحصائيًا بين درجة استخدام الطائ الطلاب للصحف الإكترونية ومدي مُتابعتهم قضايا الإرهاب

\section{جدول ( 10}

العلاقة بين درجة استخدام المبحوثين للصحف الإكترونية، ومدي مُتابعتهم لقضايا الإرهاب.

\begin{tabular}{|c|c|c|}
\hline \multicolumn{2}{|c|}{ درجة استخذام الطلاب للصحف لإكترونية } & \multirow[b]{2}{*}{ 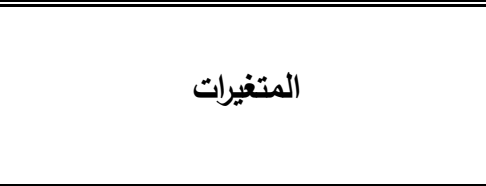 } \\
\hline الدالةتوي & ق ق قيمة ر & \\
\hline$\cdots 1$ & *** . . & مدي متابعة المبحوثين ق قضايا الارهاب \\
\hline
\end{tabular}

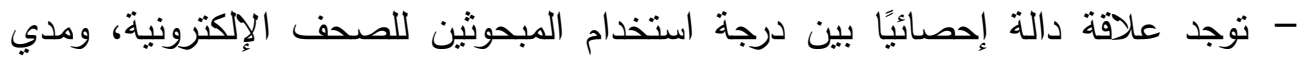

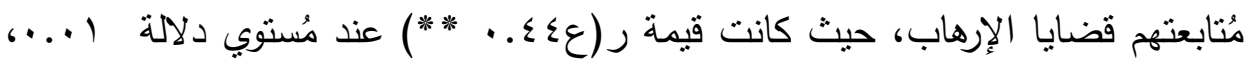

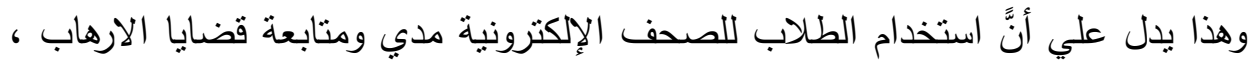

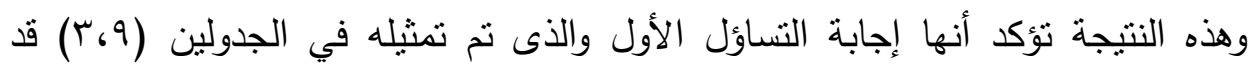
تحققوا بنسبة كبيرة.

\section{جدول (17)}

العلاقة بين دوافع استخدام المبحوثين للصحف الإكترونية ومعدل الوقت الذي يقضونه في متابعة قضايا

\begin{tabular}{|c|c|c|}
\hline \multicolumn{3}{|c|}{ الإرهاب. } \\
\hline ين للصحف الإكترونية & دوافع استخد & \\
\hline 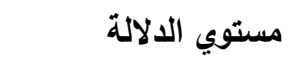 & 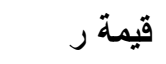 & \\
\hline$\ldots 1$ & *** . . & مُعدل الوقت الذي يقضونه في متابعة قضايا الإرهاب \\
\hline
\end{tabular}




$$
\text { يتضح من جدول (7 (1) ما يلي: }
$$

-توجد علاقة دالة إحصائيًا بين دوافع استخدام المبحوثين للصحف الإلكترونية ومعدل الوقت

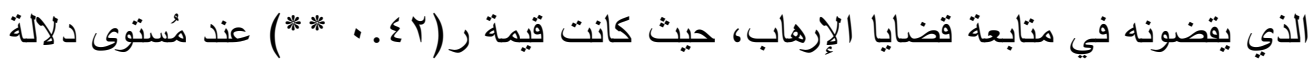

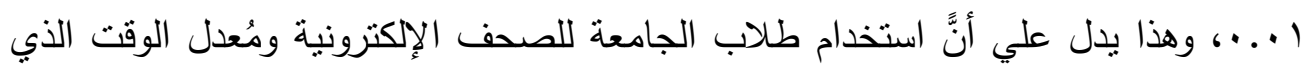
يقضونه في مُتابعة قضايا الإرهاب ينعكس على دوافعهم المعرفية من حيث الاستخدام

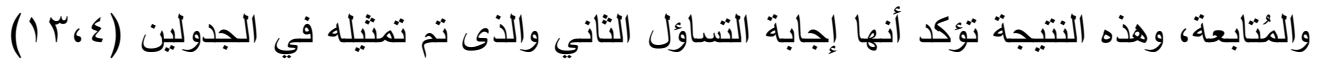
قد تحققوا بنسبة كبيرة.

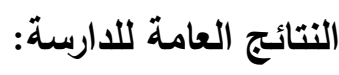

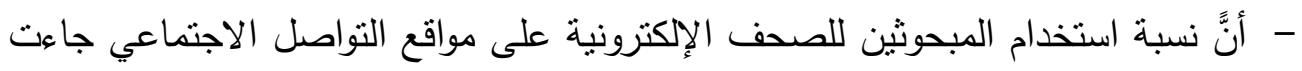

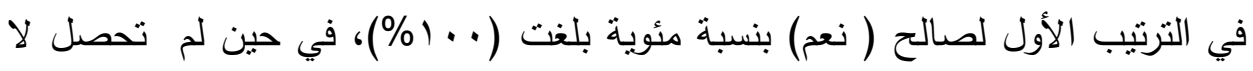
علي أي نسبة. - أنَّ نسبة تفاعل المبحوثين مع قضايا الإرهاب بصحيفة الوطن عبر مواقع شبكات

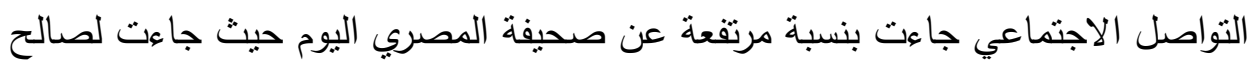

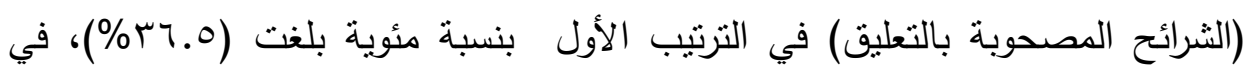

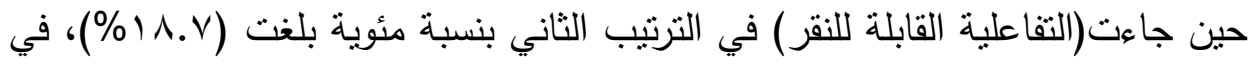

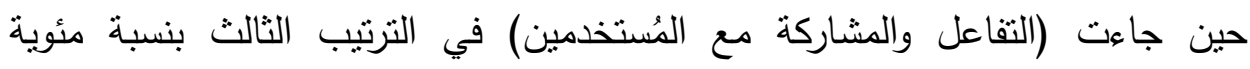
بلغت(V.7 Y \%)، في حين جاءت (التعليقات على ما ينشر) في الترتيب بنسبة مئوية

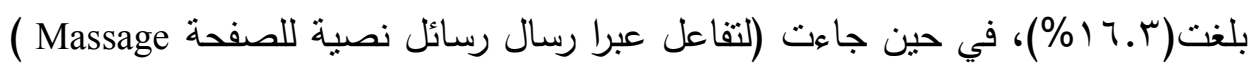

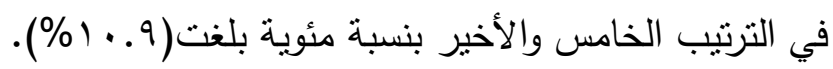

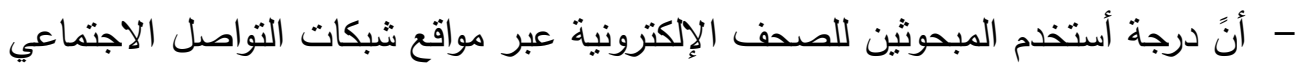

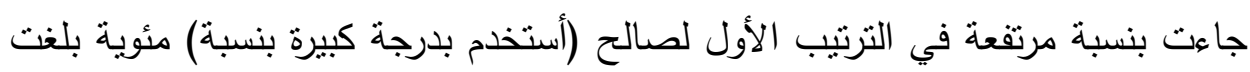

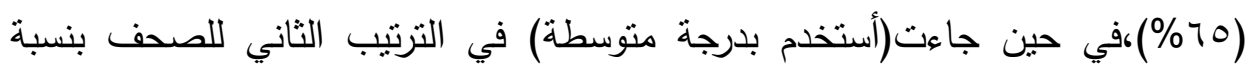

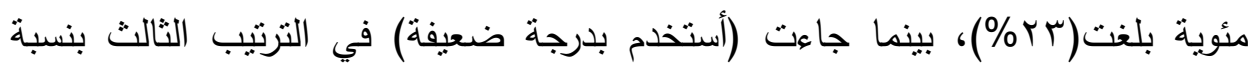

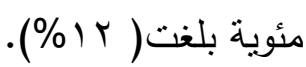
- أنَّ نسبة متابعة المبحوثين لقضايا الإرهاب بصحيفة الوطن جاءت بنسبة مرتفعة عن

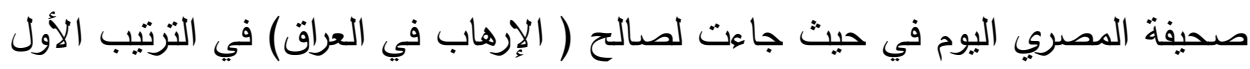

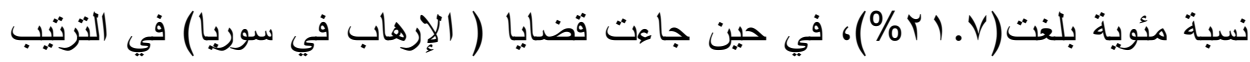




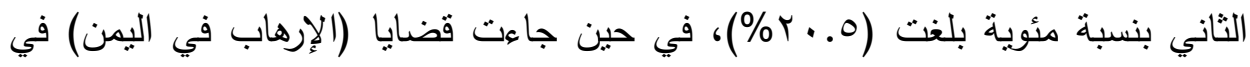

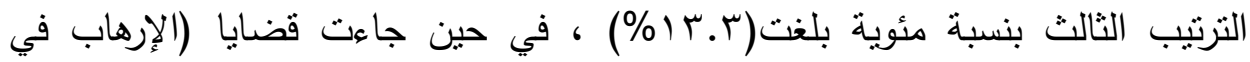

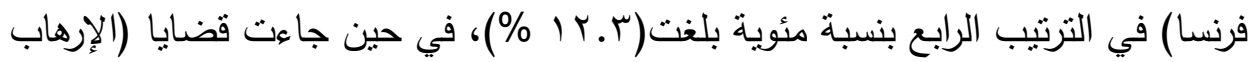

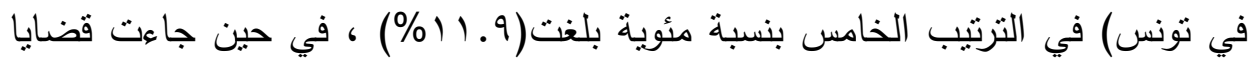

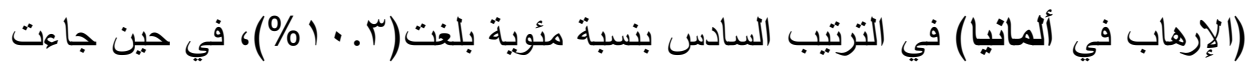

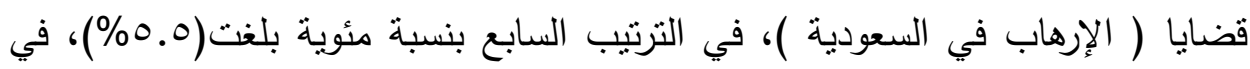

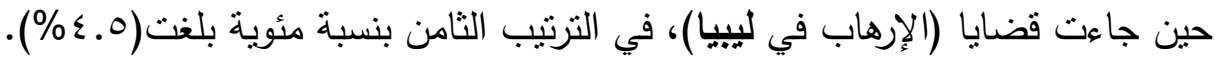

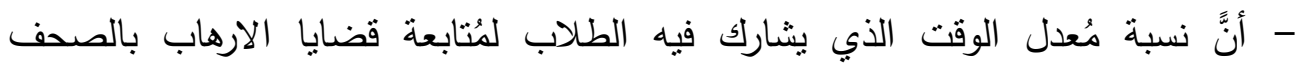
الإلكترونية عبر مواقع التواصل الاجتماعي جاء بنسبة مرتفعة حيث جاءت في الترتيب

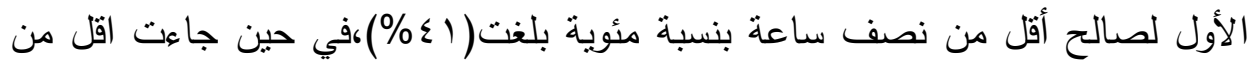

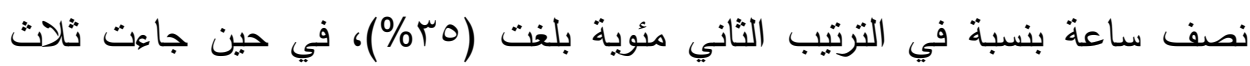

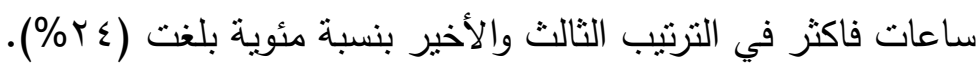
- أنَّ نسبة دوافع استخدام المبحوثين للصحف الإلكترونية علي مواقع شبكات التواصل

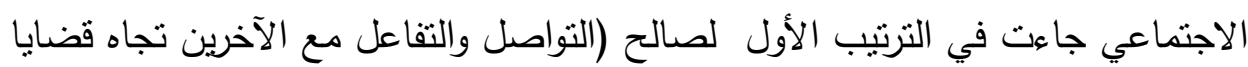

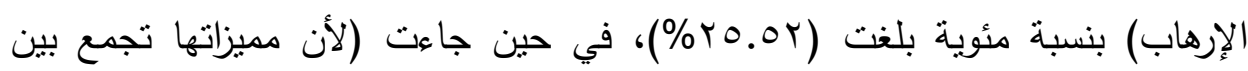

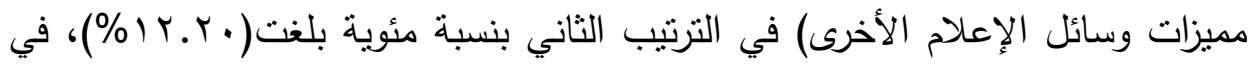

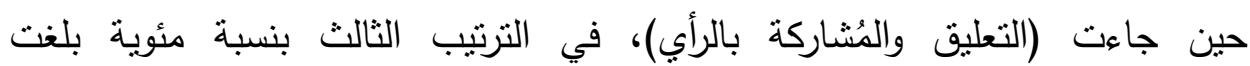

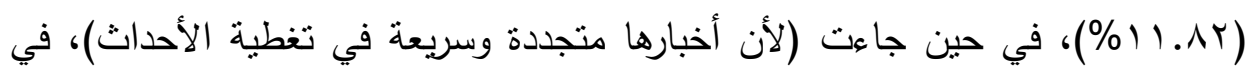

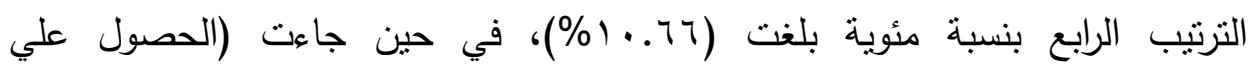

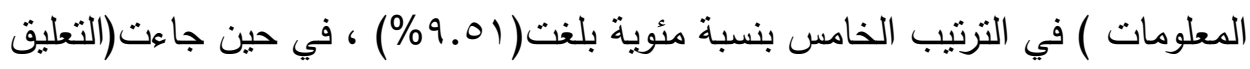

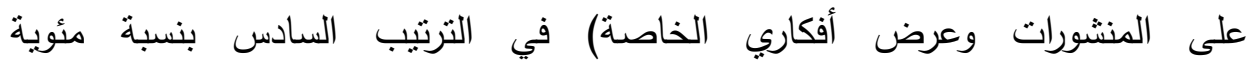

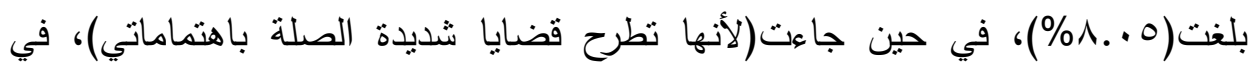

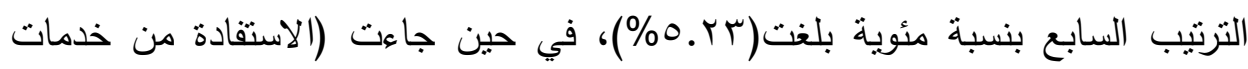

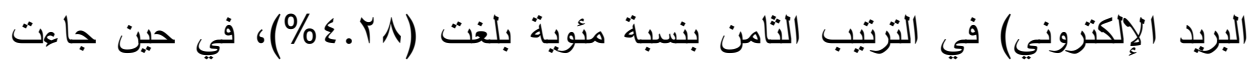

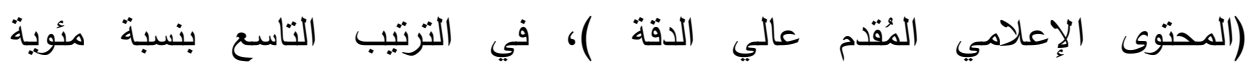

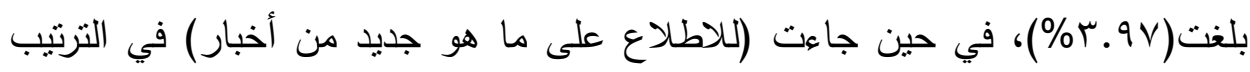

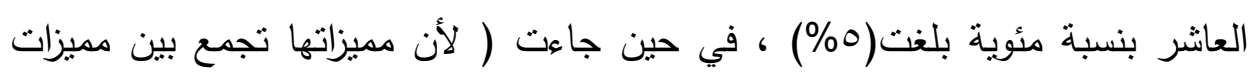

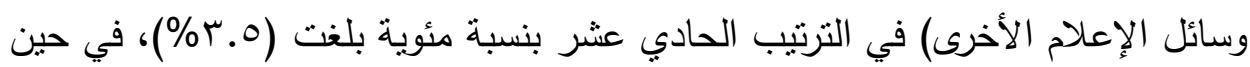


جاءت (للاطلاع على ما هو جديد من أخبار) في الترتيب الثاني عشر بنسبة مئوية

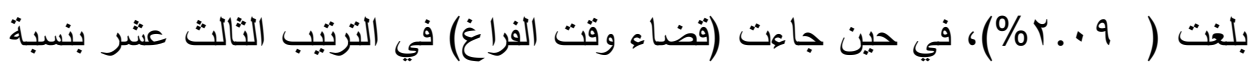

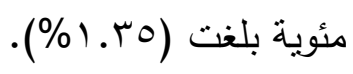

- ثبت صحة الفرض الأول: نوجد علاقة ارتباطية دالة إحصائيًا بين استخدام المبحوثين الصحف الإلكترونية ومستويات التفاعلية. - ثبت صحة الفرض الثاني: توجد علاقة ذات دالة إحصائيًا بين درجة استخدام الطلاب للصحف الإلكترونية ومتابعة قضايا الإرهاب. - ثبت صحة الفرض الثالث: توجد علاقة دالة إحصائيًا بين دوافع استخدام المبحوثين للصحف الإلكترونية ومعدل الوقت الذي يقضونه في متابعة قضايا الارهاب.

\section{مُفترحات وتوصيات الدراسة:}

1 - التأكيد على أهمية استخدام الصحف الإلكترونية علي مواقع التواصل الاجتماعي

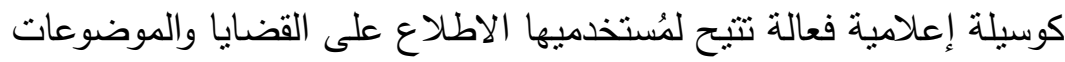
المختلفة، حيث تتيح لهم التفاعل مع الرأي والرأي الأخر تجاه القضايا، والموضوعات لهات

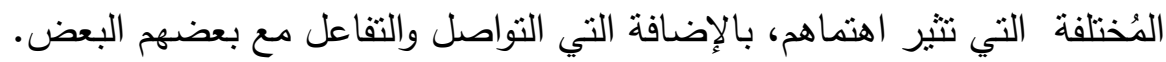
r- عمل استطلاعات رأي بصفة دورية حول معدل استخدام هذه الصحف وأدائها بالنسبة للمواطن.

r- العمل على تقديم مضمون إعلامي يلبى احتياجات جمهور القراء من مُستخدمي الصحف الإكترونية عبر مواقع التواصل الاجتماعي. ع - وضع قوانين تتظم النشر الإكتروني في وسائل الإعلام المُختلفة.

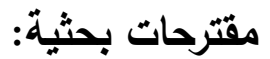
- - دور شبكات التواصل الاجتماعي في مُعالجة القضايا المرتبطة بالدين الإسلامي. - - دور وسائل الإعلام التفاعلي في مُعالجة ظاهرة ارتفاع الأسعار . 


\section{قائمة المصادر والمراجع: \\ أولاً :المصادر والمراجع العربية}

إلهام بونلجي (1) (1).الصحافة الإكترونية الجزائرية واتجاهات القراء ، رسالة ماجستير غير

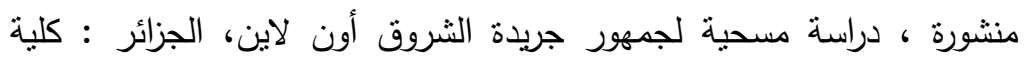

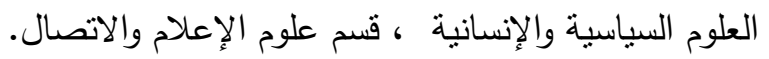

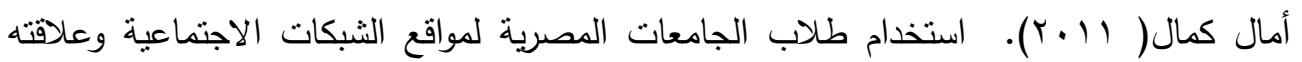
برأس المال الاجتماعي بالتطبيق علي موقع "Face book" . المجلة المصرية لبحوث الرأي العام، المجلد العاثر ، العدد الرابع، جامعة القاهرة: كلية الإعلام

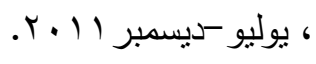

ألاء ماهر خفاجة (r ب ب). دور المواقع الإكترونية الحديثة (المدونات - الفيس بوك - اليوتيوب) في تشكيل اتجاهات الثباب المصري نحو القضايا المجتمعية: دراسة تحليلية ميدانية، رسالة ماجستير غير منشورة، كلية الآداب، جامعة جنوب الوادي.

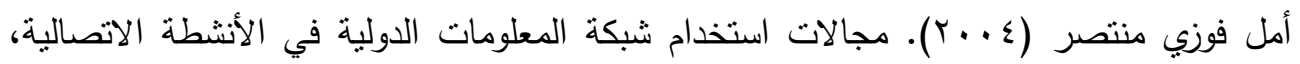
رسالة ماجستير غير منشور ، كلية الإعلام، جامعة القاهرة.

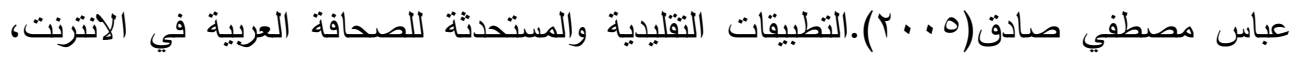
بحث مقدم لمؤتمر صحافة الانترنت في العالم العربي كلية الاتصال جامعة

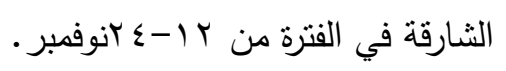

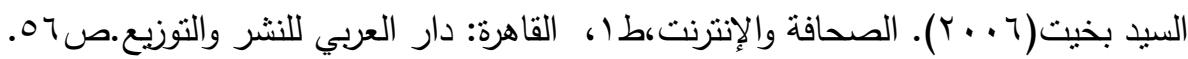
ثائر محمد(r ( ب).حراسة البوابة الإعلامية والتفاعلية في المواقع الإخبارية الفلسطينية ، كلية

$$
\text { الإعلام ،جامعة الثرق الأوسط. }
$$

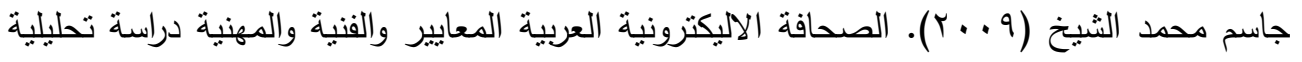
لعينة من الصحف الاليكترونية العربية أحداث المؤثمر الدولي بعنية الئوران الإعلام الجديد : تكنولوجيا جديدة العالم جديد جامعة البحرين V- 9 ابريل.

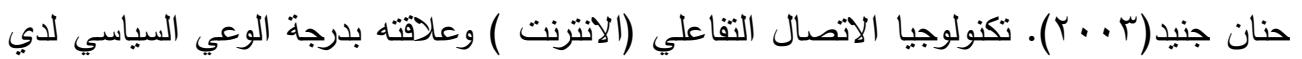

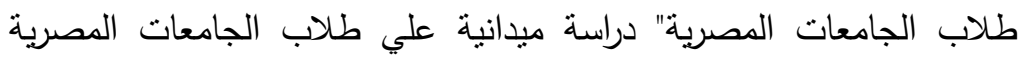
الخاصة"، المجلة المصرية لبحوث الإعلام، العدد الثامن، كلية الإعلام، دلثابه 
حمزة إسماعيل أبو شنب (r • ب). تقنيات التواصل الاجتماعي .. الاستخدامات والمميزات ، متاح علي /http://ww.alukah.net/culture/0/59302

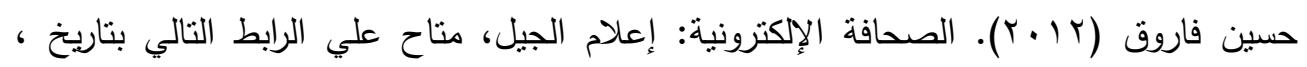

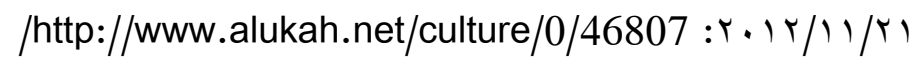

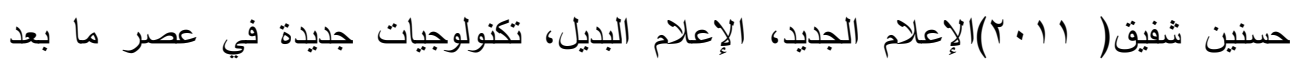

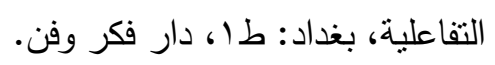

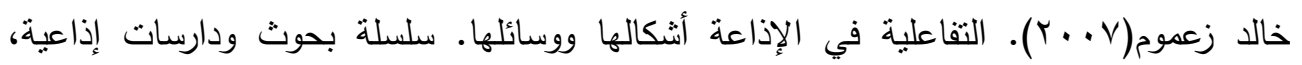

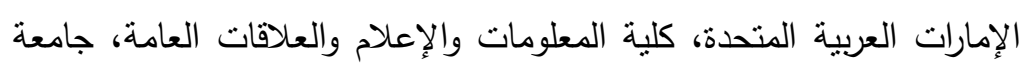
عجمان اللعلوم والتكنولوجيا. شريف درويش اللبان(9 . . . . الفيس بوك والإعلام البديل. ورقة بحثية مقدمة لمؤتمر الفيس بوك

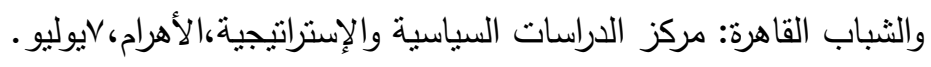

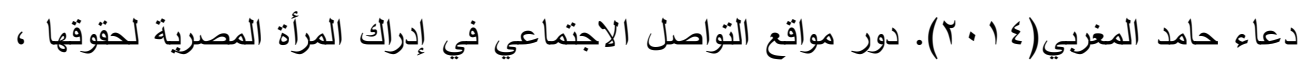
دراسة ميدانية، بحث مقدم للمؤتمر العلمي الدولي العشرون :مستقبل الإعلام الدرام

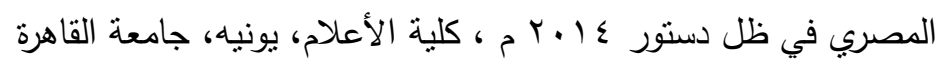

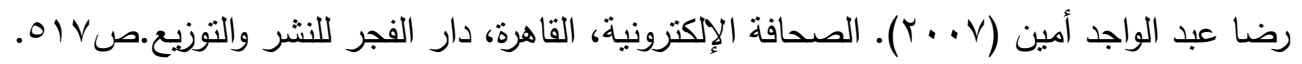

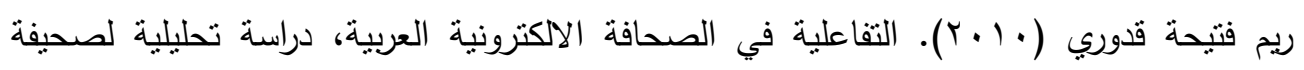
الشروق الجزائرية نموذجا، رسالة ماجستير غير منشورة : الجزائر : كلية العلوم

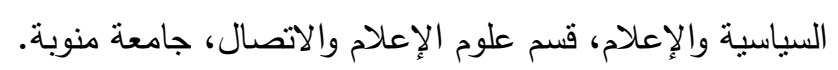

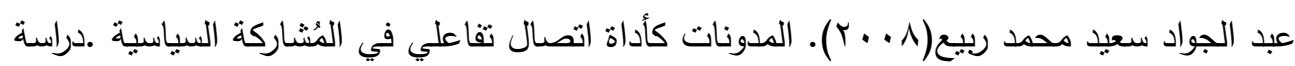

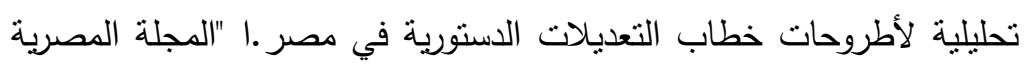

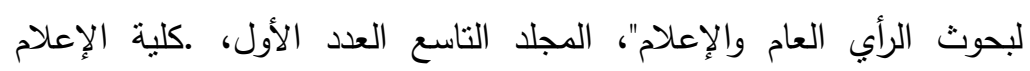
جامعة القاهرة.

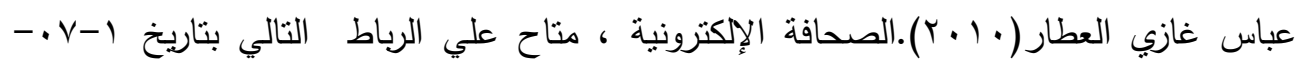
$: r \cdot 1$.

http://www.ijschool.net/news.php?action=view\&id=341\#.V6

$$
\text { 6xI_ITLIV }
$$


عذاري البلوشي (r (r) إيجابيات وسلبيات مواقع التواصل الاجتماعي، متاح علي الرابط النالي :rotr مايو، 1 .

/http://zo0o0zo0oz0o0zoz.blogspot.com.eg

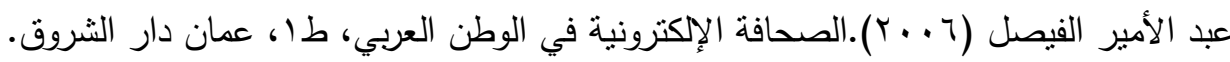

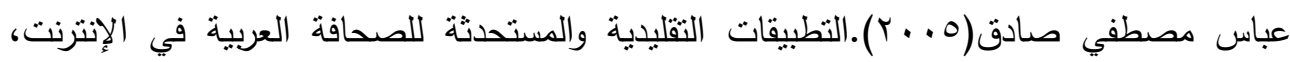

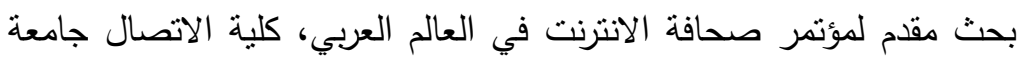

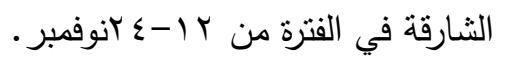

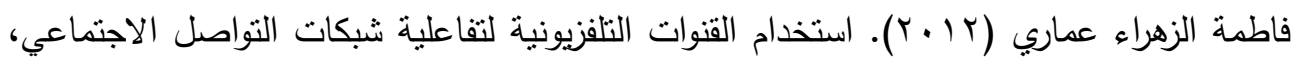
رسالة ماجستير غير منشورة، كلية العلوم السياسية والإعلام، قسم علوم

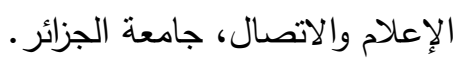

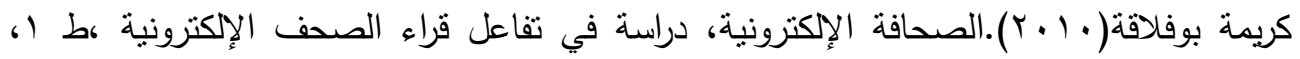

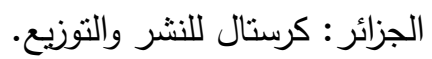

لقاء العزاوي (r . . r). ،" الصحافة الالكترونية : دراسة في الأسس وآفاق المستقبل" ، بحث منشور

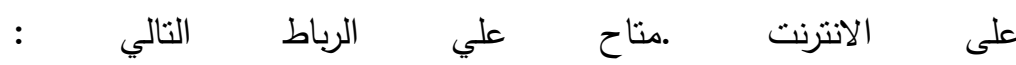
.http://www.alatman.ws//vb/show three.php? t=2174 محمد السيد عليوة (Y (Y). دور بعض الوسائط الاتصالية بالإنترنت في تتمية الوعي السياسي لدى شباب الجامعة، رسالة دكتوراه غير منشورة، جامعة عين شمس، معهد الدراسات العليا للطفولة والإعلام، قسم الإعلام وتقافة الطفل.

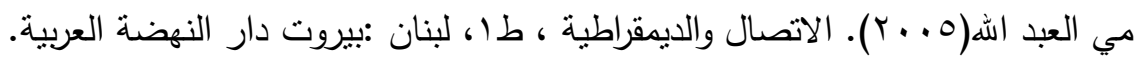

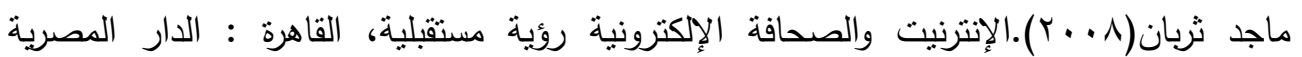
اللبنانية.

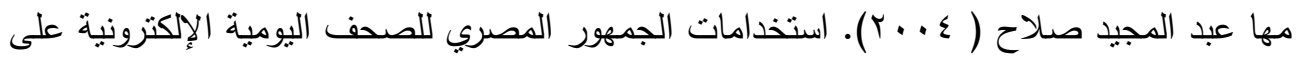
شبكة الإنترنت "دراسة تحليلية ميدانية" ،رسالة ماجستير غير منشورة ، كلية الإعلام ، قسم الصحافة والنشر ، جامعة القاهرة.

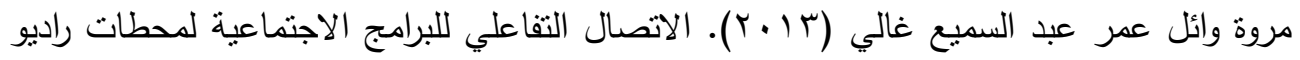

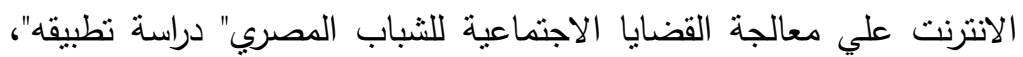
رسالة ماجستير غير منشورة ، كلية الآداب، قسم الإعلام، جامعة المنصورة. منال عبد العال مبارز سامح سعيد إسماعيل(• ( •).تطبيقات تكنولوجيا الوسائط المتعددة ، القاهرة: دار الفكر. 


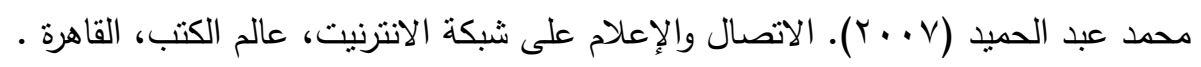

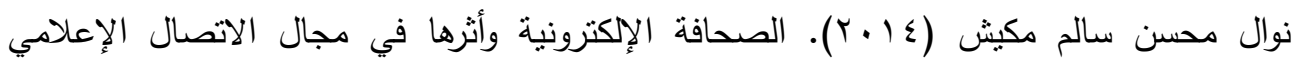

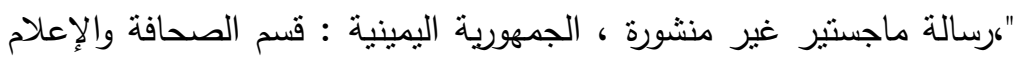

$$
\text { بكلية الآداب بجامعة عدن. }
$$

نحوي عبد السلام فهمي( (. ب). التفاعلية والمواقع الإخبارية العربية علي شبكة الانترنت .دراسة تحليلية. المجلة المصرية لبحوث الرأي العام، المجلد الثاني، كلية الإعلام

$$
\text { جامعة القاهرة. }
$$

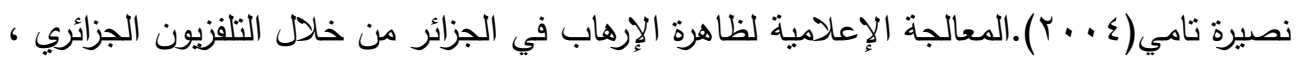

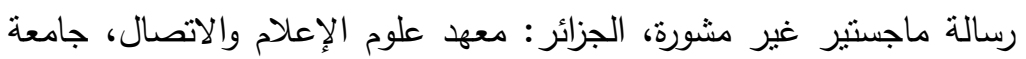

$$
\text { الجزائر }
$$

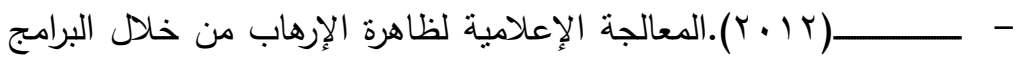

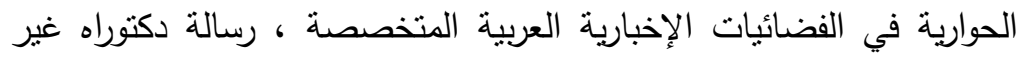

مشورة، الجزائر : كلية العلوم السياسية والإعلام والاتصال، جامعة الجزائر r.

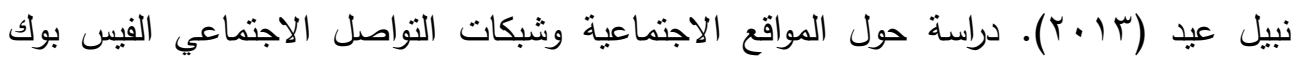

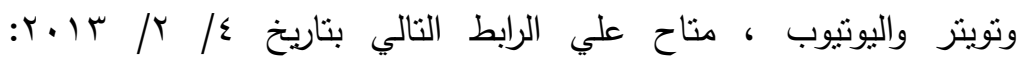
http://mogtamaa.telecentre.org/profiles/blogs/2487793:Blo

\section{gPost:80067}

\section{ثانياً :المصادر والمراجع الأجنبية:}

Boushra ,M.W. (2008). The influence of web site feature-based interactivity on users, attitudes and online behaviors ". PHD Thesis . ( college of health and human development, the Pennsylvania state university available at : http://proquest.umi.com.

Durefelt, Filip, Journalistic i ett nytt medium (2014).En studie av hur journalist studenter på två universitet i Sverige använder Twitter, Linnaeus University, Faculty of Arts and Humanities, Department of Media and Journalism.

CARROLLD.CLYNN.

Michael(2012),TUGEAND

LINFSAYT.HOFFMAN.ALL THE NEWS THATSPITTPOS AROFILE OF NEWS us on socialnted working sities computers in hwman behavov 13-1199p117'

Charlie beckette super media (2008).saving journalism so it can save the world available at: http:www.amazon.co.uk./super media -saving - journalism -save world-dp114.51729p44 
Christopher, h ( 1998).news and information in digital world, (New York: newyok university press, PP, 43-45.

Dan Grigorovici, Siho Nam \& Chris Russill(2003). The Effects of Online Syllabus Interactivity on Students Perception of the Course and Instructor,( Internet and Higher Education), Vol. 6, p. 42.

Jan H Kietzmann (2014)and al, Social media? Get serious! Understanding the functional building blocks of social media, Business Horizons, 54(3), 201, P241-251. Jan H Kietzmann, 241-251.

Gabriel Weinann, Hans-bernd brosius,(1991). The newsworthiness of international terrorism Communication resarch, vol : $18, \mathrm{~N}^{\circ}: 03$, P.P333-354.

Remediation practices in content and form(2013). Journalism StudiesVaia Doudaki and Lia-Paschalia Spyridou PRINT AND ONLINE NEWS Taylor \& FrancisVol. 14, No 6.

Michael Karlsson(2007). Immediacy of Online News: Journalistic Credo Under Pressure, available on line at: www. Allacademic.com.

Marina Vastly(2012).Use of Social Networks Sites by Young Adults in Russia " (unpublished Master's Thesis, University of Tampere "School of social Sciences and Humanities "may.

Kuan-Ju Chen(2011).A Test of the Spiral of Silence Theory on Young Adults' Use of Social Networking Sites for Political Purposes, Unpublished Master of Science, USA: Iowa State University, Ames, Iowa.

Jude Corrigan (2007).Trust uses face book website to link up staff and patients", Nursing Standard.Vol.22, no.10, Nov.14,.p1. Shedden ,David.(2005)New Media TimelinePoynter Institute, Available on the following link:

https://www.poynter.org/2006/new-media-timeline-2005/75827/

Kawamoto.K.(2003)Digital Journalism ;Emergine Media and the changing .Horizons of Journalism, Oxford ;Rowan \&Littlefield Publishers Inc.

Mashihur Rahm .(2008). Interactive options in online newspaper of Bangladesh". Pakistan journal of social sciences ( Vol.5, No.6), PP.620-624.

Mashihur Rahm (2008).."Interactive options in online newspaper of Bangladesh". Pakistan journal of social sciences ( Vol.5, No.6, PP.620-624 .

Suzanne lysak, Michael, cremefas and dohn wolf(2012). facebook anf writer in the news rom how and way local television news electronic news 20(26:187 publishef by safedec 28, p187. 
Sebastian Valenzuela, Namsu Bark\& Kerk F. Kee,(2009). Is there Transport and Shipping Is available at the following link: http://www.transportandshipping.info/Ice_skate/75.php

.Song, I. (2008).Interactivity and political attitudes formation: the elaboration likelihood model of interactivity media “. PHD thesis. (Department of telecommunications , Indiana university , available at :http://proquest.umi.com 